\title{
2017 HRS/EHRA/ECAS/APHRS/SOLAECE expert consensus statement on catheter and surgical ablation of atrial fibrillation: executive summary
}

\author{
Hugh Calkins ${ }^{1}$ • Gerhard Hindricks ${ }^{2} \cdot$ Riccardo Cappato $^{3,4,5} \cdot$ Young-Hoon Kim $^{6}$. \\ Eduardo B. Saad ${ }^{7} \cdot$ Luis Aguinaga $^{8}$ • Joseph G. Akar ${ }^{9} \operatorname{Vinay~Badhwar~}^{10} \cdot$ Josep Brugada $^{11}$. \\ John Camm ${ }^{12}$ • Peng-Sheng Chen ${ }^{13}$ • Shih-Ann Chen ${ }^{14} \cdot$ Mina K. Chung ${ }^{15}$. \\ Jens Cosedis Nielsen ${ }^{16}$ - Anne B. Curtis ${ }^{17} \cdot$ D. Wyn Davies ${ }^{18} \cdot J_{0 h n}$ D. Day ${ }^{19} \cdot$ André d'Avila $^{20}$. \\ N.M.S. (Natasja) de Groot ${ }^{21}$ • Luigi Di Biase ${ }^{22}$ • Mattias Duytschaever ${ }^{23}$ • James R. Edgerton ${ }^{24}$. \\ Kenneth A. Ellenbogen ${ }^{25}$ • Patrick T. Ellinor ${ }^{26}$ - Sabine Ernst ${ }^{27}$ - Guilherme Fenelon ${ }^{28}$. \\ Edward P. Gerstenfeld $^{29}$ • David E. Haines ${ }^{30}$ • Michel Haissaguerre ${ }^{31}$ • Robert H. Helm ${ }^{32}$. \\ Elaine Hylek $^{33}$ • Warren M. Jackman ${ }^{34}$ • Jose Jalife J5,36,37 $~$ Jonathan M. Kalman $^{38}$. \\ Josef Kautzner $^{39}$ • Hans Kottkamp ${ }^{40}$ • Karl Heinz Kuck ${ }^{41} \cdot$ Koichiro Kumagai $^{42}$ • Richard Lee ${ }^{43}$ • \\ Thorsten Lewalter $^{44}$ • Bruce D. Lindsay ${ }^{15} \cdot$ Laurent Macle $^{45} \cdot$ Moussa Mansour $^{26}$. \\ Francis E. Marchlinski ${ }^{46,47}$ • Gregory F. Michaud ${ }^{48}$ - Hiroshi Nakagawa ${ }^{34}$ - Andrea Natale ${ }^{49}$. \\ Stanley Nattel ${ }^{50,51,52,53} \cdot$ Ken Okumura $^{54} \cdot$ Douglas Packer $^{55} \cdot$ Evgeny Pokushalov $^{56}$. \\ Matthew R. Reynolds ${ }^{57}$. Prashanthan Sanders ${ }^{58,59}$ - Mauricio Scanavacca ${ }^{60}$.

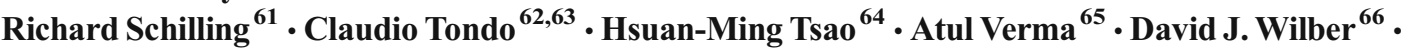 \\ Teiichi Yamane ${ }^{67}$
}

Published online: 15 September 2017

(C) HRS; EHRA, a registered branch of the ESC; ECAS; JHRS and APHRS; and SOLAECE 2017. This is an open access article under the CC BY license

Keywords Ablation · Arrhythmia - Atrial fibrillation · Atrial flutter $\cdot$ Atrial tachycardia $\cdot$ Catheter ablation $\cdot$ Surgical ablation $\cdot$ Stroke $\cdot$ Anticoagulation

Developed in partnership with and endorsed by the European Heart Rhythm Association (EHRA), the European Cardiac Arrhythmia Society (ECAS), the Asia Pacific Heart Rhythm Society (APHRS), and the Latin American Society of Cardiac Stimulation and Electrophysiology (Sociedad Latinoamericana de Estimulación Cardíaca y Electrofisiología [SOLAECE]). Developed in collaboration with and endorsed by the Society of Thoracic Surgeons (STS), the American College of Cardiology (ACC), the American Heart Association (AHA), the Canadian Heart Rhythm Society (CHRS), the Japanese Heart Rhythm Society (JHRS), and the Brazilian Society of Cardiac Arrhythmias (Sociedade Brasileira de Arritmias Cardíacas [SOBRAC]).

Gerhard Hindricks, Josep Brugada, John Camm, Jens Cosedis Nielsen, N.M.S. (Natasja) de Groot, Luigi Di Biase, Mattias Duytschaever, Sabine Ernst, Michel Haissaguerre, Josef Kautzner, Hans Kottkamp, Karl Heinz Kuck, Evgeny Pokushalov, Richard Schilling and Claudio Tondo are the Representative of the European Heart Rhythm Association (EHRA)

Gregory F. Michaud is the Representative of the American Heart Association (AHA)

Eduardo B. Saad, Luis Aguinaga, Guilherme Fenelon and Mauricio Scanavacca are the Representative of the Sociedad Latinoamericana de Estimulación Cardíaca y Electrofisiología (SOLAECE)

\author{
Abbreviations \\ AAD Antiarrhythmic drug \\ AF Atrial fibrillation
}

Young-Hoon Kim, Shih-Ann Chen, Jonathan M. Kalman, Koichiro Kumagai and Hsuan-Ming Tsao are the Representative of the Asia Pacific Heart Rhythm Society (APHRS)

Anne B. Curtis is the Representative of the American College of Cardiology (ACC)

Riccardo Cappato, D. Wyn Davies and Thorsten Lewalter are the Representative of the European Cardiac Arrhythmia Society (ECAS) Vinay Badhwar, James R. Edgerton and Richard Lee are the Representative of the Society of Thoracic Surgeons (STS)

Laurent Macle is the Representative of the Canadian Heart Rhythm Society (CHRS)

Ken Okumura and Teiichi Yamane are the Representative of the Japanese Heart Rhythm Society (JHRS)

André d'Avila is the Representative of the Sociedade Brasileira de Arritmias Cardiacas (SOBRAC)

Hugh Calkins

clinicaldocs@hrsonline.org

1 Johns Hopkins Medical Institutions, Baltimore, MD, USA 


$\begin{array}{ll}\text { AFL } & \text { Atrial flutter } \\ \text { CB } & \text { Cryoballoon } \\ \text { CFAE } & \text { Complex fractionated atrial electrogram } \\ \text { LA } & \text { Left atrial } \\ \text { LAA } & \text { Left atrial appendage } \\ \text { LGE } & \text { Late gadolinium-enhanced } \\ \text { LOE } & \text { Level of evidence } \\ \text { MRI } & \text { Magnetic resonance imaging } \\ \text { OAC } & \text { Oral anticoagulation } \\ \text { RF } & \text { Radiofrequency }\end{array}$

Chair: Hugh Calkins, MD, Johns Hopkins Medical Institutions, Baltimore, MD, USA.

Section Chairs: Definitions, Mechanisms, and Rationale for AF Ablation: Shih-Ann Chen, MD, National Yang-Ming University, Taipei, Taiwan.

Modifiable Risk Factors for AF and Impact on Ablation: Jonathan M. Kalman, MBBS, PhD, Royal Melbourne Hospital and University of Melbourne, Melbourne, Australia.

Indications: Claudio Tondo, MD, PhD, Cardiac Arrhythmia Research Center, Centro Cardiologico Monzino,

$\overline{2}$ Heart Center Leipzig, Leipzig, Germany

3 Humanitas Research Hospital, Arrhythmias and Electrophysiology Research Center, Milan, Italy

4 Present address: Department of Biomedical Sciences, Humanitas University, Milan, Italy

5 IRCCS, Humanitas Clinical and Research Center, Milan, Italy

6 Korea University, Seoul, South Korea

7 Hospital Pro-Cardiaco and Hospital Samaritano, Botafogo, Rio de Janeiro, Brazil

8 Centro Privado de Cardiología, Tucuman, Argentina

9 Yale University School of Medicine, New Haven, CT, USA

10 West Virginia University School of Medicine, Morgantown, WV, USA

11 Cardiovascular Institute, Hospital Clínic, University of Barcelona, Catalonia, Spain

12 St. George's University of London, London, UK

13 Indiana University School of Medicine, Indianapolis, IN, USA

14 National Yang-Ming University, Taipei, Taiwan

15 Cleveland Clinic, Cleveland, OH, USA

16 Aarhus University Hospital, Skejby, Denmark

17 University at Buffalo, Buffalo, NY, USA

18 Imperial College Healthcare NHS Trust, London, UK

19 Intermountain Medical Center Heart Institute, Salt Lake City, UT, USA

20 Hospital SOS Cardio, Florianopolis, SC, Brazil
IRCCS, Department of Cardiovascular Sciences, University of Milan, Milan, Italy.

Strategies, Techniques, and Endpoints: Karl Heinz Kuck, $\mathrm{MD}$, PhD, Asklepios Klinik St. Georg, Hamburg, Germany.

Technology and Tools: Andrea Natale, MD, Texas Cardiac Arrhythmia Institute, St. David's Medical Center, Austin, TX, USA.

Technical Aspects of Ablation to Maximize Safety and Anticoagulation: David E. Haines, MD, Beaumont Health System, Royal Oak, MI, USA.

Follow-up Considerations: Francis E. Marchlinski, MD, Hospital of the University of Pennsylvania, University of Pennsylvania School of Medicine, Philadelphia, PA, USA.

Outcomes and Efficacy: Matthew R. Reynolds, MD, MSc, Lahey Hospital and Medical Center, Burlington, MA, USA.

Complications: D. Wyn Davies, MD, Imperial College Healthcare NHS Trust, London, United Kingdom.

Training Requirements: Bruce D. Lindsay, MD, Cleveland Clinic, Cleveland, OH, USA.

Surgical and Hybrid AF Ablation: James R. Edgerton, MD, The Heart Hospital, Baylor Plano, Plano, TX, USA.

Clinical Trial Design: Atul Verma, MD, Southlake Regional Health Centre, University of Toronto, Toronto, Canada.

21 Erasmus Medical Center, Rotterdam, The Netherlands

22 Albert Einstein College of Medicine, Montefiore-Einstein Center for Heart \& Vascular Care, Bronx, NY, USA

23 Universitair Ziekenhuis Gent (Ghent University Hospital), Ghent, Belgium

24 The Heart Hospital, Baylor Plano, Plano, TX, USA

25 Virginia Commonwealth University School of Medicine, Richmond, VA, USA

26 Massachusetts General Hospital, Boston, MA, USA

27 Royal Brompton and Harefield NHS Foundation Trust, National Heart and Lung Institute, Imperial College London, London, UK

28 Albert Einstein Jewish Hospital, Federal University of São Paulo, São Paulo, Brazil

29 University of California, San Francisco, San Francisco, CA, USA

30 Beaumont Health System, Royal Oak, MI, USA

31 Hôpital Cardiologique du Haut-Lévêque, Pessac, France

32 Boston University Medical Center, Boston, MA, USA

33 Boston University School of Medicine, Boston, MA, USA

34 Heart Rhythm Institute, University of Oklahoma Health Sciences Center, Oklahoma City, OK, USA

35 University of Michigan, Ann Arbor, MI, USA

36 The National Center for Cardiovascular Research Carlos III (CNIC), Madrid, Spain

37 CIBERCV, Madrid, Spain

38 Royal Melbourne Hospital and University of Melbourne, Melbourne, Australia 
Correspondence: Heart Rhythm Society, 1325 G Street NW, Suite 400, Washington, DC 20005. E-mail address: clinicaldocs@hrsonline.org.

Document Reviewers: Carina Blomström-Lundqvist, MD, PhD; Angelo A.V. De Paola, MD, PhD; Peter M. Kistler, MBBS, PhD; Gregory Y.H. Lip, MD; Nicholas S. Peters, MD; Cristiano F. Pisani, MD; Antonio Raviele, MD; Eduardo B. Saad, MD, PhD; Kazuhiro Satomi, MD, PhD; Martin K. Stiles, MB ChB, PhD; Stephan Willems, MD, PhD

\section{Introduction}

During the past three decades, catheter and surgical ablation of atrial fibrillation (AF) have evolved from investigational procedures to their current role as effective treatment options for patients with AF. Surgical ablation of AF, using either standard, minimally invasive, or hybrid techniques, is available in most major hospitals throughout the world. Catheter ablation of AF is even more widely available, and is now the most commonly performed catheter ablation procedure.

In 2007, an initial Consensus Statement on Catheter and Surgical AF Ablation was developed as a joint effort of the Heart Rhythm Society (HRS), the European Heart Rhythm Association (EHRA), and the European Cardiac Arrhythmia Society (ECAS) [1]. The 2007 document was also developed in collaboration with the Society of Thoracic Surgeons (STS) and the American College of Cardiology (ACC). This Consensus Statement on Catheter and Surgical AF Ablation

\footnotetext{
39 Institute for Clinical and Experimental Medicine, Prague, Czech Republic

40 Hirslanden Hospital, Department of Electrophysiology, Zurich, Switzerland

41 Asklepios Klinik St. Georg, Hamburg, Germany

42 Heart RhythmCenter, Fukuoka Sanno Hospital, Fukuoka, Japan

43 Saint Louis University Medical School, St. Louis, MO, USA

44 Department of Cardiology and Intensive Care, Hospital Munich-Thalkirchen, Munich, Germany

45 Montreal Heart Institute, Department of Medicine, Université de Montréal, Montréal, Canada

46 Hospital of the University of Pennsylvania, Philadelphia, PA, USA

47 University of Pennsylvania School of Medicine, Philadelphia, PA, USA

48 Brigham and Women's Hospital, Boston, MA, USA

49 St. David's Medical Center, Texas Cardiac Arrhythmia Institute, Austin, TX, USA

50 Montreal Heart Institute, Montreal, QC, Canada

51 Université de Montréal, Montreal, QC, Canada

52 McGill University, Montreal, QC, Canada

53 University Duisburg-Essen, Essen, Germany
}

was rewritten in 2012 to reflect the many advances in $\mathrm{AF}$ ablation that had occurred in the interim [2]. The rate of advancement in the tools, techniques, and outcomes of $\mathrm{AF}$ ablation continue to increase as enormous research efforts are focused on the mechanisms, outcomes, and treatment of AF. For this reason, the HRS initiated an effort to rewrite and update this Consensus Statement. Reflecting both the worldwide importance of $\mathrm{AF}$, as well as the worldwide performance of AF ablation, this document is the result of a joint partnership between the HRS, EHRA, ECAS, the Asia Pacific Heart Rhythm Society (APHRS), and the Latin American Society of Cardiac Stimulation and Electrophysiology (Sociedad Latinoamericana de Estimulación Cardíaca y Electrofisiología [SOLAECE]). The purpose of this 2017 Consensus Statement is to provide a state-of-the-art review of the field of catheter and surgical ablation of AF and to report the findings of a writing group, convened by these five international societies. The writing group is charged with defining the indications, techniques, and outcomes of AF ablation procedures. Included within this document are recommendations pertinent to the design of clinical trials in the field of AF ablation and the reporting of outcomes, including definitions relevant to this topic.

The writing group is composed of 60 experts representing 11 organizations: HRS, EHRA, ECAS, APHRS, SOLAECE, STS, ACC, American Heart Association (AHA), Canadian Heart Rhythm Society (CHRS), Japanese Heart Rhythm Society (JHRS), and Brazilian Society of Cardiac Arrhythmias (Sociedade Brasileira de Arritmias Cardíacas [SOBRAC]). All

54

Division of Cardiology, Saiseikai Kumamoto Hospital, Kumamoto, Japan

55 Mayo Clinic, Rochester, MN, USA

56 State Research Institute of Circulation Pathology, Novosibirsk, Russia

57 Lahey Hospital and Medical Center, Burlington, MA, USA

58 Centre for Heart Rhythm Disorders, South Australian Health and Medical Research Institute, University of Adelaide, Adelaide, Australia

59 Royal Adelaide Hospital, Adelaide, Australia

60 Instituto do Coração (InCor), São Paulo, Brazil

61 Barts Heart Centre, London, UK

62 Cardiac Arrhythmia Research Center, Centro Cardiologico Monzino, IRCCS, Milan, Italy

63 Department of Cardiovascular Sciences, University of Milan, Milan, Italy

64 National Yang-Ming University Hospital, Yilan City, Taiwan

65 Southlake Regional Health Centre, University of Toronto, Toronto, ON, Canada

66 Loyola University of Chicago, Chicago, IL, USA

67 Jikei University School of Medicine, Tokyo, Japan 
the members of the writing group, as well as peer reviewers of the document, have provided disclosure statements for all relationships that might be perceived as real or potential conflicts of interest. All author and peer reviewer disclosure information is provided in Appendix A Table 14 and Appendix B Table 15.

In writing a consensus document, it is recognized that consensus does not mean that there was complete agreement among all the writing group members. Surveys of the entire writing group were used to identify areas of consensus concerning performance of AF ablation procedures and to develop recommendations concerning the indications for catheter and surgical AF ablation. These recommendations were systematically balloted by the 60 writing group members and were approved by a minimum of $80 \%$ of these members. The recommendations were also subject to a 1-month public comment period. Each partnering and collaborating organization then officially reviewed, commented on, edited, and endorsed the final document and recommendations.

The grading system for indication of class of evidence level was adapted based on that used by the ACC and the AHA [3, 4]. It is important to state, however, that this document is not a guideline. The indications for catheter and surgical ablation of $\mathrm{AF}$, as well as recommendations for procedure performance, are presented with a Class and Level of Evidence (LOE) to be consistent with what the reader is familiar with seeing in guideline statements. A Class I recommendation means that the benefits of the AF ablation procedure markedly exceed the risks, and that AF ablation should be performed; a Class IIa recommendation means that the benefits of an $\mathrm{AF}$ ablation procedure exceed the risks, and that it is reasonable to perform $\mathrm{AF}$ ablation; a Class IIb recommendation means that the benefit of AF ablation is greater or equal to the risks, and that $\mathrm{AF}$ ablation may be considered; and a Class III recommendation means that $\mathrm{AF}$ ablation is of no proven benefit and is not recommended.

The writing group reviewed and ranked evidence supporting current recommendations with the weight of evidence ranked as Level A if the data were derived from highquality evidence from more than one randomized clinical trial, meta-analyses of high-quality randomized clinical trials, or one or more randomized clinical trials corroborated by highquality registry studies. The writing group ranked available evidence as Level B-R when there was moderate-quality evidence from one or more randomized clinical trials, or metaanalyses of moderate-quality randomized clinical trials. Level B-NR was used to denote moderate-quality evidence from one or more well-designed, well-executed nonrandomized studies, observational studies, or registry studies. This designation was also used to denote moderate-quality evidence from metaanalyses of such studies. Evidence was ranked as Level CLD when the primary source of the recommendation was randomized or nonrandomized observational or registry studies with limitations of design or execution, meta-analyses of such studies, or physiological or mechanistic studies of human subjects. Level C-EO was defined as expert opinion based on the clinical experience of the writing group.

Despite a large number of authors, the participation of several societies and professional organizations, and the attempts of the group to reflect the current knowledge in the field adequately, this document is not intended as a guideline. Rather, the group would like to refer to the current guidelines on AF management for the purpose of guiding overall $\mathrm{AF}$ management strategies $[5,6]$. This consensus document is specifically focused on catheter and surgical ablation of AF, and summarizes the opinion of the writing group members based on an extensive literature review as well as their own experience. It is directed to all health care professionals who are involved in the care of patients with $\mathrm{AF}$, particularly those who are caring for patients who are undergoing, or are being considered for, catheter or surgical ablation procedures for $\mathrm{AF}$, and those involved in research in the field of AF ablation. This statement is not intended to recommend or promote catheter or surgical ablation of AF. Rather, the ultimate judgment regarding care of a particular patient must be made by the health care provider and the patient in light of all the circumstances presented by that patient.

The main objective of this document is to improve patient care by providing a foundation of knowledge for those involved with catheter ablation of AF. A second major objective is to provide recommendations for designing clinical trials and reporting outcomes of clinical trials of AF ablation. It is recognized that this field continues to evolve rapidly. As this document was being prepared, further clinical trials of catheter and surgical ablation of AF were under way.

\section{Definitions, mechanisms, and rationale for $\mathrm{AF}$ ablation}

This section of the document provides definitions for use in the diagnosis of AF. This section also provides an in-depth review of the mechanisms of $\mathrm{AF}$ and rationale for catheter and surgical AF ablation (Table 1, Figs. 1, 2, 3, 4, 5, and 6).

\section{Modifiable risk factors for AF and impact on ablation}

Management of patients with AF has traditionally consisted of three main components: (1) anticoagulation for stroke prevention; (2) rate control; and (3) rhythm control. With the emergence of large amounts of data, which have both defined and called attention to the interaction between modifiable risk factors and the development of $\mathrm{AF}$ and outcomes of $\mathrm{AF}$ management, we believe it is time to include risk factor modification as the fourth pillar of AF management. This section of the document reviews the link between modifiable risk factors and both the development of $\mathrm{AF}$ and their impacts on the outcomes of AF ablation. 
Table 1 Atrial fibrillation definitions
AF episode

Chronic AF

Early persistent AF

Lone AF

Long-standing persistent AF

Paroxysmal AF

Permanent AF

Persistent AF

Silent AF
An AF episode is defined as AF that is documented by ECG monitoring or intracardiac electrogram monitoring and has a duration of at least $30 \mathrm{~s}$, or if less than $30 \mathrm{~s}$, is present throughout the ECG monitoring tracing. The presence of subsequent episodes of AF requires that sinus rhythm be documented by ECG monitoring between AF episodes.

Chronic AF has variable definitions and should not be used to describe populations of $\mathrm{AF}$ patients undergoing $\mathrm{AF}$ ablation.

Early persistent AF is defined as AF that is sustained beyond 7 days but is less than 3 months in duration.

Lone $\mathrm{AF}$ is a historical descriptor that is potentially confusing and should not be used to describe populations of patients with $\mathrm{AF}$ undergoing $\mathrm{AF}$ ablation.

Long-standing persistent AF is defined as continuous AF of greater than 12 months' duration.

Paroxysmal AF is defined as AF that terminates spontaneously or with intervention within 7 days of onset.

Permanent AF is defined as the presence of AF that is accepted by the patient and physician, and for which no further attempts to restore or maintain sinus rhythm will be undertaken. The term permanent $A F$ represents a therapeutic attitude on the part of the patient and physician rather than an inherent pathophysiological attribute of AF. The term permanent $A F$ should not be used within the context of a rhythm control strategy with antiarrhythmic drug therapy or AF ablation.

Persistent AF is defined as continuous AF that is sustained beyond 7 days.

Silent $\mathrm{AF}$ is defined as asymptomatic AF diagnosed with an opportune ECG or rhythm strip.

$A F$ atrial fibrillation, $E C G$ electrocardiogram

Fig. 1 Anatomical drawings of the heart relevant to $\mathrm{AF}$ ablation. This series of drawings shows the heart and associated relevant structures from four different perspectives relevant to $\mathrm{AF}$ ablation. This drawing includes the phrenic nerves and the esophagus. a The heart viewed from the anterior perspective. $\mathbf{b}$ The heart viewed from the right lateral perspective. $\mathbf{c}$ The heart viewed from the left lateral perspective. d The heart viewed from the posterior perspective. $\mathbf{e}$ The left atrium viewed from the posterior perspective. Illustration: Tim Phelps ( 2017 Johns Hopkins University, AAM

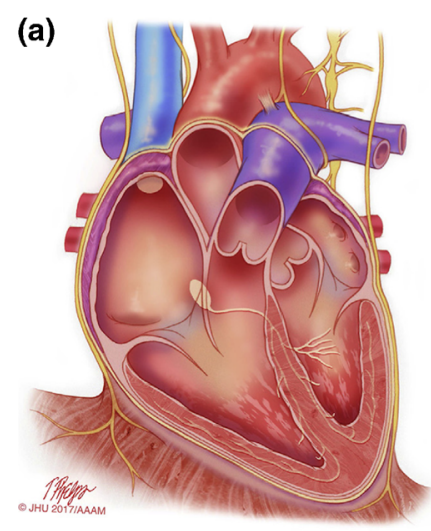

(b)

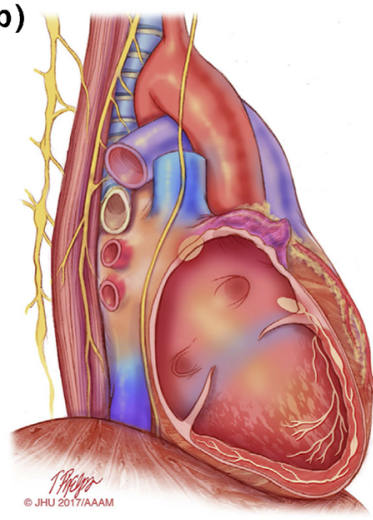

(c)

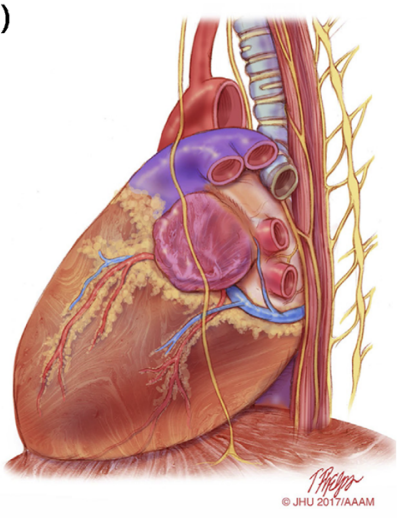

(d)

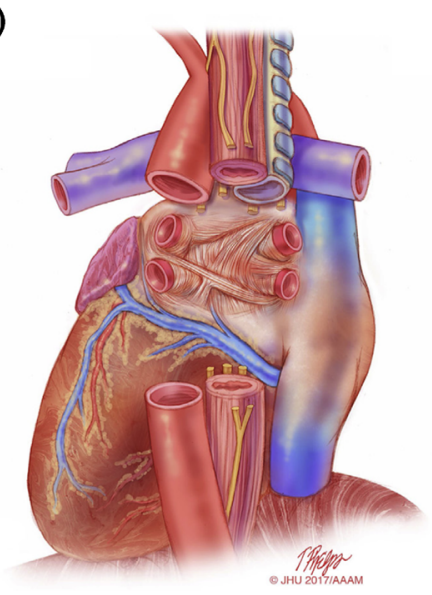

(e)

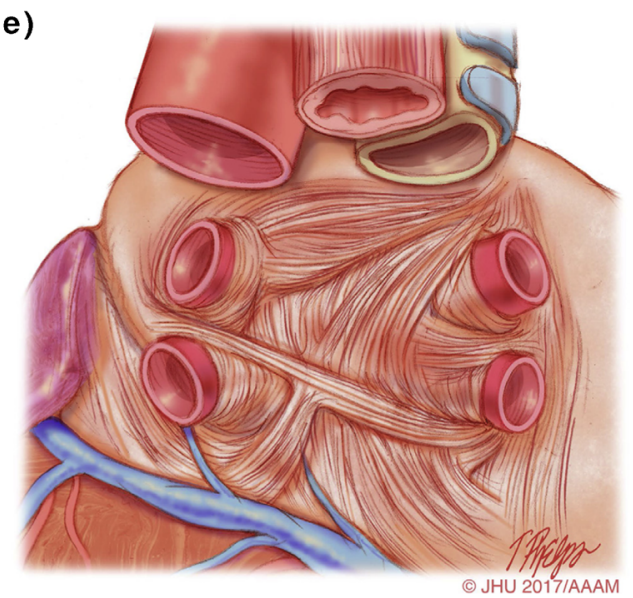



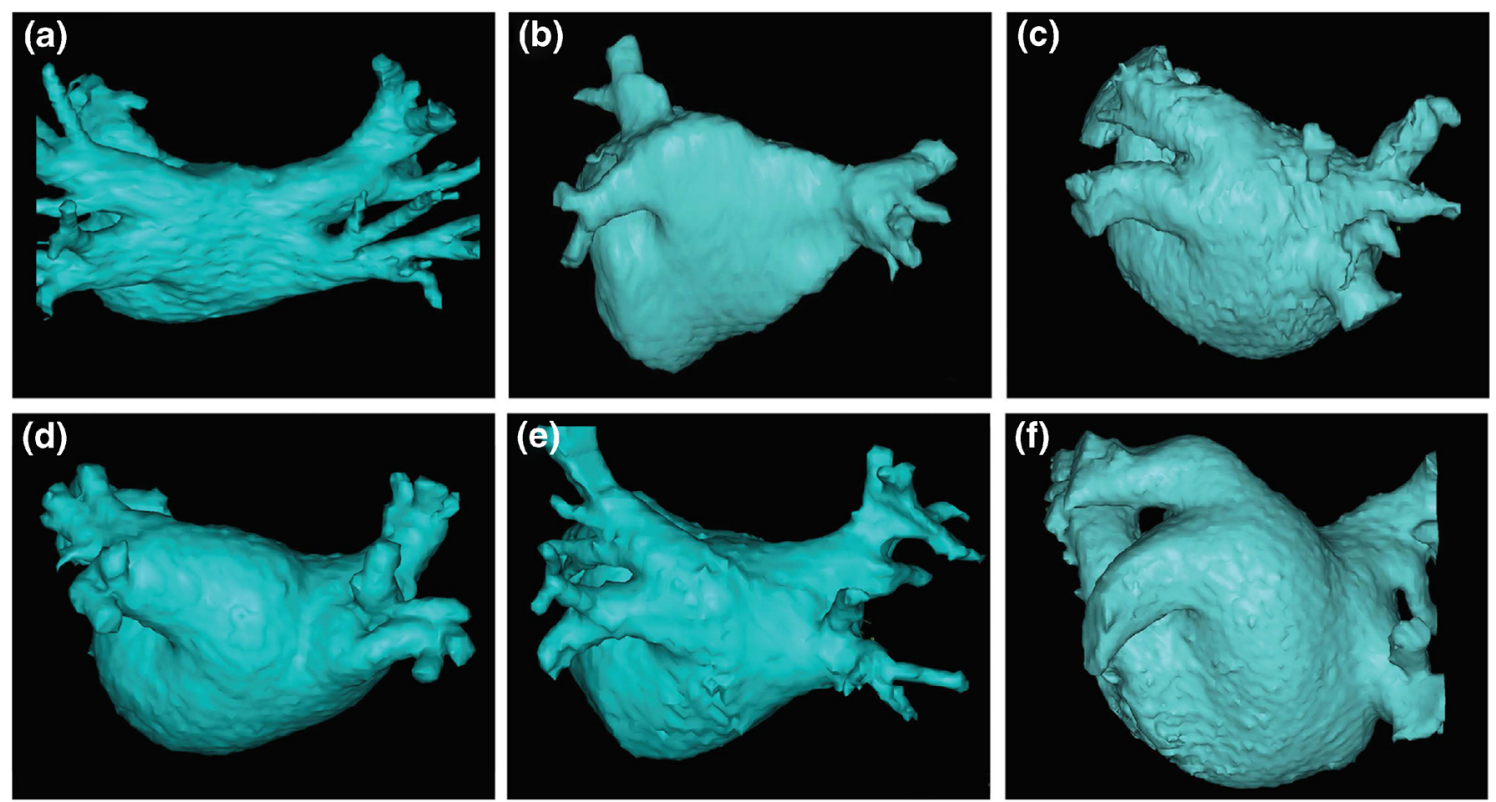

Fig. 2 This figure includes six CT or MR images of the left atrium and pulmonary veins viewed from the posterior perspective. Common and

common PV with a short trunk and an anomolous PV arising from the right posterior left atrial wall. $\mathbf{d}$ and $\mathbf{e}$ Variant $\mathrm{PV}$ anatomy with a common left PV with a long trunk. f Variant PV anatomy with a massive left common PV anatomy with 4 distinct PV ostia. b Variant PV anatomy with a right common and a left common PV. c Variant PV anatomy with a left

I, Class IIa, Class IIb, and Class III indications. The evi-

\section{Indications}

Shown in Table 2, and summarized in Figs. 7 and 8 of this document, are the Consensus Indications for Catheter and Surgical Ablation of AF. As outlined in the introduction section of this document, these indications are stratified as Class dence supporting these indications is provided, as well as a selection of the key references supporting these levels of evidence. In making these recommendations, the writing group considered the body of published literature that has defined the safety and efficacy of catheter and surgical

Fig. 3 Schematic drawing showing various hypotheses and proposals concerning the mechanisms of atrial fibrillation. a Multiple wavelets hypothesis. b Rapidly discharging automatic foci. c Single reentrant circuit with fibrillatory conduction. $\mathbf{d}$ Functional reentry resulting from rotors or spiral waves. e AF maintenance resulting from dissociation between epicardial and endocardial layers, with mutual interaction producing multiplying activity that maintains the arrhythmia (a)

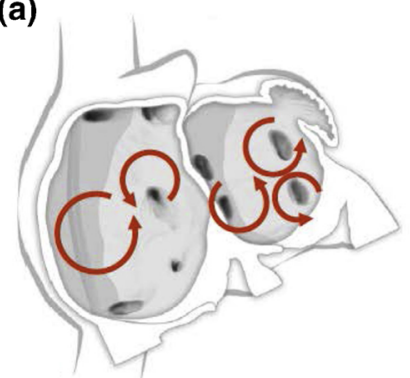

(b)

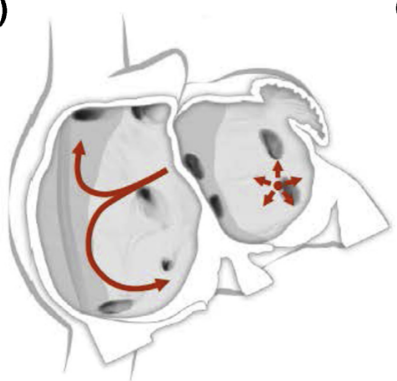

(c)

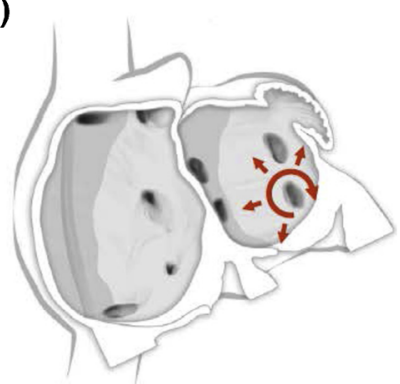

(d)

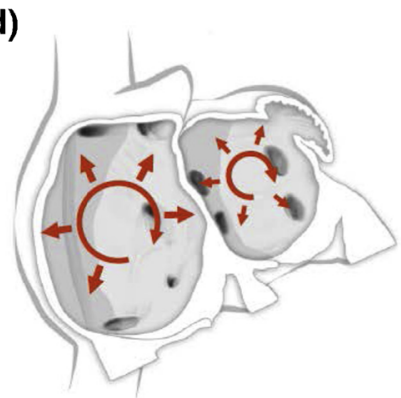

(e)

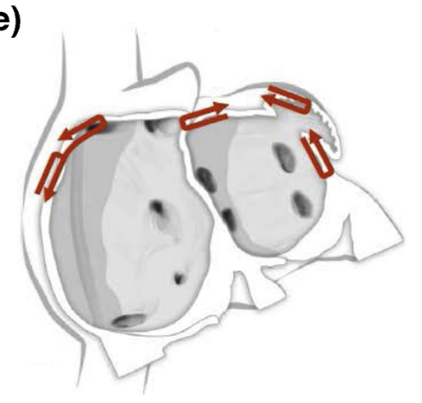



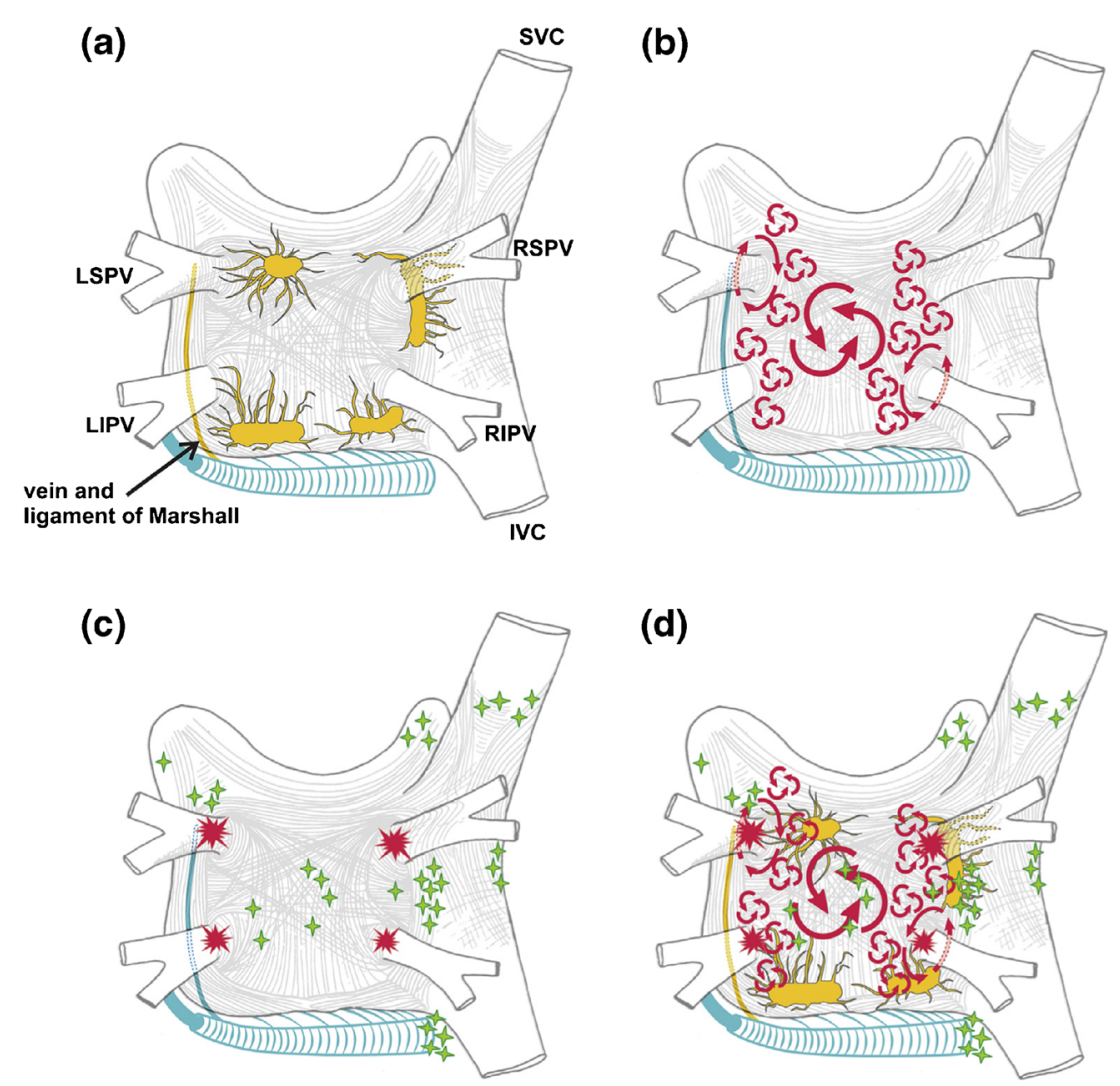

Fig. 4 Structure and mechanisms of atrial fibrillation. a Schematic drawing of the left and right atria as viewed from the posterior perspective. The extension of muscular fibers onto the PVs can be appreciated. Shown in yellow are the five major left atrial autonomic ganglionic plexi (GP) and axons (superior left GP, inferior left GP, anterior right GP, inferior right GP, and ligament of Marshall). Shown in blue is the coronary sinus, which is enveloped by muscular fibers that have connections to the atria. Also shown in blue is the vein and ligament

of Marshall, which travels from the coronary sinus to the region between the left superior PV and the left atrial appendage. b The large and small reentrant wavelets that play a role in initiating and sustaining AF. $\mathbf{c}$ The common locations of PV (red) and also the common sites of origin of non-PV triggers (shown in green). d Composite of the anatomic and arrhythmic mechanisms of AF. Adapted with permission from Calkins et al. Heart Rhythm 2012; 9:632-696.e21 [2]

Fig. 5 Schematic drawing showing mechanisms of atrial flutter and atrial tachycardia. a Isthmus-dependent reverse common (clockwise) atrial flutter. b Isthmus-dependent common (counter clockwise) atrial flutter. c Focal atrial tachycardia with circumferential spread of activation of the atria (can arise from multiple sites within the left and right atrium). $\mathbf{d}$

Microreentrant atrial tachycardia with circumferential spread of activation of the atria. e Perimitral atrial flutter. $\mathbf{f}$ Roof-dependent atrial flutter (a)

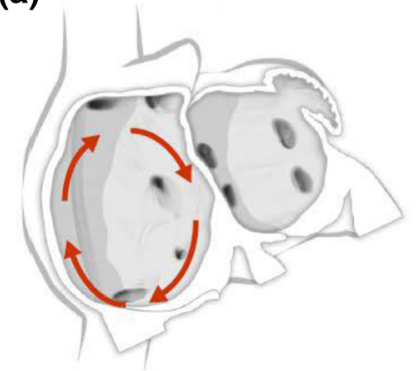

(d)

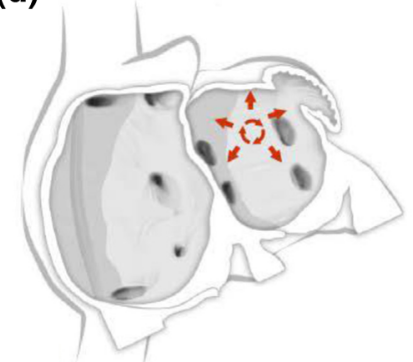

(b)

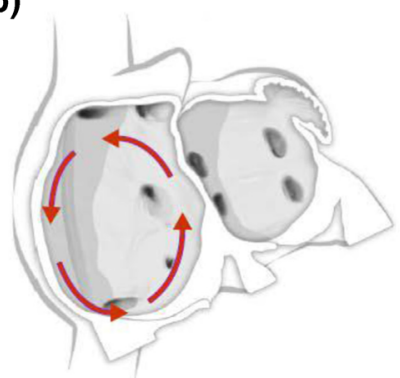

(e)

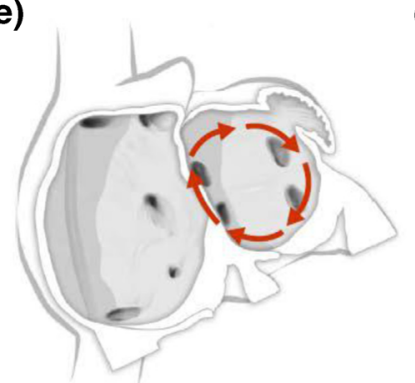

(c)

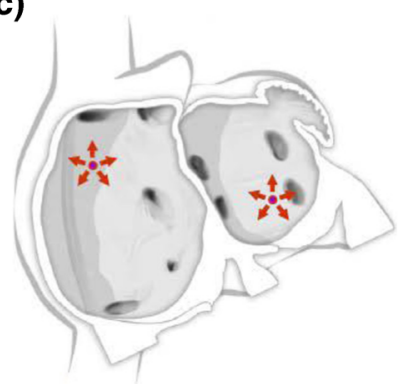

(f)

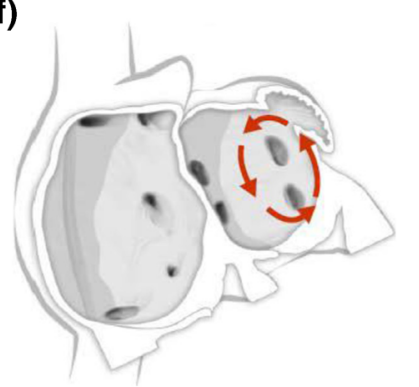




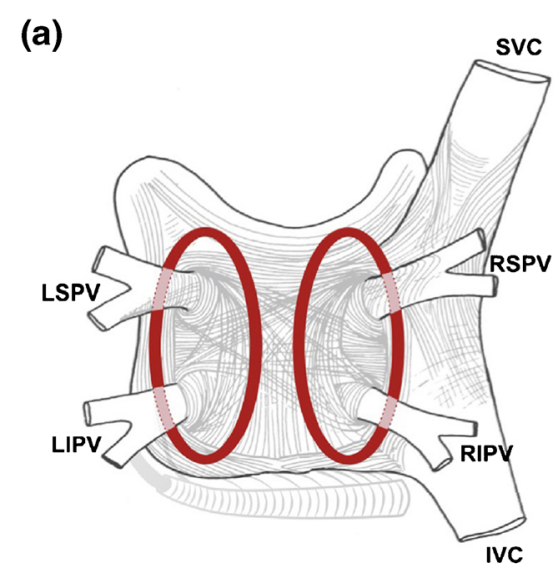

(c)

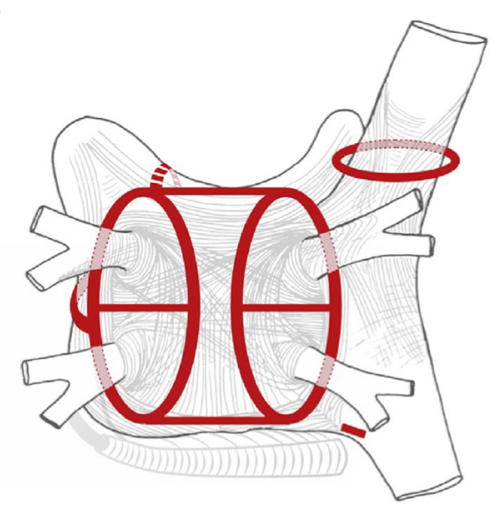

Fig. 6 Schematic of common lesion sets employed in AF ablation. a The circumferential ablation lesions that are created in a circumferential fashion around the right and the left PVs. The primary endpoint of this ablation strategy is the electrical isolation of the PV musculature. b Some of the most common sites of linear ablation lesions. These include a "roof line" connecting the lesions encircling the left and/or right PVs, a "mitral isthmus" line connecting the mitral valve and the lesion encircling the left PVs at the end of the left inferior PV, and an anterior linear lesion connecting either the "roof line" or the left or right circumferential lesion to the mitral annulus anteriorly. A linear lesion created at the cavotricuspid isthmus is also shown. This lesion is generally placed in

ablation of AF. Also considered in these recommendations is the personal lifetime experience in the field of each of the writing group members. Both the number of clinical trials and the quality of these trials were considered. In considering the class of indications recommended by this writing group, it is important to keep several points in mind. First, these classes of indications only define the indications for catheter and surgical ablation of AF when performed by an electrophysiologist or a surgeon who has received appropriate training and/or who has a certain level of experience and is performing the procedure in an experienced center (Section 11). Catheter and surgical ablation of AF are highly complex procedures, and a careful assessment of the benefit and risk must be considered for each patient. Second, these indications stratify patients based only on the type of AF and whether the procedure is being performed prior to or following a trial of one or (b)

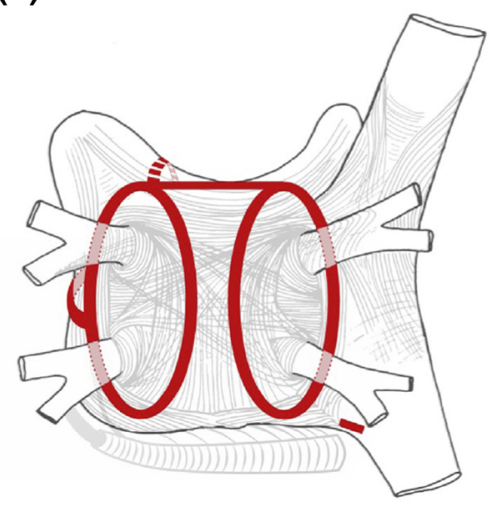

(d)

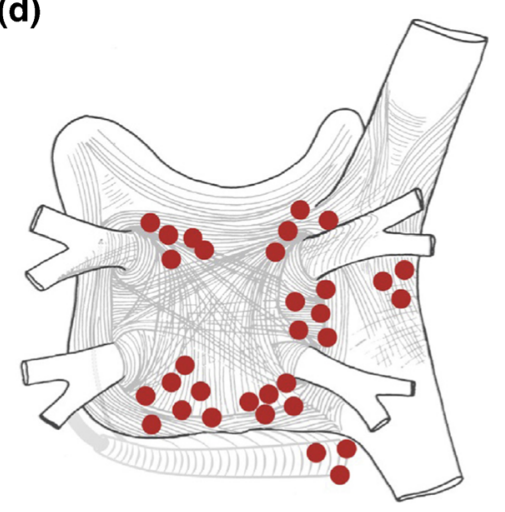

patients who have experienced cavotricuspid isthmus-dependent atrial flutter clinically or have it induced during EP testing. c Similar to 6B, but also shows additional linear ablation lesions between the superior and inferior PVs resulting in a figure of eight lesion sets as well as a posterior inferior line allowing for electrical isolation of the posterior left atrial wall. An encircling lesion of the superior vena cava (SVC) directed at electrical isolation of the SVC is also shown. SVC isolation is performed if focal firing from the SVC can be demonstrated. A subset of operators empirically isolates the SVC. d Representative sites for ablation when targeting rotational activity or CFAEs are targeted. Modified with permission from Calkins et al. Heart Rhythm 2012; 9:632-696.e21 [2]

more Class I or III antiarrhythmic medications. This document for the first time includes indications for catheter ablation of select asymptomatic patients. As detailed in Section 9, there are many other additional clinical and imaging-based variables that can be used to further define the efficacy and risk of ablation in a given patient. Some of the variables that can be used to define patients in whom a lower success rate or a higher complication rate can be expected include the presence of concomitant heart disease, obesity, sleep apnea, left atrial (LA) size, patient age and frailty, as well as the duration of time the patient has been in continuous AF. Each of these variables needs to be considered when discussing the risks and benefits of AF ablation with a particular patient. In the presence of substantial risk or anticipated difficulty of ablation, it could be more appropriate to use additional antiarrhythmic drug (AAD) options, even if the patient on face value 
Table 2 Indications for catheter (A and B) and surgical (C, D, and E) ablation of atrial fibrillation

\begin{tabular}{lllll}
\hline Recommendation & Class & LOE & References \\
\hline
\end{tabular}

Indications for catheter ablation of atrial fibrillation

A. Indications for catheter ablation of atrial fibrillation

Symptomatic AF

refractory or intolerant to at least one Class I or III antiarrhythmic medication

Symptomatic AF prior to initiation of antiarrhythmic therapy with a Class I or III antiarrhythmic medication
Paroxysmal: Catheter ablation is recommended.

Persistent: Catheter ablation is reasonable.

Long-standing persistent: Catheter ablation may be considered.

Paroxysmal: Catheter ablation is reasonable.

Persistent: Catheter ablation is reasonable.

Long-standing persistent: Catheter ablation may be considered.

B. Indications for catheter atrial fibrillation ablation in populations of patients not well represented in clinical trials

Congestive heart failure

Older patients $(>75$ years of age)

Hypertrophic cardiomyopathy

Young patients $(<45$ years of age)

Tachy-brady syndrome

Athletes with AF

Asymptomatic $\mathrm{AF}^{* *}$

It is reasonable to use similar indications for $\mathrm{AF}$ ablation in selected patients with heart failure as in patients without heart failure.

It is reasonable to use similar indications for $\mathrm{AF}$ ablation in selected older patients with $\mathrm{AF}$ as in younger patients.

It is reasonable to use similar indications for $\mathrm{AF}$ ablation in selected patients with HCM as in patients without HCM.

It is reasonable to use similar indications for $\mathrm{AF}$ ablation in young patients with $\mathrm{AF}$ ( $<45$ years of age) as in older patients.

It is reasonable to offer AF ablation as an alternative to pacemaker implantation in patients with tachy-brady syndrome.

It is reasonable to offer high-level athletes $\mathrm{AF}$ as first-line therapy due to the negative effects of medications on athletic performance.

Paroxysmal: Catheter ablation may be considered in

IIa

IIa

IIa

IIa

IIa

IIa

$\mathrm{IIb}$ select patients. $^{* *}$

Persistent: Catheter ablation may be considered in select patients.

Indications for surgical ablation of atrial fibrillation

C. Indications for concomitant open (such as mitral valve) surgical ablation of atrial fibrillation

Symptomatic AF refractory or intolerant to at least one Class I or III antiarrhythmic medication

Symptomatic AF prior to initiation of antiarrhythmic therapy with a Class I or III antiarrhythmic medication

D. Indications for concomitant closed (such as CABG and AVR) surgical ablation of atrial fibrillation

Symptomatic AF refractory or intolerant to at least one Class I or III antiarrhythmic medication

Symptomatic AF prior to initiation of antiarrhythmic therapy with a Class I or III antiarrhythmic medication
Paroxysmal: Surgical ablation is recommended.

Persistent: Surgical ablation is recommended.

Long-standing persistent: Surgical ablation is recommended.

Paroxysmal: Surgical ablation is recommended.

Persistent: Surgical ablation is recommended.

Long-standing persistent: Surgical ablation is recommended.

$\begin{array}{lll}\text { I } & \text { A } & {[7-18]} \\ \text { IIa } & \text { B-NR } & {[8,16-26]} \\ \text { IIb } & \text { C-LD } & {[8,16-26]} \\ \text { IIa } & \text { B-R } & {[27-35]} \\ \text { IIa } & \text { C-EO } & \\ \text { IIb } & \text { C-EO } & \end{array}$

B-R

[36-52]

B-NR

[53-59]

B-NR

[60-62]

B-NR

B-NR

C-LD

$[27,28,65]$

C-EO

$[66,67]$

$\mathrm{IIb}$

C-EO

B-NR

[69-82]

[69-82]

[69-82]

[69-82]

Paroxysmal: Surgical ablation is recommended.

B-NR

[83-88]

Persistent: Surgical ablation is recommended.

B-NR

[83-88]

Long-standing persistent: Surgical ablation is

B-NR recommended.

Paroxysmal: Surgical ablation is reasonable.

B-NR

[83-88]

Persistent: Surgical ablation is reasonable.

IIa

B-NR

[83-88]

Long-standing persistent: Surgical ablation is

B-NR

[83-88] reasonable.

E. Indications for stand-alone and hybrid surgical ablation of atrial fibrillation

Symptomatic AF

refractory or intolerant to at

least one Class I or III

antiarrhythmic medication
Paroxysmal: Stand-alone surgical ablation can be considered for patients who have failed one or more attempts at catheter ablation and also for those who are intolerant or refractory to antiarrhythmic drug
$\mathrm{IIb}$

B-NR

[83-85, 89-103] 
Table 2 (continued)

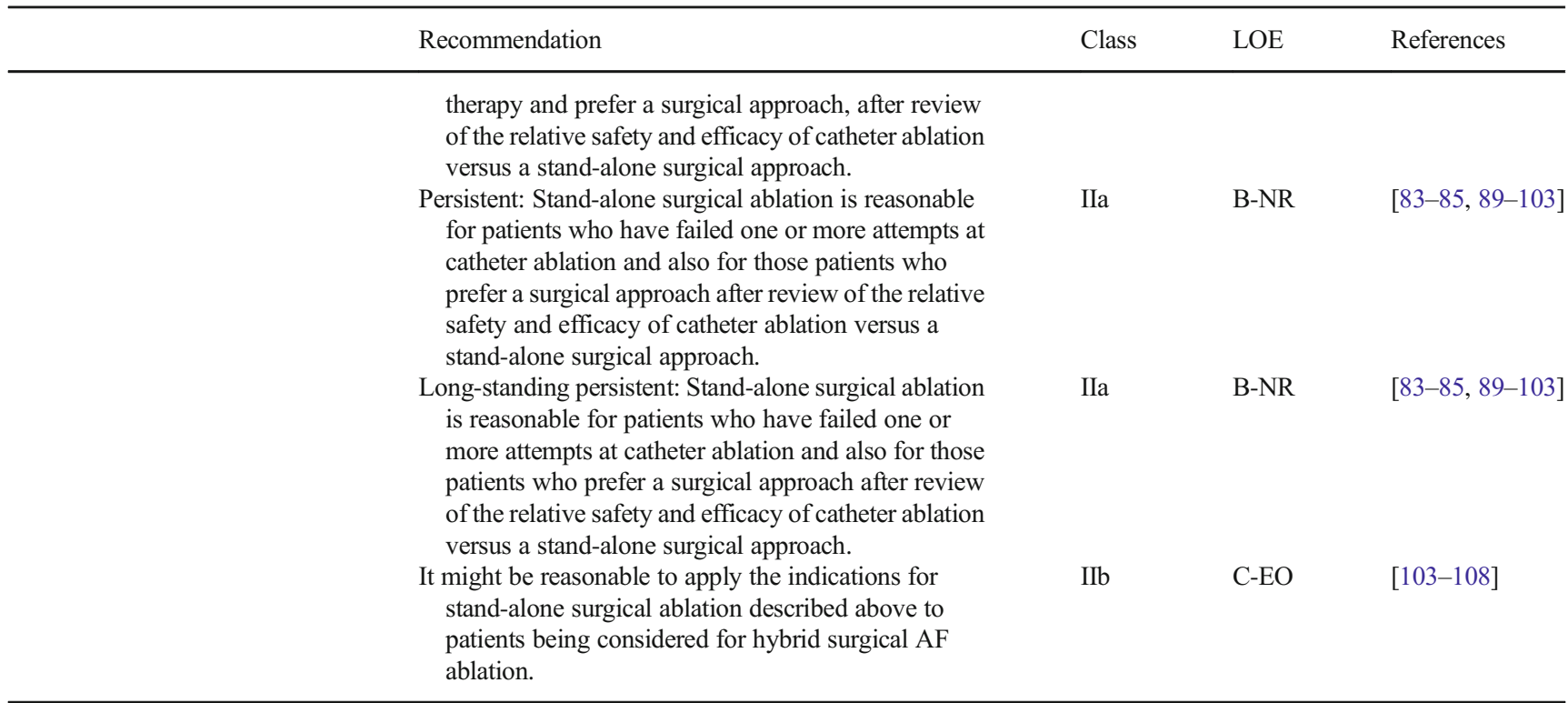

$A F$ atrial fibrillation, $L O E$ Level of Evidence, $H C M$ hypertrophic cardiomyopathy

** A decision to perform AF ablation in an asymptomatic patient requires additional discussion with the patient because the potential benefits of the procedure for the patient without symptoms are uncertain

might present with a Class I or IIa indication for ablation. Third, it is important to consider patient preference and values. Some patients are reluctant to consider a major procedure or surgery and have a strong preference for a pharmacological approach. In these patients, trials of antiarrhythmic agents including amiodarone might be preferred to catheter ablation. On the other hand, some patients prefer a nonpharmacological approach. Fourth, it is important to recognize that some patients early in the course of their AF journey might have only infrequent episodes for many years and/or could have AF that is responsive to well-tolerated AAD therapy. And finally, it is important to bear in mind that a decision to perform catheter or surgical AF ablation should only be made after a patient carefully considers the risks, benefits, and alternatives to the procedure.

\section{Strategies, techniques, and endpoints}

The writing group recommendations for techniques to be used for ablation of persistent and long-standing persistent AF (Table 3), adjunctive ablation strategies, nonablative strategies to improve outcomes of AF ablation, and endpoints for ablation of paroxysmal, persistent, and long-standing persistent $\mathrm{AF}$ are covered in this section. A schematic overview of common lesion sets created during an $\mathrm{AF}$ ablation procedure is shown in Fig. 6.

\section{Technology and tools}

This section of the consensus statement provides an update on many of the technologies and tools that are employed for AF ablation procedures. It is important to recognize that this is not a comprehensive listing and that new technologies, tools, and approaches are being developed. It is also important to recognize that

\section{Indications for Catheter Ablation of Symptomatic Atrial Fibrillation}

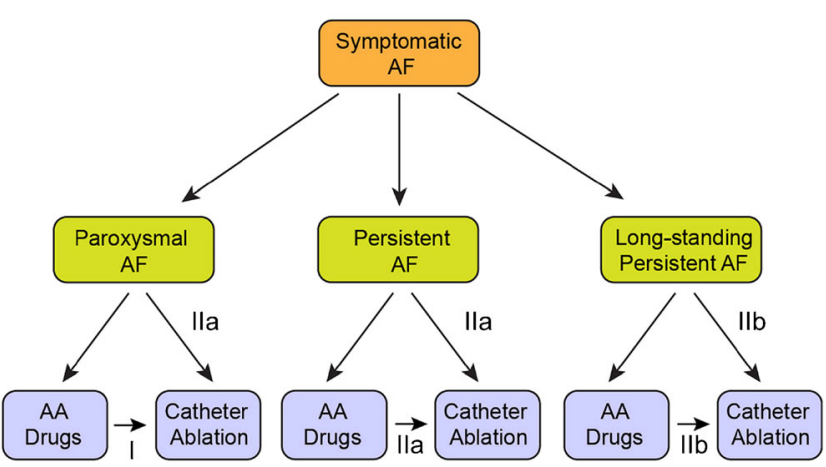

Fig. 7 Indications for catheter ablation of symptomatic atrial fibrillation. Shown in this figure are the indications for catheter ablation of symptomatic paroxysmal, persistent, and long-standing persistent AF. The Class for each indication based on whether ablation is performed after failure of antiarrhythmic drug therapy or as first-line therapy is shown. Please refer to Table $2 \mathrm{~B}$ and the text for the indications for catheter ablation of asymptomatic $\mathrm{AF}$ 
Indications for Concomitant Open (Such as Mitral Valve) Surgical Ablation of AF

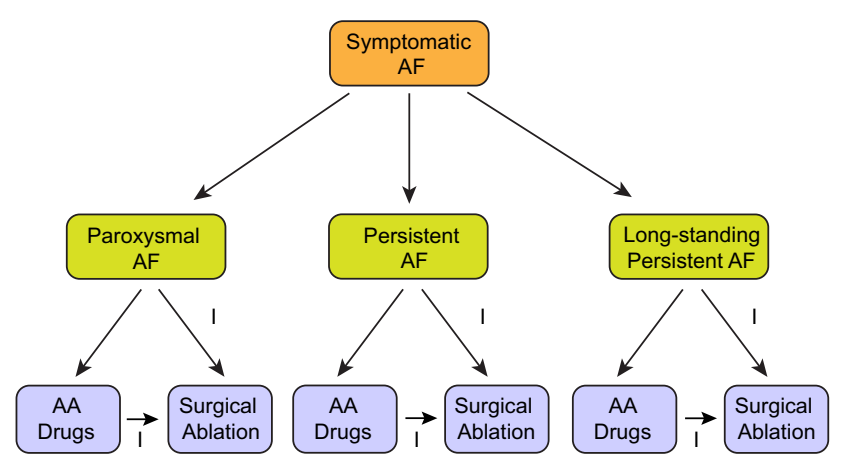

Indications for Concomitant Closed (Such as CABG or AVR) Surgical Ablation of AF

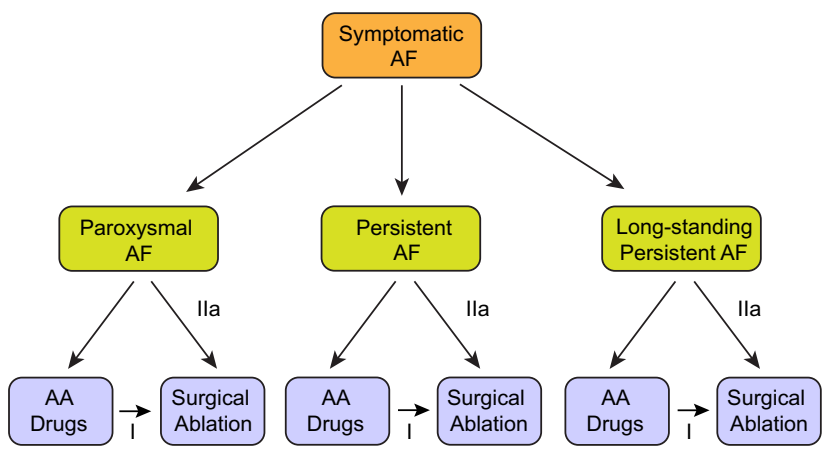

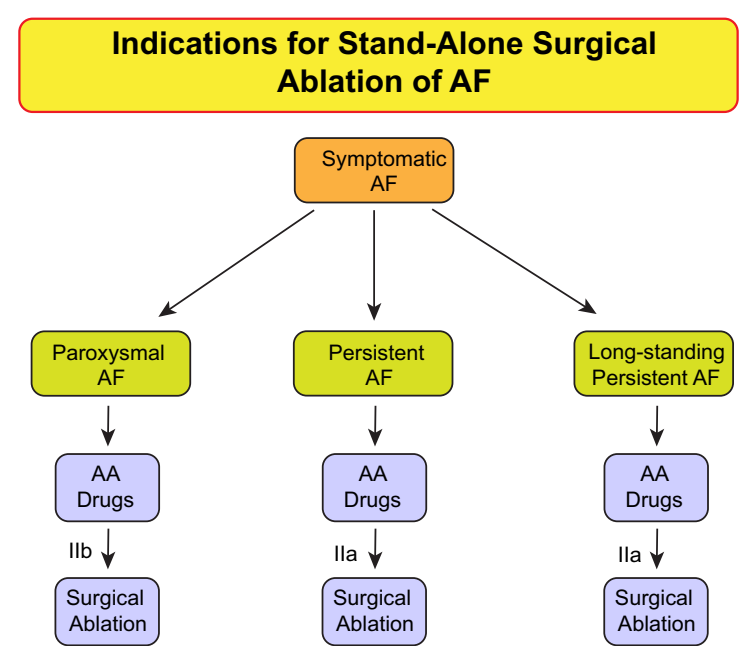

Fig. 8 Indications for surgical ablation of atrial fibrillation. Shown in this figure are the indications for surgical ablation of paroxysmal, persistent, and long-standing persistent AF. The Class for each indication based on whether ablation is performed after failure of antiarrhythmic drug therapy or as first-line therapy is shown. The indications for surgical AF ablation are divided into whether the AF ablation procedure is performed concomitantly with an open surgical procedure (such as mitral valve replacement), a closed surgical procedure (such as coronary artery bypass graft surgery), or as a stand-alone surgical AF ablation procedure performed solely for treatment of atrial fibrillation radiofrequency (RF) energy is the dominant energy source available for ablation of typical and atypical atrial flutter (AFL). Although cryoablation is a commonly employed tool for AF ablation, it is not well suited for ablation of typical or atypical AFL. Other energy sources and tools are available in some parts of the world and/or are in various stages of development and/ or clinical investigation. Shown in Fig. 9 are schematic drawings of AF ablation using point-by-point RF energy (Fig. 9a) and $\mathrm{AF}$ ablation using the cryoballoon (CB) system (Fig. 9b).

\section{Technical aspects of ablation to maximize safety and anticoagulation}

Anticoagulation strategies pre-, during, and postcatheter ablation of AF (Table 4); signs and symptoms of complications that can occur within the first several months following ablation (Table 5); anesthesia or sedation during ablation; and approaches to minimize risk of an atrial esophageal fistula are discussed in this section.

\section{Follow-up considerations}

$\mathrm{AF}$ ablation is an invasive procedure that entails risks, most of which are present during the acute procedural period. However, complications can also occur in the weeks or months following ablation. Recognizing common symptoms after AF ablation and distinguishing those that require urgent evaluation and referral to an electrophysiologist is an important part of follow-up after AF ablation. The success of AF ablation is based in large part on freedom from AF recurrence based on ECG monitoring. Arrhythmia monitoring can be performed with the use of noncontinuous or continuous 
Table 3 Atrial fibrillation ablation: strategies, techniques, and endpoints

\begin{tabular}{|c|c|c|c|c|}
\hline & Recommendation & Class & LOE & References \\
\hline \multirow[t]{6}{*}{$\begin{array}{l}\text { PV isolation by catheter } \\
\text { ablation }\end{array}$} & $\begin{array}{l}\text { Electrical isolation of the PVs is recommended during } \\
\text { all AF ablation procedures. }\end{array}$ & I & A & {$[7-16,19-26,109]$} \\
\hline & $\begin{array}{l}\text { Achievement of electrical isolation requires, at a } \\
\text { minimum, assessment and demonstration of } \\
\text { entrance block into the PV. }\end{array}$ & I & B-R & {$[7-16,19-26,109]$} \\
\hline & $\begin{array}{l}\text { Monitoring for PV reconnection for } 20 \text { min following } \\
\text { initial PV isolation is reasonable. }\end{array}$ & IIa & $\mathrm{B}-\mathrm{R}$ & {$[9,110-120]$} \\
\hline & $\begin{array}{l}\text { Administration of adenosine } 20 \text { min following initial } \\
\mathrm{PV} \text { isolation using RF energy with reablation if PV } \\
\text { reconnection might be considered. }\end{array}$ & $\mathrm{IIb}$ & B-R & {$[109,111-114,120-128]$} \\
\hline & $\begin{array}{l}\text { Use of a pace-capture (pacing along the ablation line) } \\
\text { ablation strategy may be considered. }\end{array}$ & $\mathrm{IIb}$ & B-R & [129-133] \\
\hline & Demonstration of exit block may be considered. & IIb & $\mathrm{B}-\mathrm{NR}$ & [134-139] \\
\hline \multirow[t]{13}{*}{$\begin{array}{l}\text { Ablation strategies to be } \\
\text { considered for use in } \\
\text { conjunction with PV } \\
\text { isolation }\end{array}$} & $\begin{array}{l}\text { If a patient has a history of typical atrial flutter or } \\
\text { typical atrial flutter is induced at the time of AF } \\
\text { ablation, delivery of a cavotricuspid isthmus linear } \\
\text { lesion is recommended. }\end{array}$ & I & $\mathrm{B}-\mathrm{R}$ & [140-143] \\
\hline & $\begin{array}{l}\text { If linear ablation lesions are applied, operators should } \\
\text { use mapping and pacing maneuvers to assess for line } \\
\text { completeness. }\end{array}$ & I & C-LD & {$[19,141-149]$} \\
\hline & $\begin{array}{l}\text { If a reproducible focal trigger that initiates } \mathrm{AF} \text { is } \\
\text { identified outside the } \mathrm{PV} \text { ostia at the time of an } \mathrm{AF} \\
\text { ablation procedure, ablation of the focal trigger } \\
\text { should be considered. }\end{array}$ & IIa & C-LD & {$[150-161]$} \\
\hline & $\begin{array}{l}\text { When performing AF ablation with a force-sensing RF } \\
\text { ablation catheter, a minimal targeted contact force of } \\
5 \text { to } 10 \mathrm{~g} \text { is reasonable. }\end{array}$ & IIa & C-LD & {$[13,14,128,162-178]$} \\
\hline & $\begin{array}{l}\text { Posterior wall isolation might be considered for initial } \\
\text { or repeat ablation of persistent or long-standing } \\
\text { persistent AF. }\end{array}$ & $\mathrm{IIb}$ & C-LD & {$[21,179-185]$} \\
\hline & $\begin{array}{l}\text { Administration of high-dose isoproterenol to screen for } \\
\text { and then ablate non-PV triggers may be considered } \\
\text { during initial or repeat AF ablation procedures in } \\
\text { patients with paroxysmal, persistent, or } \\
\text { long-standing persistent AF. }\end{array}$ & IIb & C-LD & {$[150-161]$} \\
\hline & $\begin{array}{l}\text { DF-based ablation strategy is of unknown usefulness } \\
\text { for AF ablation. }\end{array}$ & $\mathrm{IIb}$ & C-LD & [186-193] \\
\hline & $\begin{array}{l}\text { The usefulness of creating linear ablation lesions in the } \\
\text { right or left atrium as an initial or repeat ablation } \\
\text { strategy for persistent or long-standing persistent AF } \\
\text { is not well established. }\end{array}$ & IIb & B-NR & {$[19,20,142,145-149,194-201]$} \\
\hline & $\begin{array}{l}\text { The usefulness of linear ablation lesions in the absence } \\
\text { of macroreentrant atrial flutter is not well } \\
\text { established. }\end{array}$ & IIb & C-LD & {$[19,20,142,145-149,194-201]$} \\
\hline & $\begin{array}{l}\text { The usefulness of mapping and ablation of areas of } \\
\text { abnormal myocardial tissue identified with voltage } \\
\text { mapping or MRI as an initial or repeat ablation } \\
\text { strategy for persistent or long-standing persistent AF } \\
\text { is not well established. }\end{array}$ & IIb & B-R & {$[179,202-211]$} \\
\hline & $\begin{array}{l}\text { The usefulness of ablation of complex fractionated } \\
\text { atrial electrograms as an initial or repeat ablation } \\
\text { strategy for persistent and long-standing persistent } \\
\text { AF is not well established. }\end{array}$ & $\mathrm{IIb}$ & B-R & {$[19,20,195-197,212-220]$} \\
\hline & $\begin{array}{l}\text { The usefulness of ablation of rotational activity as an } \\
\text { initial or repeat ablation strategy for persistent and } \\
\text { long-standing persistent AF is not well established. }\end{array}$ & IIb & B-NR & {$[221-241]$} \\
\hline & $\begin{array}{l}\text { The usefulness of ablation of autonomic ganglia as an } \\
\text { initial or repeat ablation strategy for paroxysmal, } \\
\text { persistent, and long-standing persistent AF is not } \\
\text { well established. }\end{array}$ & $\mathrm{IIb}$ & B-NR & {$[19,89,242-259]$} \\
\hline
\end{tabular}


Table 3 (continued)

\begin{tabular}{|c|c|c|c|c|}
\hline & Recommendation & Class & LOE & References \\
\hline \multirow[t]{6}{*}{$\begin{array}{l}\text { Nonablation strategies to } \\
\text { improve outcomes }\end{array}$} & $\begin{array}{l}\text { Weight loss can be useful for patients with } \mathrm{AF} \text {, } \\
\text { including those who are being evaluated to undergo } \\
\text { an } \mathrm{AF} \text { ablation procedure, as part of a } \\
\text { comprehensive risk factor management strategy. }\end{array}$ & IIa & B-R & {$[260-288]$} \\
\hline & $\begin{array}{l}\text { It is reasonable to consider a patient's BMI when } \\
\text { discussing the risks, benefits, and outcomes of } \mathrm{AF} \\
\text { ablation with a patient being evaluated for an } \mathrm{AF} \\
\text { ablation procedure. }\end{array}$ & IIa & B-R & {$[260-288]$} \\
\hline & $\begin{array}{l}\text { It is reasonable to screen for signs and symptoms of } \\
\text { sleep apnea when evaluating a patient for an AF } \\
\text { ablation procedure and to recommend a sleep } \\
\text { evaluation if sleep apnea is suspected. }\end{array}$ & IIa & B-R & {$[270,276-278,289-307]$} \\
\hline & $\begin{array}{l}\text { Treatment of sleep apnea can be useful for patients with } \\
\text { AF, including those who are being evaluated to } \\
\text { undergo an AF ablation procedure. }\end{array}$ & IIa & B-R & {$[270,276-278,289-307]$} \\
\hline & $\begin{array}{l}\text { The usefulness of discontinuation of antiarrhythmic } \\
\text { drug therapy prior to AF ablation in an effort to } \\
\text { improve long-term outcomes is unclear. }\end{array}$ & $\mathrm{IIb}$ & C-LD & [308-312] \\
\hline & $\begin{array}{l}\text { The usefulness of initiation or continuation of } \\
\text { antiarrhythmic drug therapy during the postablation } \\
\text { healing phase in an effort to improve long-term } \\
\text { outcomes is unclear. }\end{array}$ & IIb & C-LD & [308-312] \\
\hline \multirow[t]{3}{*}{$\begin{array}{l}\text { Strategies to reduce the risks } \\
\text { of AF ablation }\end{array}$} & $\begin{array}{l}\text { Careful identification of the PV ostia is mandatory to } \\
\text { avoid ablation within the PVs. }\end{array}$ & I & B-NR & [313-335] \\
\hline & $\begin{array}{l}\text { It is recommended that RF power be reduced when } \\
\text { creating lesions along the posterior wall near the } \\
\text { esophagus. }\end{array}$ & I & C-LD & {$[68,336-365]$} \\
\hline & $\begin{array}{l}\text { It is reasonable to use an esophageal temperature probe } \\
\text { during } \mathrm{AF} \text { ablation procedures to monitor } \\
\text { esophageal temperature and help guide energy } \\
\text { delivery. }\end{array}$ & IIa & C-EO & {$[68,336,345,365]$} \\
\hline
\end{tabular}

$A F$ atrial fibrillation, $L O E$ Level of Evidence, $P V$ pulmonary vein, $R F$ radiofrequency, $M R I$ magnetic resonance imaging, $B M I$ body mass index

(a)

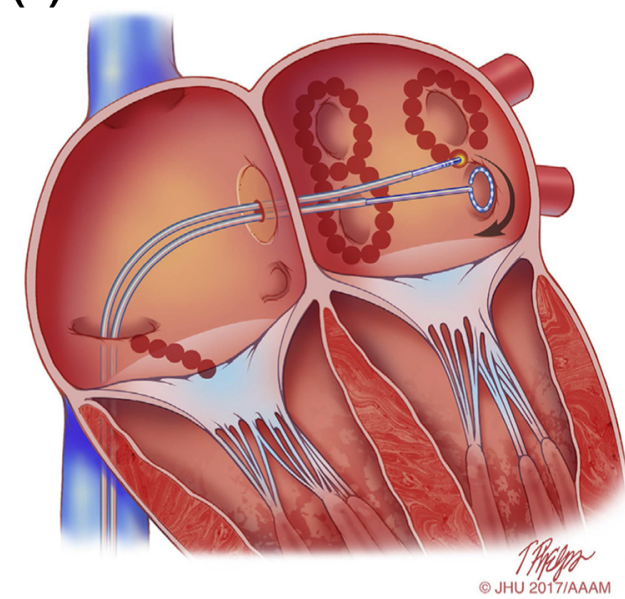

Fig. 9 Schematic drawing showing catheter ablation of atrial fibrillation using either RF energy or cryoballoon AF ablation. a Shows a typical wide area lesion set created using RF energy. Ablation lesions are delivered in a figure of eight pattern around the left and right PV veins. Also shown is a linear cavotricuspid isthmus lesion created for ablation of typical atrial flutter in a patient with a prior history of typical atrial flutter or inducible isthmus-dependent typical atrial flutter at the time of (b)

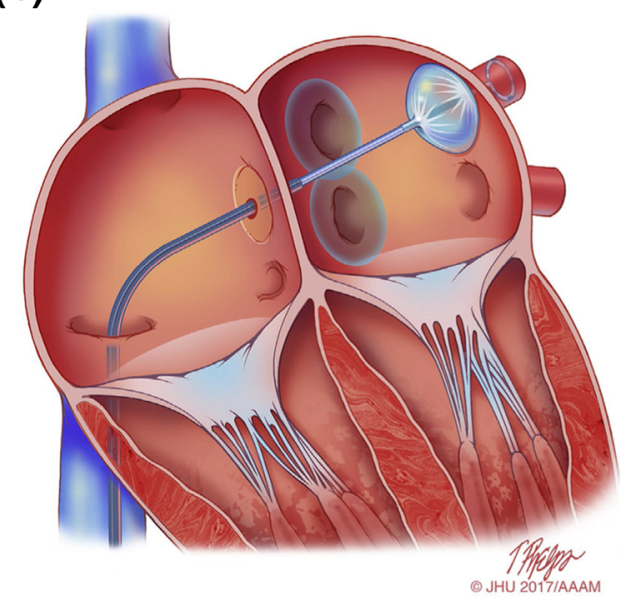

ablation. A multielectrode circular mapping catheter is positioned in the left inferior PV. b Shows an ablation procedure using the cryoballoon system. Ablation lesions have been created surrounding the right PVs, and the cryoballoon ablation catheter is positioned in the left superior PV. A through the lumen multielectrode circular mapping catheter is positioned in the left superior PV. Illustration: Tim Phelps (C) 2017 Johns Hopkins University, AAM 
Table 4 Anticoagulation strategies: pre-, during, and postcatheter ablation of AF

\begin{tabular}{|c|c|c|c|c|}
\hline & Recommendation & Class & LOE & References \\
\hline \multirow[t]{8}{*}{ Preablation } & $\begin{array}{l}\text { For patients undergoing AF catheter ablation who have } \\
\text { been therapeutically anticoagulated with warfarin or } \\
\text { dabigatran, performance of the ablation procedure } \\
\text { without interruption of warfarin or dabigatran is } \\
\text { recommended. }\end{array}$ & I & A & {$[366-373]$} \\
\hline & $\begin{array}{l}\text { For patients undergoing AF catheter ablation who have } \\
\text { been therapeutically anticoagulated with } \\
\text { rivaroxaban, performance of the ablation procedure } \\
\text { without interruption of rivaroxaban is } \\
\text { recommended. }\end{array}$ & I & B-R & [374] \\
\hline & $\begin{array}{l}\text { For patients undergoing AF catheter ablation who have } \\
\text { been therapeutically anticoagulated with a NOAC } \\
\text { other than dabigatran or rivaroxaban, performance of } \\
\text { the ablation procedure without withholding a NOAC } \\
\text { dose is reasonable. }\end{array}$ & IIa & B-NR & {$[375]$} \\
\hline & $\begin{array}{l}\text { Anticoagulation guidelines that pertain to } \\
\text { cardioversion of AF should be adhered to in patients } \\
\text { who present for an AF catheter ablation procedure. }\end{array}$ & I & B-NR & {$[5,6]$} \\
\hline & $\begin{array}{l}\text { For patients anticoagulated with a NOAC prior to AF } \\
\text { catheter ablation, it is reasonable to hold one to two } \\
\text { doses of the NOAC prior to AF ablation with } \\
\text { reinitiation postablation. }\end{array}$ & IIa & B-NR & {$[372,376-380]$} \\
\hline & $\begin{array}{l}\text { Performance of a TEE in patients who are in AF on } \\
\text { presentation for AF catheter ablation and who have } \\
\text { been receiving anticoagulation therapeutically for } 3 \\
\text { weeks or longer is reasonable. }\end{array}$ & IIa & C-EO & {$[5,6]$} \\
\hline & $\begin{array}{l}\text { Performance of a TEE in patients who present for } \\
\text { ablation in sinus rhythm and who have not been } \\
\text { anticoagulated prior to catheter ablation is } \\
\text { reasonable. }\end{array}$ & IIa & C-EO & {$[5,6]$} \\
\hline & $\begin{array}{l}\text { Use of intracardiac echocardiography to screen for } \\
\text { atrial thrombi in patients who cannot undergo TEE } \\
\text { may be considered. }\end{array}$ & $\mathrm{IIb}$ & C-EO & [381-386] \\
\hline \multirow[t]{2}{*}{ During ablation } & $\begin{array}{l}\text { Heparin should be administered prior to or immediately } \\
\text { following transseptal puncture during AF catheter } \\
\text { ablation procedures and adjusted to achieve and } \\
\text { maintain an ACT of at least } 300 \mathrm{~s} \text {. }\end{array}$ & I & B-NR & {$[369,380-382,387-393]$} \\
\hline & $\begin{array}{l}\text { Administration of protamine following AF catheter } \\
\text { ablation to reverse heparin is reasonable. }\end{array}$ & IIa & B-NR & [394] \\
\hline \multirow[t]{5}{*}{ Postablation } & $\begin{array}{l}\text { In patients who are not therapeutically anticoagulated } \\
\text { prior to catheter ablation of AF and in whom } \\
\text { warfarin will be used for anticoagulation } \\
\text { postablation, low molecular weight heparin or } \\
\text { intravenous heparin should be used as a bridge for } \\
\text { initiation of systemic anticoagulation with warfarin } \\
\text { following AF ablation.* }\end{array}$ & I & C-EO & \\
\hline & $\begin{array}{l}\text { Systemic anticoagulation with warfarin* or a NOAC is } \\
\text { recommended for at least } 2 \text { months postcatheter } \\
\text { ablation of AF. }\end{array}$ & I & C-EO & {$[1,2]$} \\
\hline & $\begin{array}{l}\text { Adherence to } \mathrm{AF} \text { anticoagulation guidelines is } \\
\text { recommended for patients who have undergone an } \\
\mathrm{AF} \text { ablation procedure, regardless of the apparent } \\
\text { success or failure of the procedure. }\end{array}$ & I & C-EO & {$[5,6]$} \\
\hline & $\begin{array}{l}\text { Decisions regarding continuation of systemic } \\
\text { anticoagulation more than } 2 \text { months post ablation } \\
\text { should be based on the patient's stroke risk profile } \\
\text { and not on the perceived success or failure of the } \\
\text { ablation procedure. }\end{array}$ & I & C-EO & {$[5,6]$} \\
\hline & In patients who have not been anticoagulated prior to & IIa & C-EO & {$[372,376-380]$} \\
\hline
\end{tabular}
with a NOAC or warfarin has been interrupted prior to ablation, administration of a NOAC 3 to $5 \mathrm{~h}$ after 
Table 4 (continued)

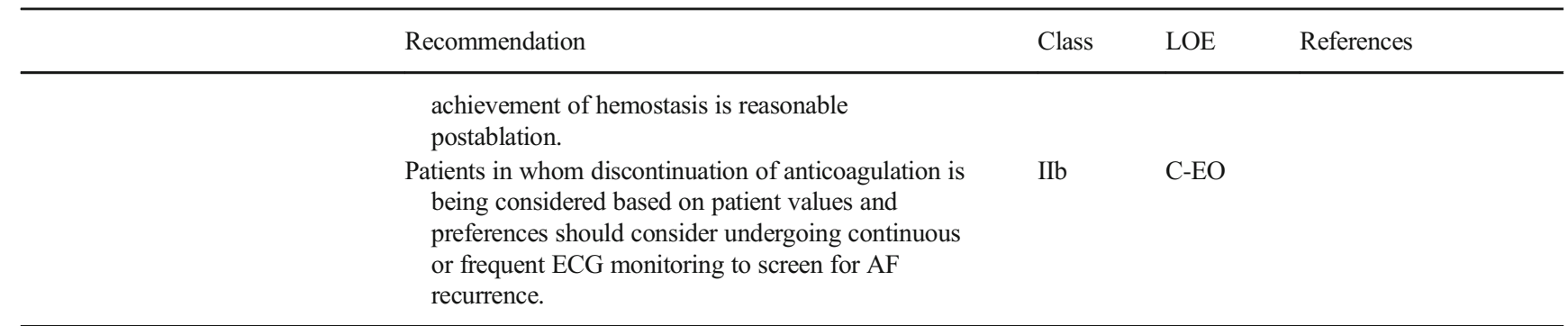

$A F$ atrial fibrillation, $L O E$ Level of Evidence, $N O A C$ novel oral anticoagulant, $T E E$ transesophageal electrocardiogram, $A C T$ activated clotting time

* Time in therapeutic range (TTR) should be $>65 \%-70 \%$ on warfarin

ECG monitoring tools (Table 6). This section also discusses the important topics of AAD and non-AAD use prior to and following AF ablation, the role of cardioversion, as well as the indications for and timing of repeat $\mathrm{AF}$ ablation procedures.

\section{Outcomes and efficacy}

This section provides a comprehensive review of the outcomes of catheter ablation of AF. Table 7 summarizes the

Table 5 Signs and symptoms following AF ablation

\begin{tabular}{|c|c|c|}
\hline & Differential & Suggested evaluation \\
\hline \multicolumn{3}{|c|}{ Signs and symptoms of complications within a month postablation } \\
\hline Back pain & Musculoskeletal, retroperitoneal hematoma & Physical exam, CT imaging \\
\hline Chest pain & $\begin{array}{l}\text { Pericarditis, pericardial effusion, coronary stenosis } \\
\text { (ablation related), pulmonary vein stenosis, } \\
\text { musculoskeletal (after cardioversion), worsening } \\
\text { reflux }\end{array}$ & $\begin{array}{l}\text { Physical exam, chest X-ray, ECG, echocardiogram, } \\
\text { stress test, cardiac catheterization, chest CT }\end{array}$ \\
\hline Cough & $\begin{array}{l}\text { Infectious process, bronchial irritation (mechanical, } \\
\text { cryoballoon), pulmonary vein stenosis }\end{array}$ & Physical exam, chest X-ray, chest CT \\
\hline Dysphagia & $\begin{array}{l}\text { Esophageal irritation (related to transesophageal } \\
\text { echocardiography), atrioesophageal fistula }\end{array}$ & Physical exam, chest CT or MRI \\
\hline Early satiety, nausea & Gastric denervation & Physical exam, gastric emptying study \\
\hline Fever & Infectious process, pericarditis, atrioesophageal fistula & $\begin{array}{l}\text { Physical exam, chest X-ray, chest CT, urinalysis, } \\
\text { laboratory blood work }\end{array}$ \\
\hline $\begin{array}{l}\text { Fever, dysphagia, } \\
\text { neurological symptoms }\end{array}$ & Atrial esophageal fistula & $\begin{array}{l}\text { Physical exam, laboratory blood work, chest CT or } \\
\text { MRI; avoid endoscopy with air insufflation }\end{array}$ \\
\hline Groin pain at site of access & Pseudoaneurysm, AV fistula, hematoma & $\begin{array}{l}\text { Ultrasound of the groin, laboratory blood work; } \\
\text { consider CT scan if ultrasound negative }\end{array}$ \\
\hline Headache & $\begin{array}{l}\text { Migraine (related to anesthesia or transseptal access, } \\
\text { hemorrhagic stroke), effect of general anesthetic }\end{array}$ & Physical exam, brain imaging (MRI) \\
\hline Hypotension & $\begin{array}{l}\text { Pericardial effusion/tamponade, bleeding, sepsis, } \\
\text { persistent vagal reaction }\end{array}$ & Echocardiography, laboratory blood work \\
\hline Hemoptysis & PV stenosis or occlusion, pneumonia & Chest X-ray, chest CT or MR scan, VQ scan \\
\hline Neurological symptoms & Cerebral embolic event, atrial esophageal fistula & Physical exam, brain imaging, chest CT or MRI \\
\hline Shortness of breath & $\begin{array}{l}\text { Volume overload, pneumonia, pulmonary vein } \\
\text { stenosis, phrenic nerve injury }\end{array}$ & $\begin{array}{l}\text { Physical exam, chest X-ray, chest CT, laboratory blood } \\
\text { work }\end{array}$ \\
\hline \multicolumn{3}{|c|}{ Signs and symptoms of complications more than a month postablation } \\
\hline $\begin{array}{l}\text { Fever, dysphagia, } \\
\text { neurological symptoms }\end{array}$ & Atrial esophageal fistula & $\begin{array}{l}\text { Physical exam, laboratory blood work, chest CT or } \\
\text { MRI; avoid endoscopy with air insufflation }\end{array}$ \\
\hline $\begin{array}{l}\text { Persistent cough, atypical } \\
\text { chest pain }\end{array}$ & Infectious process, pulmonary vein stenosis & $\begin{array}{l}\text { Physical exam, laboratory blood work, chest X-ray, } \\
\text { chest CT or MRI }\end{array}$ \\
\hline Neurological symptoms & Cerebral embolic event, atrial esophageal fistula & Physical exam, brain imaging, chest CT or MRI \\
\hline Hemoptysis & PV stenosis or occlusion, pneumonia & CT scan, VQ scan \\
\hline
\end{tabular}

$A F$ atrial fibrillation, $E C G$ electrocardiogram, $C T$ computed tomography, $M R I$ magnetic resonance imaging, $V Q$ ventilation-perfusion 
Table 6 Types of ambulatory cardiac monitoring devices

\begin{tabular}{|c|c|c|c|c|c|}
\hline Type of recorder & $\begin{array}{l}\text { Typical monitoring } \\
\text { duration }\end{array}$ & $\begin{array}{l}\text { Continuous } \\
\text { recording }\end{array}$ & $\begin{array}{l}\text { Event } \\
\text { recording }\end{array}$ & $\begin{array}{l}\text { Auto } \\
\text { trigger }\end{array}$ & Unique features \\
\hline Holter monitor & $\begin{array}{l}24-48 \mathrm{~h} \text {, approximately } \\
7-30 \text { days }\end{array}$ & Yes & Yes & N/A & $\begin{array}{l}\text { Short term, provides quantitative data on arrhythmia } \\
\text { burden }\end{array}$ \\
\hline Patch monitor & $1-3$ weeks & Yes & Yes & N/A & $\begin{array}{l}\text { Intermediate term, can provide continuous data for up } \\
\text { to several weeks; improved patient compliance } \\
\text { without lead wires }\end{array}$ \\
\hline External loop recorder & 1 month & Yes & Yes & Variable & $\begin{array}{l}\text { Good correlation between symptoms and even brief } \\
\text { arrhythmias }\end{array}$ \\
\hline External nonloop recorder & Months & No & Yes & No & $\begin{array}{l}\text { May be used long term and intermittently; will not } \\
\text { capture very brief episodes }\end{array}$ \\
\hline Smartphone monitor & Indefinite & No & Yes & No & $\begin{array}{l}\text { Provides inexpensive long-term intermittent } \\
\text { monitoring; dependent on patient compliance; } \\
\text { requires a smartphone }\end{array}$ \\
\hline Mobile cardiac telemetry & 30 days & Yes & Yes & Yes & $\begin{array}{l}\text { Real time central monitoring and alarms; relatively } \\
\text { expensive }\end{array}$ \\
\hline Implantable loop recorder & Up to 3 years & Yes & Yes & Yes & $\begin{array}{l}\text { Improved patient compliance for long-term use; not } \\
\text { able to detect } 30 \text {-s episodes of AF due to detection } \\
\text { algorithm; presence of AF needs to be confirmed by } \\
\text { EGM review because specificity of detection } \\
\text { algorithm is imperfect; expensive }\end{array}$ \\
\hline $\begin{array}{l}\text { Pacemakers or ICDs with } \\
\text { atrial leads }\end{array}$ & Indefinite & Yes & Yes & Yes & $\begin{array}{l}\text { Excellent AF documentation of burden and trends; } \\
\text { presence of AF needs to be confirmed by } \\
\text { electrogram tracing review because specificity of } \\
\text { detection algorithms is imperfect; expensive }\end{array}$ \\
\hline $\begin{array}{l}\text { Wearable multisensor } \\
\text { ECG monitors }\end{array}$ & Indefinite & Yes & Yes & Yes & $\begin{array}{l}\text { ECG } 3 \text { leads, temp, heart rate, HRV, activity tracking, } \\
\text { respiratory rate, galvanic skin response }\end{array}$ \\
\hline
\end{tabular}

$A F$ atrial fibrillation, $I C D$ implantable cardioverter defibrillator, $E C G$ electrocardiogram, $H R V$ heart rate variability

main findings of the most important clinical trials in this field. Outcomes of AF ablation in subsets of patients not well represented in these trials are reviewed. Outcomes for specific ablation systems and strategies (CB ablation, rotational activity ablation, and laser balloon ablation) are also reviewed.

\section{Complications}

Catheter ablation of AF is one of the most complex interventional electrophysiological procedures. AF ablation by its nature involves catheter manipulation and ablation in the delicate thin-walled atria, which are in close proximity to other important organs and structures that can be impacted through collateral damage. It is therefore not surprising that AF ablation is associated with a significant risk of complications, some of which might result in life-long disability and/or death. This section reviews the complications associated with catheter ablation procedures performed to treat AF. The types and incidence of complications are presented, their mechanisms are explored, and the optimal approach to prevention and treatment is discussed (Tables 8 and 9).

\section{Training requirements}

This section of the document outlines the training requirements for those who wish to perform catheter ablation of $\mathrm{AF}$.

\section{Surgical and hybrid AF ablation}

Please refer to Table 2 and Fig. 8 presented earlier in this Executive Summary.

\section{Clinical trial design}

Although there have been many advances made in the field of catheter and surgical ablation of AF, there is still much to be learned about the mechanisms of initiation and maintenance of $\mathrm{AF}$ and how to apply this knowledge to the still-evolving techniques of AF ablation. Although single-center, observational reports have dominated the early days of this field, we are quickly moving into an era in which hypotheses are put through the rigor of testing in well-designed, randomized, 


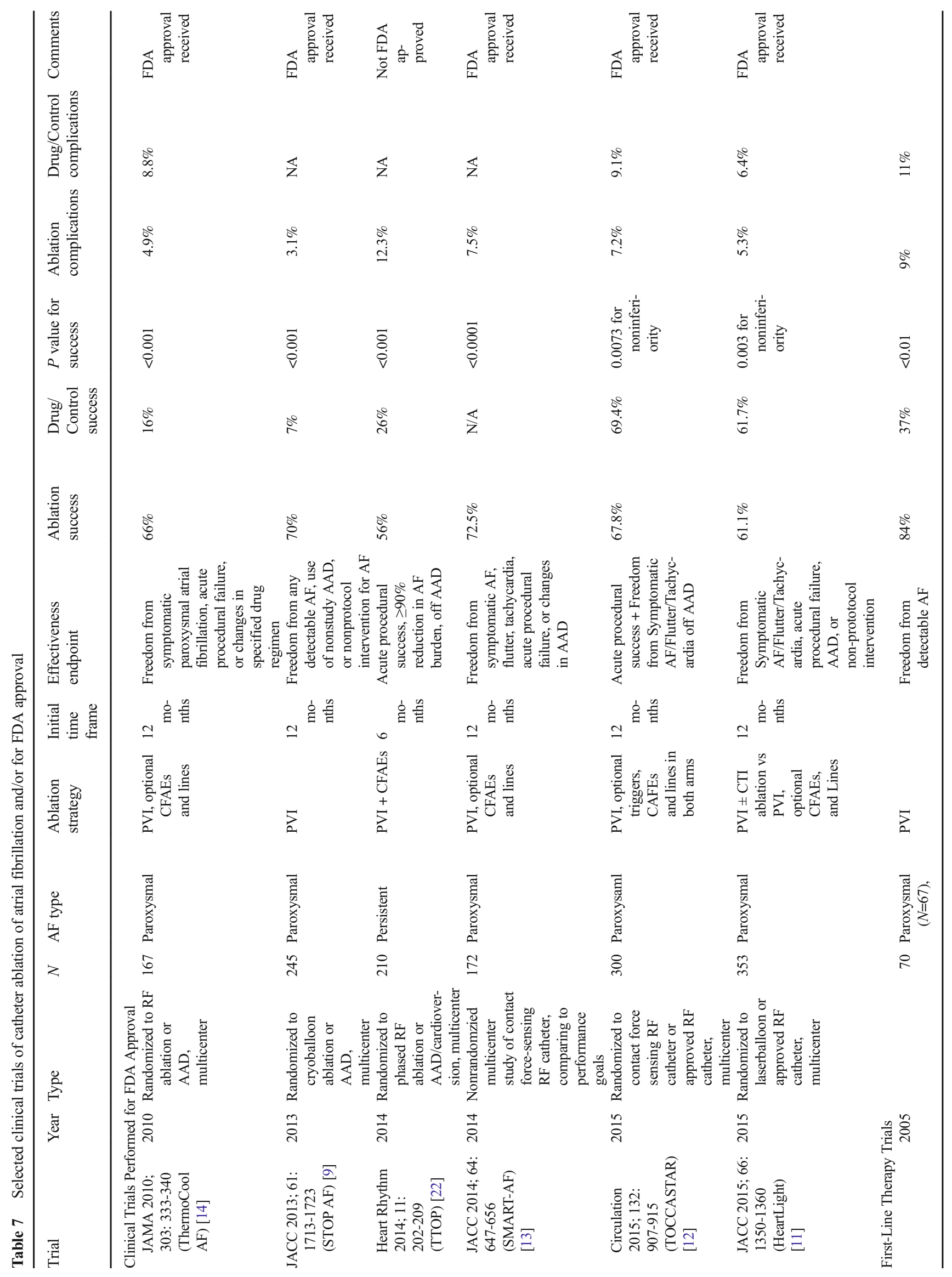




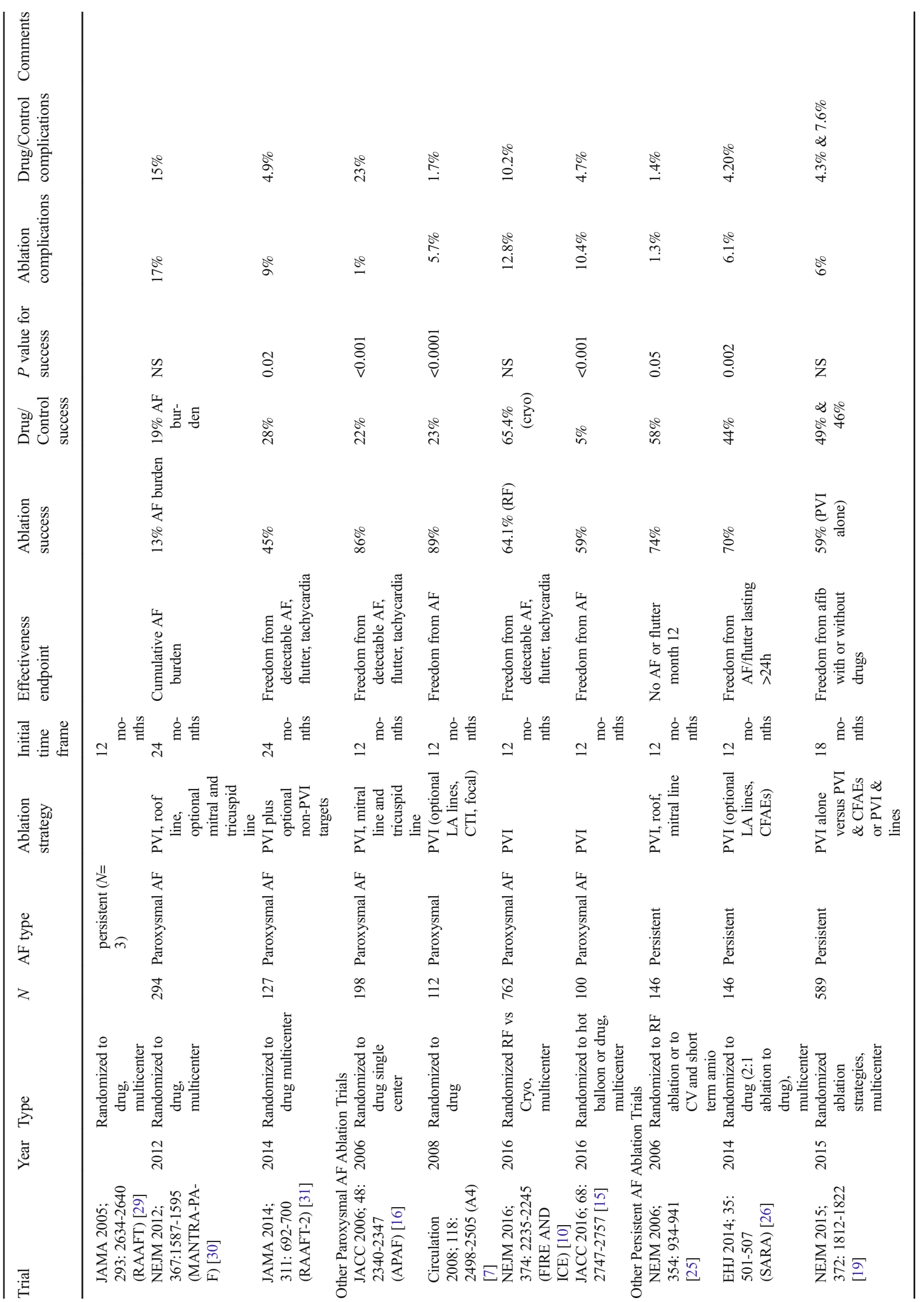




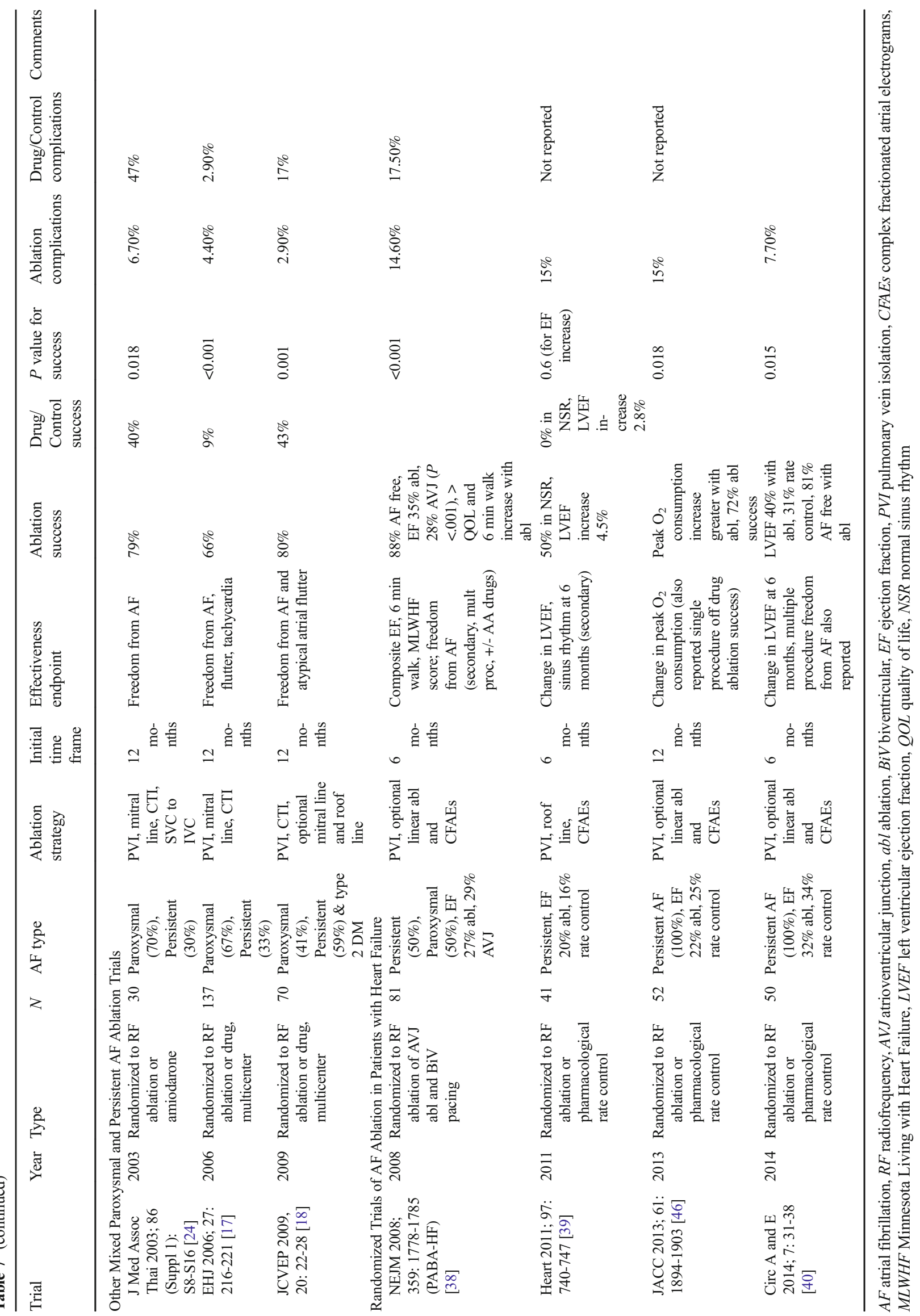


Table 8 Definitions of complications associated with AF ablation

Asymptomatic cerebral embolism

Atrioesophageal fistula

Bleeding

Bleeding following cardiac surgery

Cardiac perforation

Cardiac tamponade

Cardiac tamponade/perforation

Deep sternal wound infection/mediastinitis following cardiac surgery

Esophageal injury

Gastric motility/pyloric spasm disorders

Major complication

Mediastinitis

Myocardial infarction in the context of $\mathrm{AF}$ ablation

Pericarditis

Phrenic nerve paralysis
Asymptomatic cerebral embolism is defined as an occlusion of a blood vessel in the brain due to an embolus that does not result in any acute clinical symptoms. Silent cerebral embolism is generally detected using a diffusion weighted MRI.

An atrioesophageal fistula is defined as a connection between the atrium and the lumen of the esophagus. Evidence supporting this diagnosis includes documentation of esophageal erosion combined with evidence of a fistulous connection to the atrium, such as air emboli, an embolic event, or direct observation at the time of surgical repair. A CT scan or MRI scan is the most common method of documentation of an atrioesophageal fistula.

Bleeding is defined as a major complication of $\mathrm{AF}$ ablation if it requires and/or is treated with transfusion or results in a $20 \%$ or greater fall in hematocrit.

Excessive bleeding following a surgical $\mathrm{AF}$ ablation procedure is defined as bleeding requiring reoperation or $\geq 2$ units of PRBC transfusion within any $24 \mathrm{~h}$ of the first 7 days following the index procedure.

We recommend that cardiac perforation be defined together with cardiac tamponade. See "Cardiac tamponade/perforation."

We recommend that cardiac tamponade be defined together with cardiac perforation. See "Cardiac tamponade/perforation."

Cardiac tamponade/perforation is defined as the development of a significant pericardial effusion during or within 30 days of undergoing an $\mathrm{AF}$ ablation procedure. A significant pericardial effusion is one that results in hemodynamic compromise, requires elective or urgent pericardiocentesis, or results in a 1-cm or more pericardial effusion as documented by echocardiography. Cardiac tamponade/perforation should also be classified as "early" or "late" depending on whether it is diagnosed during or following initial discharge from the hospital.

Deep sternal wound infection/mediastinitis following cardiac surgery requires one of the following: (1) an organism isolated from culture of mediastinal tissue or fluid; (2) evidence of mediastinitis observed during surgery; (3) one of the following conditions: chest pain, sternal instability, or fever $\left(>38^{\circ} \mathrm{C}\right)$, in combination with either purulent discharge from the mediastinum or an organism isolated from blood culture or culture of mediastinal drainage.

Esophageal injury is defined as an erosion, ulceration, or perforation of the esophagus. The method of screening for esophageal injury should be specified. Esophageal injury can be a mild complication (erosion or ulceration) or a major complication (perforation).

Gastric motility/pyloric spasm disorder should be considered a major complication of AF ablation when it prolongs or requires hospitalization, requires intervention, or results in late disability, such as weight loss, early satiety, diarrhea, or GI disturbance.

A major complication is a complication that results in permanent injury or death, requires intervention for treatment, or prolongs or requires hospitalization for more than $48 \mathrm{~h}$. Because early recurrences of $\mathrm{AF} / \mathrm{AFL} / \mathrm{AT}$ are to be expected following $\mathrm{AF}$ ablation, recurrent $\mathrm{AF} / \mathrm{AFL} / \mathrm{AT}$ within 3 months that requires or prolongs a patient's hospitalization should not be considered to be a major complication of $\mathrm{AF}$ ablation.

Mediastinitis is defined as inflammation of the mediastinum. Diagnosis requires one of the following: (1) an organism isolated from culture of mediastinal tissue or fluid; (2) evidence of mediastinitis observed during surgery; (3) one of the following conditions: chest pain, sternal instability, or fever $\left(>38^{\circ} \mathrm{C}\right)$, in combination with either purulent discharge from the mediastinum or an organism isolated from blood culture or culture of mediastinal drainage.

The universal definition of myocardial infarction [395] cannot be applied in the context of catheter or surgical $\mathrm{AF}$ ablation procedures because it relies heavily on cardiac biomarkers (troponin and $\mathrm{CPK}$ ), which are anticipated to increase in all patients who undergo $\mathrm{AF}$ ablation as a result of the ablation of myocardial tissue. Similarly, chest pain and other cardiac symptoms are difficult to interpret in the context of AF ablation both because of the required sedation and anesthesia and also because most patients experience chest pain following the procedure as a result of the associated pericarditis that occurs following catheter ablation. We therefore propose that a myocardial infarction, in the context of catheter or surgical ablation, be defined as the presence of any one of the following criteria: (1) detection of ECG changes indicative of new ischemia (new ST-T wave changes or new LBBB) that persist for more than $1 \mathrm{~h}$; (2) development of new pathological $\mathrm{Q}$ waves on an ECG; (3) imaging evidence of new loss of viable myocardium or new regional wall motion abnormality.

Pericarditis should be considered a major complication following ablation if it results in an effusion that leads to hemodynamic compromise or requires pericardiocentesis, prolongs hospitalization by more than $48 \mathrm{~h}$, requires hospitalization, or persists for more than 30 days following the ablation procedure.

Phrenic nerve paralysis is defined as absent phrenic nerve function as assessed by a sniff test. A phrenic nerve paralysis is considered to be permanent when it is documented to be present 12 months or longer following ablation. 
Table 8 (continued)

Pulmonary vein stenosis

Serious adverse device effect

Stiff left atrial syndrome

Stroke or TIA postablation

Unanticipated adverse device effect

Vagal nerve injury

Vascular access complication
Pulmonary vein stenosis is defined as a reduction of the diameter of a PV or PV branch. PV stenosis can be categorized as mild $<50 \%$, moderate $50 \%-70 \%$, and severe $\geq 70 \%$ reduction in the diameter of the PV or PV branch. A severe PV stenosis should be considered a major complication of AF ablation.

A serious adverse device effect is defined as a serious adverse event that is attributed to use of a particular device.

Stiff left atrial syndrome is a clinical syndrome defined by the presence of signs of right heart failure in the presence of preserved LV function, pulmonary hypertension (mean PA pressure $>25 \mathrm{mmHg}$ or during exercise $>30 \mathrm{mmHg}$ ), and large $\mathrm{V}$ waves $\geq 10 \mathrm{mmHg}$ or higher) on PCWP or left atrial pressure tracings in the absence of significant mitral valve disease or PV stenosis.

Stroke diagnostic criteria

-Rapid onset of a focal or global neurological deficit with at least one of the following: change in level of consciousness, hemiplegia, hemiparesis, numbness or sensory loss affecting one side of the body, dysphasia or aphasia, hemianopia, amaurosis fugax, or other neurological signs or symptoms consistent with stroke

-Duration of a focal or global neurological deficit $\geq 24 \mathrm{~h}$; OR $<24 \mathrm{~h}$ if therapeutic intervention(s) were performed (e.g., thrombolytic therapy or intracranial angioplasty); OR available neuroimaging documents a new hemorrhage or infarct; OR the neurological deficit results in death.

-No other readily identifiable nonstroke cause for the clinical presentation (e.g., brain tumor, trauma, infection, hypoglycemia, peripheral lesion, pharmacological influences). ${ }^{*}$ -Confirmation of the diagnosis by at least one of the following: neurology or neurosurgical specialist; neuroimaging procedure (MRI or CT scan or cerebral angiography); lumbar puncture (i.e., spinal fluid analysis diagnostic of intracranial hemorrhage)

Stroke definitions

- Transient ischemic attack: new focal neurological deficit with rapid symptom resolution (usually 1 to $2 \mathrm{~h}$ ), always within $24 \mathrm{~h}$; neuroimaging without tissue injury

-Stroke: (diagnosis as above, preferably with positive neuroimaging study);

Minor-Modified Rankin score $<2$ at 30 and 90 days $^{\dagger}$

Major-Modified Rankin score $\geq 2$ at 30 and 90 days

Unanticipated adverse device effect is defined as complication of an ablation procedure that has not been previously known to be associated with catheter or surgical ablation procedures.

Vagal nerve injury is defined as injury to the vagal nerve that results in esophageal dysmotility or gastroparesis. Vagal nerve injury is considered to be a major complication if it prolongs hospitalization, requires hospitalization, or results in ongoing symptoms for more than 30 days following an ablation procedure.

Vascular access complications include development of a hematoma, an AV fistula, or a pseudoaneurysm. A major vascular complication is defined as one that requires intervention, such as surgical repair or transfusion, prolongs the hospital stay, or requires hospital admission.

$A F$ atrial fibrillation, $C T$ computed tomography, $M R I$ magnetic resonance imaging, $P R B C$ packed red blood cell, $A F L$ atrial flutter, $A T$ atrial tachycardia, $C P K$ creatine phosphokinase, $E C G$ electrocardiogram, $L B B B$ left bundle branch block

* Patients with nonfocal global encephalopathy will not be reported as a stroke without unequivocal evidence based on neuroimaging studies

${ }^{\dagger}$ Modified Rankin score assessments should be made by qualified individuals according to a certification process. If there is discordance between the 30 and 90-day modified Rankin scores, a final determination of major versus minor stroke will be adjudicated by the neurology members of the clinical events committee

multicenter clinical trials. It is as a result of these trials that conventional thinking about the best techniques, success rates, complication rates, and long-term outcomes beyond AF recurrence - such as thromboembolism and mortality-is being put to the test. The ablation literature has also seen a proliferation of meta-analyses and other aggregate analyses, which reinforce the need for consistency in the approach to reporting the results of clinical trials. This section reviews the minimum requirements for reporting on AF ablation trials. It also acknowledges the potential limitations of using specific primary outcomes and emphasizes the need for broad and consistent reporting of secondary outcomes to assist the end-user in determining not only the scientific, but also the clinical relevance of the results (Tables 10,11, 12, and 13). 
Table 9 Incidence, prevention, diagnosis, and treatment of selected complications of AF ablation

\begin{tabular}{|c|c|c|c|c|c|}
\hline Complication & Incidence & Selected prevention techniques & Diagnostic testing & Selected treatment options & References \\
\hline Air embolism & $<1 \%$ & Sheath management & $\begin{array}{l}\text { Nothing or cardiac } \\
\text { catheterization }\end{array}$ & $\begin{array}{l}\text { Supportive care with fluid, } \\
\text { oxygen, head down tilt, } \\
\text { hyperbaric oxygen }\end{array}$ & {$[388,396-401]$} \\
\hline $\begin{array}{l}\text { Asymptomatic } \\
\text { cerebral emboli } \\
\text { (ACE) }\end{array}$ & $\begin{array}{l}2 \% \text { to } \\
15 \%\end{array}$ & $\begin{array}{l}\text { Anticoagulation, catheter and sheath } \\
\text { management, TEE }\end{array}$ & Brain MRI & None & [402-419] \\
\hline $\begin{array}{l}\text { Atrial esophageal } \\
\text { fistula }\end{array}$ & $\begin{array}{r}0.02 \% \text { to } \\
0.11 \%\end{array}$ & $\begin{array}{l}\text { Reduce power, force, and RF time } \\
\text { on posterior wall, monitor } \\
\text { esophageal temp, use proton } \\
\text { pump inhibitors; avoid energy } \\
\text { delivery over esophagus }\end{array}$ & $\begin{array}{l}\text { CT scan of chest, MRI; } \\
\text { avoid endoscopy with } \\
\text { air insufflation }\end{array}$ & Surgical repair & {$[337-365,420-456]$} \\
\hline $\begin{array}{l}\text { Cardiac } \\
\quad \text { tamponade }\end{array}$ & $\begin{array}{c}0.2 \% \text { to } \\
5 \%\end{array}$ & $\begin{array}{l}\text { Cather manipulation, transseptal } \\
\text { technique, reduce power, force, } \\
\text { and RF time }\end{array}$ & Echocardiography & $\begin{array}{l}\text { Pericardiocentesis or } \\
\text { surgical drainage }\end{array}$ & $\begin{array}{l}{[338,343,347,} \\
457-467]\end{array}$ \\
\hline $\begin{array}{l}\text { Coronary artery } \\
\text { stenosis/- } \\
\text { occlusion }\end{array}$ & $<0.1 \%$ & $\begin{array}{l}\text { Avoid high-power energy delivery } \\
\text { near coronary arteries }\end{array}$ & Cardiac catheterization & PTCA & {$[468-476]$} \\
\hline Death & $\begin{array}{c}<0.1 \% \text { to } \\
0.4 \%\end{array}$ & $\begin{array}{l}\text { Meticulous performance of } \\
\text { procedure, attentive } \\
\text { postprocedure care }\end{array}$ & NA & NA & $\begin{array}{l}{[338,343,347,458,} \\
\quad 477]\end{array}$ \\
\hline $\begin{array}{l}\text { Gastric } \\
\text { hypomotility }\end{array}$ & $\begin{array}{l}0 \% \text { to } \\
\quad 17 \%\end{array}$ & $\begin{array}{l}\text { Reduce power, force, and RF time } \\
\text { on posterior wall }\end{array}$ & $\begin{array}{l}\text { Endoscopy, barium } \\
\text { swallow, gastric } \\
\text { emptying study }\end{array}$ & $\begin{array}{l}\text { Metoclopramide, possibly } \\
\text { intravenous } \\
\text { erythromycin }\end{array}$ & {$[478-490]$} \\
\hline $\begin{array}{l}\text { Mitral valve } \\
\text { entrapment }\end{array}$ & $<0.1 \%$ & $\begin{array}{l}\text { Avoid circular catheter placement } \\
\text { near or across mitral valve; } \\
\text { clockwise torque on catheter }\end{array}$ & Echocardiography & $\begin{array}{l}\text { Gentle catheter } \\
\text { manipulation, surgical } \\
\text { extraction }\end{array}$ & [491-498] \\
\hline Pericarditis & $\begin{array}{l}0 \% \text { to } \\
50 \%\end{array}$ & None proven & $\begin{array}{l}\text { Clinical history, ECG, } \\
\text { sedimentation rate, } \\
\text { echocardiogram }\end{array}$ & $\begin{array}{l}\text { NSAID, colchicine, } \\
\text { steroids }\end{array}$ & [499-506] \\
\hline $\begin{array}{l}\text { Permanent } \\
\text { phrenic nerve } \\
\text { paralysis }\end{array}$ & $\begin{array}{l}0 \% \text { to } \\
0.4 \%\end{array}$ & $\begin{array}{l}\text { Monitor diaphragm during phrenic } \\
\text { pacing, CMAP monitoring, } \\
\text { phrenic pacing to identify location } \\
\text { and adjust lesion location }\end{array}$ & CXR, sniff test & Supportive care & $\begin{array}{l}{[9,11,156,347,367,} \\
\quad 446,457,478, \\
479,487-490, \\
507-528]\end{array}$ \\
\hline $\begin{array}{l}\text { Pulmonary vein } \\
\text { stenosis }\end{array}$ & $<1 \%$ & Avoid energy delivery within PV & CT or MRI, V/Q wave scan & Angioplasty, stent, surgery & $\begin{array}{c}{[9,11,313,316-335} \\
457,529-531]\end{array}$ \\
\hline Radiation injury & $<0.1 \%$ & $\begin{array}{l}\text { Minimize fluoroscopy exposure, } \\
\text { especially in obese and repeat } \\
\text { ablation patients, X-ray } \\
\text { equipment }\end{array}$ & None & $\begin{array}{l}\text { Supportive care, rarely skin } \\
\text { graft }\end{array}$ & {$[513,532-550]$} \\
\hline $\begin{array}{l}\text { Stiff left atrial } \\
\text { syndrome }\end{array}$ & $<1.5 \%$ & Limit extent of left atrial ablation & $\begin{array}{l}\text { Echocardiography, cardiac } \\
\text { catheterization }\end{array}$ & Diuretics & [551-558] \\
\hline Stroke and TIA & $0 \%$ to $2 \%$ & $\begin{array}{l}\text { Pre-, post-, and intraprocedure } \\
\text { anticoagulation, catheter and } \\
\text { sheath management, TEE }\end{array}$ & $\begin{array}{l}\text { Head CT or MRI, cerebral } \\
\text { angiography }\end{array}$ & $\begin{array}{l}\text { Thrombolytic therapy, } \\
\text { angioplasty }\end{array}$ & $\begin{array}{l}{[10-13,338,347} \\
367,458 \\
559-565]\end{array}$ \\
\hline $\begin{array}{l}\text { Vascular } \\
\text { complications }\end{array}$ & $\begin{array}{r}0.2 \% \text { to } \\
1.5 \%\end{array}$ & $\begin{array}{l}\text { Vascular access techniques, } \\
\text { ultrasound-guided access, } \\
\text { anticoagulation management }\end{array}$ & $\begin{array}{l}\text { Vascular ultrasound, CT } \\
\text { scan }\end{array}$ & $\begin{array}{l}\text { Conservative treatment, } \\
\text { surgical repair, } \\
\text { transfusion }\end{array}$ & $\begin{array}{c}{[338,347,371,373,} \\
374,380,458, \\
511,566-575]\end{array}$ \\
\hline
\end{tabular}

$A F$ atrial fibrillation, $C T$ computed tomography, $M R I$ magnetic resonance imaging, $T E E$ transesophageal electrocardiogram, $R F$ radiofrequency, $P T C A$ percutaneous transluminal coronary angioplasty, $N A$ not applicable, $E C G$ electrocardiogram, NSAID nonsteroidal anti-inflammatory drug, $C M A P$ compound motor action potentials, CXR chest X-ray, TIA transient ischemic attack

\subsection{Unanswered questions in AF ablation}

There is still much to be learned about the mechanisms of AF, techniques of AF ablation, and long-term outcomes. The following are unanswered questions for future investigation:
$1 \mathrm{AF}$ ablation and modification of stroke risk and need for ongoing oral anticoagulation (OAC): The $\mathrm{CHA}_{2} \mathrm{DS}_{2}-$ VASc score was developed for patients with clinical AF. If a patient has received a successful ablation such that he/she no longer has clinical AF (subclinical, or no 
Table 10 Definitions for use when reporting outcomes of AF ablation and in designing clinical trials of catheter or surgical ablation of AF

Acute procedural success (pulmonary vein isolation)

Acute procedural success (not related by pulmonary vein isolation)

One-year success ${ }^{*}$

Alternative one-year success

Clinical/partial success*

Long-term success*

Recurrent AF/AFL/AT

Early recurrence of AF/AFL/AT

Recurrence of AF/AFL/AT
Acute procedural success is defined as electrical isolation of all pulmonary veins. A minimal assessment of electrical isolation of the PVs should consist of an assessment of entrance block. If other methods are used to assess PVI, including exit block and/or the use of provocative agents such as adenosine or isoproterenol, they should be prespecified. Furthermore, it is recommended that the wait time used to screen for early recurrence of PV conduction once initial electrical isolation is documented be specified in all prospective clinical trials.

Typically, this would apply to substrate ablation performed in addition to PVI for persistent AF. Although some have proposed AF termination as a surrogate for acute procedural success, its relationship to long-term success is controversial. Complete elimination of the additional substrate (localized rotational activation, scar region, non-PV trigger, or other target) and/or demonstration of bidirectional conduction block across a linear ablation lesion would typically be considered the appropriate endpoint.

One-year success is defined as freedom from AF/AFL/AT after removal from antiarrhythmic drug therapy as assessed from the end of the 3 month blanking period to 12 months following the ablation procedure. Because cavotricuspid isthmus-dependent atrial flutter is easily treated with cavotricuspid isthmus ablation and is not an iatrogenic arrhythmia following a left atrial ablation procedure for $\mathrm{AF}$, it is reasonable for clinical trials to choose to prespecify that occurrence of isthmus-dependent atrial flutter, if confirmed by entrainment maneuvers during electrophysiology testing, should not be considered an ablation failure or primary effectiveness endpoint.

Although the one-year success definition provided above remains the recommended end point that should be reported in all $\mathrm{AF}$ ablation trials, and the endpoint for which the objective performance criteria listed below were developed, the Task Force recognizes that alternative definitions for success can be used if the main goal of therapy in the study is to relieve AF-related symptoms and to improve patient QOL. In particular, it is appropriate for clinical trials to define success as freedom from only symptomatic $\mathrm{AF} / \mathrm{AFL} / \mathrm{AT}$ after removal from antiarrhythmic drug therapy as assessed from the end of the 3-month blanking period to 12 months following the ablation procedure if the main goal of therapy in the study is to relieve AF-related symptoms and to improve patient QOL. However, because symptoms of AF can resolve over time, and because studies have shown that asymptomatic $\mathrm{AF}$ represents a greater proportion of all $\mathrm{AF}$ postablation than prior to ablation, clinical trials need to continue to report freedom from both symptomatic and asymptomatic $\mathrm{AF}$ even if this alternative one year success definition is used as the primary trial endpoint.

It is reasonable for clinical trials to define and incorporate one or more secondary definitions of success that can be referred to as "clinical success" or "partial success." If these alternative definitions of success are included, they should be defined prospectively. In prior Consensus Documents the Task Force has proposed that clinical/partial success be defined as a " $75 \%$ or greater reduction in the number of AF episodes, the duration of AF episodes, or the \% time a patient is in $\mathrm{AF}$ as assessed with a device capable of measuring AF burden in the presence or absence of previously ineffective antiarrhythmic drug therapy." Because there is no firm scientific basis for selecting the cutoff of $75 \%$ rather than a different cutoff, this prior recommendation is provided only as an example of what future clinical trials may choose to use as a definition of clinical/partial success.

Long-term success is defined as freedom from $\mathrm{AF} / \mathrm{AFL} / \mathrm{AT}$ recurrences following the 3-month blanking period through a minimum of 36-month follow-up from the date of the ablation procedure in the absence of Class I and III antiarrhythmic drug therapy.

Recurrent AF/AFL/AT is defined as AF/AFL/AT of at least 30 s' duration that is documented by an ECG or device recording system and occurs following catheter ablation. Recurrent AF/AFL/AT may occur within or following the post ablation blanking period. Recurrent AF/AFL/AT that occurs within the postablation blanking period is not considered a failure of $\mathrm{AF}$ ablation.

Early recurrence of $\mathrm{AF} / \mathrm{AFL} / \mathrm{AT}$ is defined as a recurrence of atrial fibrillation within three months of ablation. Episodes of atrial tachycardia or atrial flutter should also be classified as a "recurrence." These are not counted toward the success rate if a blanking period is specified.

Recurrence of $\mathrm{AF} / \mathrm{AFL} / \mathrm{AT}$ postablation is defined as a recurrence of atrial fibrillation more than 3 months following AF ablation. Episodes of atrial tachycardia or atrial flutter should also be classified as a "recurrence." 
Table 10 (continued)

Late recurrence of $\mathrm{AF} / \mathrm{AFL} / \mathrm{AT}$

Blanking period

Stroke screening

Detectable AF/AFL/AT

AF/AFL/AT burden

Entrance block

Procedural endpoints for AF ablation strategies not targeting the PVs

Esophageal temperature monitoring

Enrolled subject
Late recurrence of AF/AFL/AT is defined as a recurrence of atrial fibrillation 12 months or more after AF ablation. Episodes of atrial tachycardia or atrial flutter should also be classified as a "recurrence."

A blanking period of three months should be employed after ablation when reporting efficacy outcomes. Thus, early recurrences of AF/AFL/AT within the first 3 months should not be classified as treatment failure. If a blanking period of less than 3 months is chosen, it should be prespecified and included in the Methods section.

A risk-based approach to determine the level of postablation stroke screening in clinical trials is recommended by the Task Force. For ablation devices with a lower risk of stroke and for which a stroke signal has not been reported, a minimum standardized neurological assessment of stroke should be conducted by a physician at baseline and at hospital discharge or $24 \mathrm{~h}$ after the procedure, whichever is later. If this neurological assessment demonstrates new abnormal findings, the patient should have a formal neurological consult and examination with appropriate imaging (i.e., DW-MRI), used to confirm any suspected diagnosis of stroke. For devices in which a higher risk of stroke is suspected or revealed in prior trials, a formal neurological examination by a neurologist at discharge or $24 \mathrm{~h}$ after the procedure, whichever is later, is recommended. Appropriate imaging should be obtained if this evaluation reveals a new neurological finding. In some studies in which delayed stroke is a concern, repeat neurological screening at 30 days postablation might be appropriate.

Detectable $\mathrm{AF}$ is defined as $\mathrm{AF} / \mathrm{AFL} / \mathrm{AT}$ of at least $30 \mathrm{~s}$ ' duration when assessed with ECG monitoring. If other monitoring systems are used, including implantable pacemakers, implantable defibrillators, and subcutaneous ECG monitoring devices, the definition of detectable AF needs to be prespecified in the clinical trial based on the sensitivity and specificity of AF detection with the particular device. We recommend that episodes of atrial flutter and atrial tachycardia be included within the broader definition of a detectable $\mathrm{AF} / \mathrm{AFL} / \mathrm{AT}$ episode.

It is reasonable for clinical trials to incorporate $\mathrm{AF} / \mathrm{AFL} / \mathrm{AT}$ burden as a secondary endpoint in a clinical trial of AF ablation. In stating this it is recognized that there are no conclusive data that have validated a rate of $\mathrm{AF}$ burden reduction as a predictor of patient benefit (i.e. reduction in mortality and major morbidities such as stroke, CHF, QOL, or hospitalization). If AF burden is included, it is important to predefine and standardize the monitoring technique that will be used to measure AF burden. Available monitoring techniques have been discussed in this document. Should AF burden be selected as an endpoint in a clinical trial, the chosen monitoring technique should be employed at least a month prior to ablation to establish a baseline burden of AF.

Entrance block is defined as the absence, or if present, the dissociation, of electrical activity within the PV antrum. Entrance block is most commonly evaluated using a circular multielectrode mapping catheter positioned at the PV antrum. Entrance block can also be assessed using detailed point-by-point mapping of the PV antrum guided by an electroanatomical mapping system. The particular method used to assess entrance block should be specified in all clinical trials. Entrance block of the left PVs should be assessed during distal coronary sinus or left atrial appendage pacing in order to distinguish far-field atrial potentials from PV potentials. It is recommended that reassessment of entrance block be performed a minimum of $20 \mathrm{~min}$ after initial establishment of PV isolation. Procedural endpoints for AF ablation strategies not targeting the PVs: The acute procedural endpoints for ablation strategies not targeting the PVs vary depending on the specific ablation strategy and tool. It is important that they be prespecified in all clinical trials. For example, if a linear ablation strategy is used, documentation of bidirectional block across the ablation line must be shown. For ablation of CFAEs, rotational activity, or non-PV triggers, the acute endpoint should at a minimum be elimination of CFAEs, rotational activity, or non-PV triggers. Demonstration of AF slowing or termination is an appropriate procedural endpoint, but it is not required as a procedural endpoint for $\mathrm{AF}$ ablation strategies not targeting the PVs.

Esophageal temperature monitoring should be performed in all clinical trials of AF ablation. At a minimum, a single thermocouple should be used. The location of the probe should be adjusted during the procedure to reflect the location of energy delivery. Although this document does not provide formal recommendations regarding the specific temperature or temperature change at which energy delivery should be terminated, the Task Force does recommend that all trials prespecify temperature guidelines for termination of energy delivery.

An enrolled subject is defined as a subject who has signed written informed consent to participate in the trial in question. 
Table 10 (continued)

Exit block

Nonablative strategies

Noninducibility of atrial fibrillation

Patient populations for inclusion in clinical trials

Therapy consolidation period

Recommendations regarding repeat ablation procedures

Cardioversion definitions

Failed electrical cardioversion

Successful electrical cardioversion

Immediate $\mathrm{AF}$ recurrence

postcardioversion

Early AF recurrence postcardioversion

Late $\mathrm{AF}$ recurrence postcardioversion

Surgical ablation definitions

Hybrid AF surgical ablation procedure
Exit block is defined as the inability to capture the atrium during pacing at multiple sites within the PV antrum. Local capture of musculature within the pulmonary veins and/or antrum must be documented to be present to make this assessment. Exit block is demonstrated by a dissociated spontaneous pulmonary vein rhythm.

The optimal nonablative therapy for patients with persistent and long-standing persistent $\mathrm{AF}$ who are randomized to the control arm of an $\mathrm{AF}$ ablation trial is a trial of a new Class I or III antiarrhythmic agent or a higher dose of a previously failed antiarrhythmic agent. For patients with persistent or long-standing persistent AF, performance of a directcurrent cardioversion while taking the new or dose adjusted antiarrhythmic agent should be performed, if restoration of sinus rhythm is not achieved following initiation and/or dose adjustment of antiarrhythmic drug therapy. Failure of pharmacological cardioversion alone is not adequate to declare this pharmacological strategy unsuccessful. Noninducibility of atrial fibrillation is defined as the inability to induce atrial fibrillation with a standardized prespecified pharmacological or electrical stimulation protocol. The stimulation protocol should be prespecified in the specific clinical trial. Common stimulation approaches include a high-dose isoproterenol infusion protocol or repeated atrial burst pacing at progressively more rapid rates.

It is considered optimal for clinical trials to enroll patients with only one type of AF: paroxysmal, persistent, or long-standing persistent. If more than one type of AF patient is enrolled, the results of the trial should also be reported separately for each of the AF types. It is recognized that "early persistent" AF responds to AF ablation to a similar degree as patients with paroxysmal AF and that the response of patients with "late persistent AF" is more similar to that in those with long-standing persistent AF.

Following a 3-month blanking period, it is reasonable for clinical trials to incorporate an additional 1- to 3-month therapy consolidation period. During this time, adjustment of antiarrhythmic medications and/or cardioversion can be performed. Should a consolidation period be incorporated into a clinical trial design, the minimum follow-up duration should be 9 months following the therapy consolidation period. Performance of a repeat ablation procedure during the blanking or therapy consolidation period would "reset" the endpoint of the study and trigger a new 3-month blanking period.

Incorporation of a therapy consolidation period can be especially appropriate for clinical trials evaluating the efficacy of $\mathrm{AF}$ ablation for persistent or long-standing persistent $\mathrm{AF}$. The challenge of this approach is that it prolongs the overall study duration. Because of this concern regarding overall study duration, we suggest that the therapy consolidation period be no more than 3 months in duration following the 3-month blanking period. It is recommended that all clinical trials report the single procedure efficacy of catheter ablation. Success is defined as freedom from symptomatic or asymptomatic AF/AFL/AT of $30 \mathrm{~s}$ or longer at 12 months postablation. Recurrences of AF/AFL/AT during the first 3month blanking period post-AF ablation are not considered a failure. Performance of a repeat ablation procedure at any point after the initial ablation procedure should be considered a failure of a single procedure strategy. It is acceptable for a clinical trial to choose to prespecify and use a multiprocedure success rate as the primary endpoint of a clinical trial. When a multiprocedure success is selected as the primary endpoint, efficacy should be defined as freedom from $\mathrm{AF} /$ flutter or tachycardia at 12 months after the final ablation procedure. In the case of multiple procedures, repeat ablation procedures can be performed at any time following the initial ablation procedure. All ablation procedures are subject to a 3-month post blanking window, and all ablation trials should report efficacy at 12 months after the final ablation procedure.

Failed electrical cardioversion is defined as the inability to restore sinus rhythm for $30 \mathrm{~s}$ or longer following electrical cardioversion.

Successful electrical cardioversion is defined as the ability to restore sinus rhythm for at least $30 \mathrm{~s}$ following cardioversion.

Immediate $\mathrm{AF}$ recurrence postcardioversion is defined as a recurrence of $\mathrm{AF}$ within $24 \mathrm{~h}$ following cardioversion. The most common time for an immediate recurrence is within 30-60 min postcardioversion.

Early AF recurrence postcardioversion is defined as a recurrence of AF within 30 days of a successful cardioversion.

Late $\mathrm{AF}$ recurrence postcardioversion is defined as recurrence of AF more than 30 days following a successful cardioversion.

Hybrid AF surgical ablation procedure is defined as a joint AF ablation procedure performed by electrophysiologists and cardiac surgeons either as part of a single "joint" 
Table 10 (continued)

Surgical Maze ablation procedure

Stand-alone surgical AF ablation

Nomenclature for types of surgical AF ablation procedures

Hybrid epicardial and endocardial AF ablation

procedure or performed as two preplanned separate ablation procedures separated by no more than 6 months.

Surgical Maze ablation procedure is defined as a surgical ablation procedure for AF that includes, at a minimum, the following components: (1) line from SVC to IVC; (2) line from IVC to the tricuspid valve; (3) isolation of the PVs; (4) isolation of the posterior left atrium; (5) line from MV to the PVs; (6) management of the LA appendage.

A surgical AF ablation procedure during which other cardiac surgical procedures are not performed such as $\mathrm{CABG}$, valve replacement, or valve repair.

We recommend that the term "Maze" procedure is appropriately used only to refer to the biatrial lesion set of the Cox-Maze operation. It requires ablation of the RA and LA isthmuses. Less extensive lesion sets should not be referred to as a "Maze" procedure, but rather as a surgical AF ablation procedure. In general, surgical ablation procedures for $\mathrm{AF}$ can be grouped into three different groups: (1) a full biatrial Cox-Maze procedure; (2) PVI alone; and (3) PVI combined with left atrial lesion sets.

This term refers to a combined AF ablation procedure involving an off-pump minimally invasive surgical $\mathrm{AF}$ ablation as well as a catheter-based $\mathrm{AF}$ ablation procedure designed to complement the surgical lesion set. Hybrid ablation procedures may be performed in a single-procedure setting in a hybrid operating room or a cardiac catheterization laboratory environment, or it can be staged. When staged, it is most typical to have the patient undergo the minimally invasive surgical ablation procedure first following by a catheter ablation procedure 1 to 3 months later. This latter approach is referred to as a "staged Hybrid AF ablation procedure."

Minimum AF documentation, endpoints, TEE performance, and success rates in clinical trials

Minimum documentation for paroxysmal $\mathrm{AF}$

Minimum documentation for persistent AF

Minimum documentation for early persistent AF

Minimum documentation for long-standing persistent $\mathrm{AF}$

Symptomatic AF/AFL/AT

Documentation of AF-related symptoms

Minimum effectiveness endpoint for patients with symptomatic and asymptomatic $\mathrm{AF}$

Minimum chronic acceptable success rate: paroxysmal $\mathrm{AF}$ at 12-month follow-up

Minimum chronic acceptable success rate: persistent $\mathrm{AF}$ at 12-month follow-up

Minimum chronic acceptable success rate: long-standing persistent $\mathrm{AF}$ at 12 -month follow-up

Minimum follow-up screening for paroxysmal $\mathrm{AF}$ recurrence
The minimum $\mathrm{AF}$ documentation requirement for paroxysmal $\mathrm{AF}$ is (1) physician's note indicating recurrent self-terminating AF and (2) one electrocardiographically documented $\mathrm{AF}$ episode within 6 months prior to the ablation procedure. The minimum $\mathrm{AF}$ documentation requirement for persistent $\mathrm{AF}$ is (1) physician's note indicating continuous AF $>7$ days but no more than 1 year and (2) a 24-h Holter within 90 days of the ablation procedure showing continuous AF.

The minimum $\mathrm{AF}$ documentation requirement for persistent $\mathrm{AF}$ is (1) physician's note indicating continuous AF $>7$ days but no more than 3 months and (2) a 24-h Holter showing continuous AF within 90 days of the ablation procedure.

The minimum $\mathrm{AF}$ documentation requirement for long-standing persistent $\mathrm{AF}$ is as follows: physician's note indicating at least 1 year of continuous AF plus a 24-h Holter within 90 days of the ablation procedure showing continuous AF. The performance of a successful cardioversion (sinus rhythm $>30 \mathrm{~s}$ ) within 12 months of an ablation procedure with documented early recurrence of $\mathrm{AF}$ within 30 days should not alter the classification of $\mathrm{AF}$ as long-standing persistent.

$\mathrm{AF} / \mathrm{AFL} / \mathrm{AT}$ that results in symptoms that are experienced by the patient. These symptoms can include but are not limited to palpitations, presyncope, syncope, fatigue, and shortness of breath. For patients in continuous AF, reassessment of symptoms after restoration of sinus rhythm is recommended to establish the relationship between symptoms and AF.

Documentation by a physician evaluating the patient that the patient experiences symptoms that could be attributable to AF. This does not require a time-stamped ECG, Holter, or event monitor at the precise time of symptoms. For patients with persistent AF who initially report no symptoms, it is reasonable to reassess symptom status after restoration of sinus rhythm with cardioversion.

The minimum effectiveness endpoint is freedom from symptomatic and asymptomatic episodes of AF/AFL/AT recurrences at 12 months following ablation, free from antiarrhythmic drug therapy, and including a prespecified blanking period.

If a minimum chronic success rate is selected as an objective effectiveness endpoint for a clinical trial, we recommend that the minimum chronic acceptable success rate for paroxysmal $\mathrm{AF}$ at 12 -month follow-up is $50 \%$.

If a minimum chronic success rate is selected as an objective effectiveness endpoint for a clinical trial, we recommend that the minimum chronic acceptable success rate for persistent $\mathrm{AF}$ at 12 -month follow-up is $40 \%$.

If a minimum chronic success rate is selected as an objective effectiveness endpoint for a clinical trial, we recommend that the minimum chronic acceptable success rate for longstanding persistent $\mathrm{AF}$ at 12 -month follow-up is $30 \%$.

For paroxysmal AF, the minimum follow-up screening should include (1) 12-lead ECG at each follow-up visit; (2) 24-h Holter at the end of the follow-up period (e.g., 12 months); and (3) event recording with an event monitor regularly and when symptoms occur from the end of the 3-month blanking period to the end of follow-up (e.g., 12 months). 
Table 10 (continued)

Minimum follow-up screening for persistent or long-standing AF recurrence

Requirements for transesophageal echocardiogram
For persistent and long-standing persistent $\mathrm{AF}$, the minimum follow-up screening should include (1) 12-lead ECG at each follow-up visit; (2) 24-h Holter every 6 months; and (3) symptom-driven event monitoring.

It is recommended that the minimum requirement for performance of a TEE in a clinical trial should be those requirements set forth in ACC/AHA/HRS 2014 Guidelines for AF Management pertaining to anticoagulation at the time of cardioversion. Prior to undergoing an $\mathrm{AF}$ ablation procedure a TEE should be performed in all patients with $\mathrm{AF}$ of $>48$ h' duration or of unknown duration if adequate systemic anticoagulation has not been maintained for at least 3 weeks prior to AF ablation. If a TEE is performed for this indication, it should be performed within $24 \mathrm{~h}$ of the ablation procedure.

$A F$ atrial fibrillation, $D W-M R I$ diffusion-weighted magnetic resonance imaging, $C H F$ congestive heart failure, $Q O L$ quality of life, $E C G$ electrocardiogram, $C A B G$ coronary artery bypass grafting, $P V$ pulmonary vein, $S V C$ superior vena cava, $I V C$ inferior vena cava, $C F A E$ complex fractionated atrial electrogram, $P V I$ pulmonary vein isolation, $A F L$ atrial flutter, $A T$ atrial tachycardia, ACC American College of Cardiology, AHA American Heart Association, HRS Heart Rhythm Society

${ }^{*}$ When reporting outcomes of AF ablation, the development of atrial tachycardia or atrial flutter should be included in the broad definition of recurrence following AF ablation. All studies should report freedom from AF, atrial tachycardia, and atrial flutter. These endpoints can also be reported separately. All studies should also clearly specify the type and frequency of ECG monitoring as well as the degree of compliance with the prespecified monitoring protocol

$\mathrm{AF})$, then what is the need for ongoing OAC? Are there any patients in whom successful ablation could lead to discontinuation of OAC?

2 Substrate modification in catheter-based management of AF-particularly for persistent AF: What is the proper lesion set required beyond pulmonary vein isolation? Do lines and complex fractionated atrial electrogram (CFAE) have any remaining role? Are these approaches ill-advised or simply discouraged?

What is the role of targeting localized rotational activations? How do we ablate a localized rotational activation? How can scar be characterized and targeted for ablation? Do we need to replicate the MAZE procedure? Does the right atrium need to be targeted as well as the left atrium?

3 Autonomic influence in AF: Is clinical AF really an autonomic mediated arrhythmia? Is elimination of ganglionated plexi required? Is there a role for autonomic modulation, for example, spinal cord or vagal stimulation?

4 Contribution and modulation of risk factors on outcomes of AF ablation: Obesity reduction has been shown to reduce AF burden and recurrence in patients undergoing ablation. What is the role of bariatric surgery? Does the modulation of other risk factors influence outcome such as hypertension, sleep apnea, and diabetes?

5 Outcomes in ablation of high-risk populations: Do highrisk populations benefit from $\mathrm{AF}$ ablation? Congestive heart failure has been assessed in smaller trials, but larger trials are required. Outcome data are needed in patients with very enlarged LAs, hypertrophic cardiomyopathy, patients with renal failure on dialysis, and the very elderly.

6 Surgical vs catheter-based vs hybrid ablation: There should be more comparative work between percutaneous and minimally invasive surgical approaches. Both report similar outcomes, but there is a dearth of comparative data. Is there any patient benefit to hybrid procedures?

7 How do we characterize patients who are optimal candidates for ablation? Preablation late gadoliniumenhanced (LGE)-magnetic resonance imaging (MRI) might identify patients with heavy burdens of scar who are unlikely to respond to ablation. These techniques must become reproducible and reliable and must be assessed in multicenter trials. Other markers need to be investigated, including genetic markers, biochemical markers, and clinical markers based on aggregated risk scores.

8 The incremental role of new technologies: As newer and often more expensive technologies are produced for AF ablation, their definitive incremental value must be determined in order to justify change in practice or case cost. These technologies include global (basket) mapping techniques, newer ablation indices for assessing lesion durability, advanced imaging for viewing lesions in the myocardium, etc. New energy sources, including laser, low-intensity ultrasound, photonic particle therapy, external beam ablation, and MRI-guided ablation, must be assessed in comparative fashion.

9 Outcomes of AF ablation: We need to better understand the clinical relevance of ablation outcomes. What is the significance of time to recurrence of 
Table 11 Quality-of-life scales, definitions, and strengths

\begin{tabular}{|c|c|c|}
\hline Scale & Definition/Details & Strengths/Weaknesses \\
\hline $\begin{array}{l}\text { Short Form (36) Health } \\
\text { Survey } \\
\text { (SF36)38(General) }\end{array}$ & $\begin{array}{l}\text { Consists of } 8 \text { equally weighted, scaled scores in the } \\
\text { following sections: vitality, physical functioning, } \\
\text { bodily pain, general health perceptions, physical role } \\
\text { functioning, emotional role functioning, social role } \\
\text { functioning, mental health. Each section receives a }\end{array}$ & $\begin{array}{l}\text { Advantages: extensively validated in a number of } \\
\text { disease and health states. Might have more } \\
\text { resolution than EQ-50 for AF QOL.Disadvantages: } \\
\text { not specific for AF, so might not have resolution to } \\
\text { detect AF-specific changes in QOL. }\end{array}$ \\
\hline
\end{tabular}

EuroQol Five Dimensions Questionnaire (EQ-5D)39(General)

\author{
AF effect on Quality of \\ Life Survey (AFEQT)40 \\ (AF specific)
}

\section{Quality of Life Questionnaire for Patients with AF(AF-QoL)41(AF specific) \\ Arrhythmia-Related Symptom Checklist (SCL)42 (AF specific) \\ Mayo AF Specific Symptom Inventory (MAFSI)43 (AF specific)}

University of Toronto Atrial Fibrillation Severity Scale (AFSS) (AF specific) 44

Arrhythmia Specific Questionnaire in Tachycardia and Arrhythmia (ASTA)45 (AF specific)

European Heart Rhythm Association (EHRA)46 (AF specific)

Canadian Cardiovascular Society Severity of scale score from 0 to 100.Physical component summary (PCS) and mental component summary (MCS) is an average of all the physically and mentally relevant questions, respectively. The Short Form (12) Health Survey (SF12) is a shorter version of the SF-36, which uses just 12 questions and still provides scores that can be compared with SF-36 norms, especially for summary physical and mental functioning.Gives more precision in measuring QOL than EQ-5D but can be harder to transform into cost utility analysis.

Two components: Health state description is measured in five dimensions: mobility, self-care, usual activities, pain/discomfort, anxiety/depression. Answers may be provided on a three-level (3L) or five-level (5L) scale. In the Evaluation section, respondents evaluate their overall health status using a visual analogue scale (EQ-VAS). Results can easily be converted to quality-adjusted life years for cost utility analysis.

20 questions: 4 targeting AF-related symptoms, 8 evaluating daily function, and 6 assessing AF treatment concerns. Each item scored on a 7-point Likert scale.

18-item self-administered questionnaire with three domains: psychological, physical, and sexual activity. Each item scores on a 5-point Likert scale.

16 items covering AF symptom frequency and symptom severity.

10 items covering AF symptom frequency and severity. Combination of 5- point and 3-point Likert scale responses.Used in CABANA trial.

10 items covering frequency, duration, and severity. 7-point Likert scale responses.

Records number of AF episodes and average episode duration during last 3 months. 8 symptoms and 2 disabling symptoms are recorded with scores from 1-4 for each.

Like NYHA scale. $\mathrm{I}=$ no symptoms, $\mathrm{II}=$ mild symptoms not affecting daily activity, III = severe symptoms affecting daily activity, and IV = disabling symptoms terminating daily activities.

Like NYHA scale. $\mathrm{O}=$ asymptomatic, $\mathrm{I}=\mathrm{AF}$ symptoms have minimal effect on patient's QOL, II
Advantages: extensively validated in a number of disease and health states. Can easily be converted into quality-adjusted life years for cost-effectiveness analysis.Disadvantages: might not be specific enough to detect AF-specific changes in QOL. Might be less specific than SF-36.

Advantages: brief, simple, very responsive to AF interventions. Good internal validity and well validated against a number of other global and AF-specific QOL scales. Used in CABANA.Disadvantages: validation in only two published studies (approximately 219 patients).

Advantages: brief, simple, responsive to $\mathrm{AF}$ interventions; good internal validity; used in SARA trial.Disadvantages: external validity compared only to SF-36; formal validation in 1 study (approximately 400 patients).

Advantages: most extensively validated in a number of arrhythmia cohorts and clinical trials.Disadvantages: time-consuming and uncertain generalizability.

Advantages: validated in an AF ablation population and responsive to ablation outcome; used in CABANA trial.Disadvantages: external validity compared only to SF-36; 1 validation study (approximately 300 patients).

Advantages: validated and reproducible; used in CTAF trial.Disadvantages: time-consuming and uncertain generalizability.

Advantages: validated in various arrhythmia groups; external validity compared with SCL, EQ5D, and SF-36; used in MANTRA-PAF; brief; simple.Disadvantages: one validation study (approximately 300 patients).

Advantage: very simple, like NYHA.Disadvantages: not used in studies and not well validated; not very specific; unknown generalizability.

Advantages: very simple, like NYHA; validated against SF-36 and University of Toronto 
Table 11 (continued)

\begin{tabular}{lll}
\hline Scale & Definition/Details & Strengths/Weaknesses \\
\hline $\begin{array}{ll}\text { Atrial Fibrillation Scale } \\
\text { (CCS-SAF)47 (AF }\end{array}$ & = AF symptoms have minor effect on patient QOL, \\
specific) & III = symptoms have moderate effect on patient & AFSS.Disadvantages: poor correlation with \\
& QOL, IV= AF symptoms have severe effect on \\
patient QOL.
\end{tabular}

$A F$ atrial fibrillation, $Q O L$ quality of life, CABANA Catheter Ablation vs Anti-arrhythmic Drug Therapy for Atrial Fibrillation, $S A R A$ Study of Ablation Versus antiaRrhythmic Drugs in Persistent Atrial Fibrillation, CTAF Canadian Trial of Atrial Fibrillation, MANTRA-PAF Medical ANtiarrhythmic Treatment or Radiofrequency Ablation in Paroxysmal Atrial Fibrillation, NYHA New York Heart Association, AFSS atrial fibrillation severity scale

30 s of arrhythmia? How do we best quantify AF burden? How do these outcomes relate to quality of life and stroke risk?

10 What is the role of surgical LA reduction? Does left atrial appendage (LAA) occlusion or obliteration improve outcome of persistent AF ablation with an accompanying reduction in stroke? Does ablation work through atrial size reduction? What is the incidence of "stiff atrial" syndrome and does this mitigate the clinical impact of ablation?

11 Working in teams: What is the role of the entire heart team in AF ablation? Does a team approach achieve better outcomes than a "silo" approach?

12 Improving the safety of catheter ablation: As ablation extends to more operators and less experienced
Table 12 Non-AF recurrencerelated endpoints for reporting in $\mathrm{AF}$ ablation trials

\begin{tabular}{|c|c|}
\hline Stroke and bleeding endpoints & Definitions/Details \\
\hline $\begin{array}{l}\text { Stroke (2014 ACC/AHA Key Data } \\
\text { Elements) }\end{array}$ & $\begin{array}{l}\text { An acute episode of focal or global neurological dysfunction caused } \\
\text { by brain, spinal cord, or retinal vascular injury as a result of } \\
\text { hemorrhage or infarction. Symptoms or signs must persist } \geq 24 \mathrm{~h} \text {, } \\
\text { or if documented by CT, MRI or autopsy, the duration of } \\
\text { symptoms/signs may be less than } 24 \mathrm{~h} \text {. Stroke may be classified as } \\
\text { ischemic (including hemorrhagic transformation of ischemic } \\
\text { stroke), hemorrhagic, or undetermined. Stroke disability } \\
\text { measurement is typically performed using the modified Rankin } \\
\text { Scale (mRS). }\end{array}$ \\
\hline $\begin{array}{l}\text { Transient ischemic attack ( } 2014 \\
\text { ACC/AHA Key Data Elements) }\end{array}$ & $\begin{array}{l}\text { Transient episode of focal neurological dysfunction caused by brain, } \\
\text { spinal cord, or retinal ischemia without acute infarction and with } \\
\text { signs and symptoms lasting less than } 24 \mathrm{~h} \text {. }\end{array}$ \\
\hline Major bleeding (ISTH definition) & $\begin{array}{l}\text { Fatal bleeding AND/OR symptomatic bleeding in a critical area or } \\
\text { organ, such as intracranial, intraspinal, intraocular, retroperitoneal, } \\
\text { intraarticular, pericardial, or intramuscular with compartment } \\
\text { syndrome AND/OR bleeding causing a fall in hemoglobin level of } \\
2 \mathrm{~g} / \mathrm{dL}(1.24 \mathrm{mmol} / \mathrm{L}) \text { or more, or leading to transfusion of two or } \\
\text { more units of blood. }\end{array}$ \\
\hline $\begin{array}{l}\text { Clinically relevant nonmajor bleed } \\
\text { (ISTH definition) }\end{array}$ & $\begin{array}{l}\text { An acute or subacute clinically overt bleed that does not meet the } \\
\text { criteria for a major bleed but prompts a clinical response such that } \\
\text { it leads to one of the following: hospital admission for bleeding; } \\
\text { physician-guided medical or surgical treatment for bleeding; } \\
\text { change in antithrombotic therapy (including interruption or } \\
\text { discontinuation). }\end{array}$ \\
\hline Minor bleeding (ISTH definition) & $\begin{array}{l}\text { All nonmajor bleeds. Minor bleeds are further divided into clinically } \\
\text { relevant and not. }\end{array}$ \\
\hline $\begin{array}{l}\text { Incidence and discontinuation of oral } \\
\text { anticoagulation }\end{array}$ & $\begin{array}{l}\text { The number of patients receiving oral anticoagulation and the type of } \\
\text { oral anticoagulation should be documented at the end of } \\
\text { follow-up. If patients have their oral anticoagulation discontinued, } \\
\text { the number of patients discontinuing, the timing of } \\
\text { discontinuation, and the reasons for discontinuation of oral } \\
\text { anticoagulation, as well as the clinical characteristics and stroke } \\
\text { risk profile of the patients should be reported. }\end{array}$ \\
\hline
\end{tabular}

$A F$ atrial fibrillation, $C T$ computed tomography, $M R I$ magnetic resonance imaging 
Table 13 Advantages and disadvantages of AF-related endpoints in AF ablation trials

\begin{tabular}{|c|c|c|c|}
\hline Endpoint & Advantages & Disadvantages & Relevance and Comments \\
\hline \multirow{3}{*}{$\begin{array}{l}\text { Freedom from } \mathrm{AF} / \mathrm{AFL} / \mathrm{AT} \\
\text { recurrence "gold standard" } \\
\text { is } 30 \mathrm{~s}\end{array}$} & - Has been in use for many years & \multirow{3}{*}{$\begin{array}{l}\text { - Can systematically underestimate the } \\
\text { efficacy of AF ablation, particularly } \\
\text { for persistent AF, if } 30 \text {-s cutoff is } \\
\text { used }\end{array}$} & $\begin{array}{l}\text { - Particularly well suited for } \\
\text { paroxysmal AF outcomes }\end{array}$ \\
\hline & $\begin{array}{l}\text { - Can be used to compare results of } \\
\text { new trials with historical trials }\end{array}$ & & $\begin{array}{l}\text { - Reporting of cutoffs other than } 30 \mathrm{~s} \\
\text { encouraged as secondary endpoints } \\
\text { to better contextualize results }\end{array}$ \\
\hline & - Sets a high bar for AF elimination & & $\begin{array}{l}\text { - May be reported as proportion of } \\
\text { patients free from arrhythmia or } \\
\text { time to recurrence }\end{array}$ \\
\hline \multirow{2}{*}{$\begin{array}{l}\text { Freedom from stroke-relevant } \\
\text { AF/AFL/AT-duration } \\
\text { cutoff of } 1 \mathrm{~h}\end{array}$} & \multirow{2}{*}{$\begin{array}{l}\text { - Useful for trials in which interest is } \\
\text { more for prognostic change } \\
\text { conferred by ablation rather than } \\
\text { elimination of all arrhythmias }\end{array}$} & \multirow{2}{*}{$\begin{array}{l}\text { - No consistent definition of what a } \\
\text { stroke-relevant duration of AF is: } \\
\text { ranges from } 6 \text { min to } 24 \mathrm{~h} \text { in } \\
\text { literature }\end{array}$} & $\begin{array}{l}\text { - More than } 1 \mathrm{~h} \text { could be a useful } \\
\text { cutoff based on results of } 505 \text { trial }\end{array}$ \\
\hline & & & $\begin{array}{l}\text { - May be reported as proportion of } \\
\text { patients free from arrhythmia or } \\
\text { time to recurrence }\end{array}$ \\
\hline $\begin{array}{l}\text { Freedom from } \mathrm{AF} / \mathrm{AFL} / \mathrm{AT} \\
\text { requiring intervention } \\
\text { (emergency visits, } \\
\text { cardioversion, urgent care } \\
\text { visit, reablation, etc.) }\end{array}$ & $\begin{array}{l}\text { - Can provide an endpoint more } \\
\text { relevant to systemic costs of } \mathrm{AF} \\
\text { recurrence } \\
\text { - Clinically relevant }\end{array}$ & $\begin{array}{l}\text { - Will overestimate efficacy of ablation } \\
\text { by ignoring shorter episodes not } \\
\text { requiring intervention that still } \\
\text { might be important to quality of life } \\
\text { or stroke }\end{array}$ & $\begin{array}{l}\text { - Determination of what is an } \\
\text { "intervention" must be prespecified } \\
\text { in protocol and biases mitigated to } \\
\text { avoid over- or underintervention in } \\
\text { the trial }\end{array}$ \\
\hline $\begin{array}{l}\text { Freedom from persistent } \\
\text { AF/AFL/AT-duration } \\
\text { cutoff of } 7 \text { days }\end{array}$ & $\begin{array}{l}\text { - Useful for trials assessing additional } \\
\text { substrate modification in persistent } \\
\text { AF }\end{array}$ & $\begin{array}{l}\text { - Can systematically overestimate the } \\
\text { efficacy of AF ablation, particularly } \\
\text { for persistent AF }\end{array}$ & $\begin{array}{l}\text { - Can require continuous monitoring to } \\
\text { definitively assess if episode is }>7 \\
\text { days }\end{array}$ \\
\hline $\begin{array}{l}\text { Freedom from AF/AFL/AT on } \\
\text { previously ineffective } \\
\text { antiarrhythmic therapy }\end{array}$ & $\begin{array}{l}\text { - If patient maintains sinus rhythm on } \\
\text { previously ineffective drug therapy, } \\
\text { this may be considered a clinically } \\
\text { relevant, successful outcome }\end{array}$ & $\begin{array}{l}\text { - Will increase the success rate } \\
\text { compared with off-drug success } \\
\text { - May not be relevant to patients } \\
\text { hoping to discontinue drug therapy }\end{array}$ & $\begin{array}{l}\text { - Postablation drug and dosage of drug } \\
\text { should be identical to preablation } \\
\text { drug and dosage }\end{array}$ \\
\hline \multirow[t]{3}{*}{$\begin{array}{l}\text { Significant reduction in AF } \\
\text { burden: }>75 \% \text { reduction } \\
\text { from pre- to postablation } \\
\text { and/or total postablation } \\
\text { burden }<12 \%\end{array}$} & \multirow[t]{3}{*}{$\begin{array}{l}\text { - Can be useful in persistent AF } \\
\text { studies, but might not be suited for } \\
\text { early, paroxysmal AF studies }\end{array}$} & $\begin{array}{l}\text { - Ideally requires continuous } \\
\text { monitoring using an implantable } \\
\text { device }\end{array}$ & $\begin{array}{l}\text { - AF burden can be estimated by } \\
\text { intermittent monitoring and } \\
\text { reporting of patient symptoms and } \\
\text { recurrences like a "time in } \\
\text { therapeutic range" report for oral } \\
\text { anticoagulation; see text }\end{array}$ \\
\hline & & \multirow[t]{2}{*}{$\begin{array}{l}\text { - No scientific basic exists showing } \\
\text { that a } 75 \% \text { reduction in AF burden } \\
\text { impacts hard endpoints, including } \\
\text { heart failure, stroke, and mortality }\end{array}$} & $\begin{array}{l}\text { - Could also see } 75 \% \text { reduction in } \\
\text { number and duration of AF } \\
\text { episodes }\end{array}$ \\
\hline & & & $\begin{array}{l}\text { - Because there is no firm scientific } \\
\text { basis for selecting the cutoff of } \\
75 \%, \text { this prior recommendation is } \\
\text { provided only as an example of } \\
\text { what future clinical trials may } \\
\text { choose to use as a definition of } \\
\text { clinical/partial success }\end{array}$ \\
\hline \multirow[t]{3}{*}{$\begin{array}{l}\text { Prevention in AF progression: } \\
\text { time to first episode of } \\
\text { persistent AF ( }>7 \text { days) }\end{array}$} & $\begin{array}{l}\text { - Does not assume that total } \\
\text { elimination of AF is required }\end{array}$ & $\begin{array}{l}\text { - Prevention in progression might be } \\
\text { irrelevant for stroke or } \\
\text { thromboembolic outcomes }\end{array}$ & \multirow{3}{*}{$\begin{array}{l}\text { - Might be useful for specific } \\
\text { populations such as heart failure or } \\
\text { hypertrophic cardiomyopathy, in } \\
\text { which progression to persistent AF } \\
\text { can lead to increased hospitalization }\end{array}$} \\
\hline & $\begin{array}{l}\text { - Well suited for paroxysmal or "early" } \\
\text { AF studies in which goal is to } \\
\text { prevent progression to persistent AF }\end{array}$ & $\begin{array}{l}\text { - Long follow-up time might be } \\
\text { required unless population is } \\
\text { "enriched" }\end{array}$ & \\
\hline & & $\begin{array}{l}\text { - Can ideally require continuous } \\
\text { implantable monitoring }\end{array}$ & \\
\hline $\begin{array}{l}\text { Regression of AF: reduction } \\
\text { in burden to a given } \\
\text { threshold or conversion of }\end{array}$ & $\begin{array}{l}\text { - Does not assume that total } \\
\text { elimination of AF is required }\end{array}$ & $\begin{array}{l}\text { - Regression endpoint will } \\
\text { overestimate efficacy of AF } \\
\text { ablation }\end{array}$ & $\begin{array}{l}\text { - Could be particularly useful for } \\
\text { long-standing persistent AF } \\
\text { populations with structural heart } \\
\text { disease, heart failure, etc. }\end{array}$ \\
\hline
\end{tabular}
disease, heart failure, etc. 
Table 13 (continued)

\begin{tabular}{|c|c|c|c|}
\hline Endpoint & Advantages & Disadvantages & Relevance and Comments \\
\hline $\begin{array}{l}\text { persistent to paroxysmal } \\
\text { AF }\end{array}$ & $\begin{array}{l}\text { - Well suited for persistent "late" AF } \\
\text { studies in which goal is to regress to } \\
\text { paroxysmal AF, which might be } \\
\text { easier to control with drug therapy }\end{array}$ & $\begin{array}{l}\text { - Might ideally require continuous } \\
\text { implantable monitoring } \\
\text { - Patients will require ongoing drug } \\
\text { therapy }\end{array}$ & \\
\hline \multirow[t]{3}{*}{$\begin{array}{l}\text { Acute } \mathrm{AF} \text { termination during } \\
\text { ablation procedure }\end{array}$} & $\begin{array}{l}\text { - Could provide indication of } \\
\text { successful modification of substrate } \\
\text { responsible for maintaining AF, } \\
\text { most relevant to persistent or } \\
\text { long-standing persistent AF }\end{array}$ & $\begin{array}{l}\text { - Relevance of acute AF termination } \\
\text { has not consistently been shown to } \\
\text { correlate to long-term success }\end{array}$ & $\begin{array}{l}\text { - Intraprocedural administration of } \\
\text { preprocedural oral antiarrhythmics } \\
\text { or intraprocedural intravenous } \\
\text { antiarrhythmics are discouraged }\end{array}$ \\
\hline & $\begin{array}{l}\text { - Limited studies have linked acute AF } \\
\text { termination to long-term success }\end{array}$ & $\begin{array}{l}\text { - Endpoint might not be relevant to } \\
\text { paroxysmal AF patients in whom } \\
\text { AF might terminate spontaneously }\end{array}$ & $\begin{array}{l}\text { - If antiarrhythmics are used, their use } \\
\text { and dosage before and during the } \\
\text { ablation should be clearly } \\
\text { documented }\end{array}$ \\
\hline & $\begin{array}{l}\text { - Studies consider termination as } \\
\text { reversion to sinus rhythm, whereas } \\
\text { others consider reversion to any } \\
\text { regular tachycardia as termination }\end{array}$ & $\begin{array}{l}\text { - Some studies employ administration } \\
\text { of intravenous or oral } \\
\text { antiarrhythmics during ablation that } \\
\text { could cause spontaneous } \\
\text { termination }\end{array}$ & $\begin{array}{l}\text { - Termination to sinus rhythm and } \\
\text { termination to another regular } \\
\text { tachycardia (AT or AFL) should be } \\
\text { separately reported }\end{array}$ \\
\hline
\end{tabular}

$A F$ atrial fibrillation, $A F L$ atrial flutter, $A T$ atrial tachycardia

operators, the statistical occurrence of complications will increase. We need newer techniques to minimize complications and institute standards for operators to improve the reproducibility of ablation results and safety profiles at a variety of centers worldwide.

13 How does catheter ablation affect mortality, stroke, and hospitalization in broad and selected patient populations receiving catheter ablation for $\mathrm{AF}$ ?

14 Management of patients who fail initial attempts at catheter ablation: Should there be specific criteria for repeat ablations (e.g., atrial size, body mass index)? Should patients be referred for surgery for repeat ablation?

In order to address these and other important questions in the field of catheter and surgical AF ablation, we urge investigators to create and participate in multisite collaborations and electrophysiology research networks with involvement of senior and junior investigators on the steering committees to push forward the next phase of AF research. We also urge funding bodies to support these important initiatives.

\section{Conclusion}

Catheter ablation of AF is a very commonly performed procedure in hospitals throughout the world. This document provides an up-to-date review of the indications, techniques, and outcomes of catheter and surgical ablation of AF. Areas for which a consensus can be reached concerning AF ablation are identified, and a series of consensus definitions have been developed for use in future clinical trials of $\mathrm{AF}$ ablation. Also included within this document are recommendations concerning indications for AF ablation, technical performance of this procedure, and training. It is our hope to improve patient care by providing a foundation for those involved with care of patients with $\mathrm{AF}$ as well as those who perform AF ablation. It is recognized that this field continues to evolve rapidly and that this document will need to be updated. Successful AF ablation programs optimally should consist of a cooperative team of cardiologists, electrophysiologists, and surgeons to ensure appropriate indications, procedure selection, and follow-up.

Acknowledgements The authors acknowledge the support of Jun Dong, MD, PhD; Kan Fang, MD; and Mark Fellman at the Division of Cardiovascular Devices, Center for Devices and Radiological Health, U.S. Food and Drug Administration (FDA) during the preparation of this document. This document does not necessarily represent the opinions, policies, or recommendations of the FDA. 


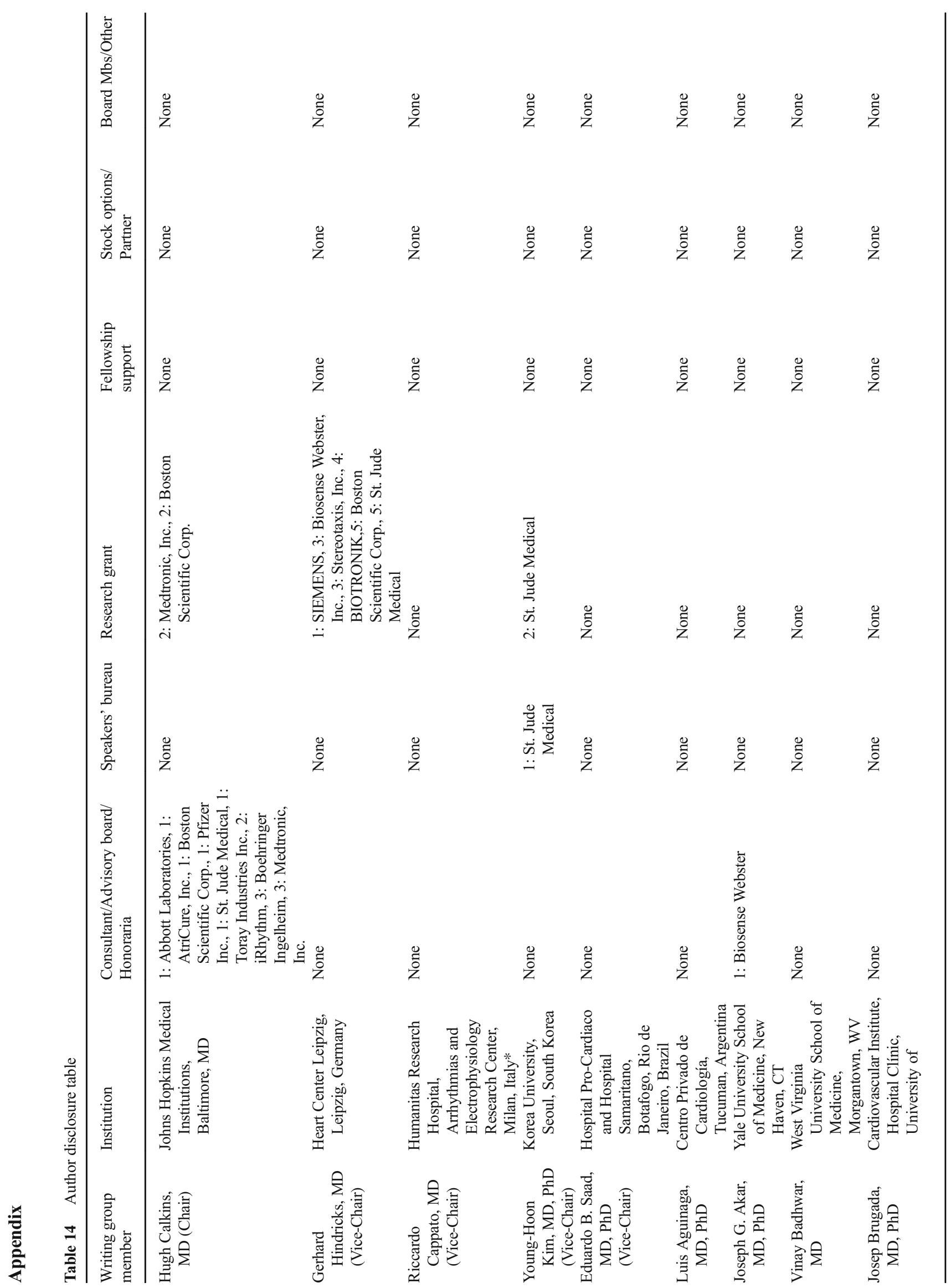




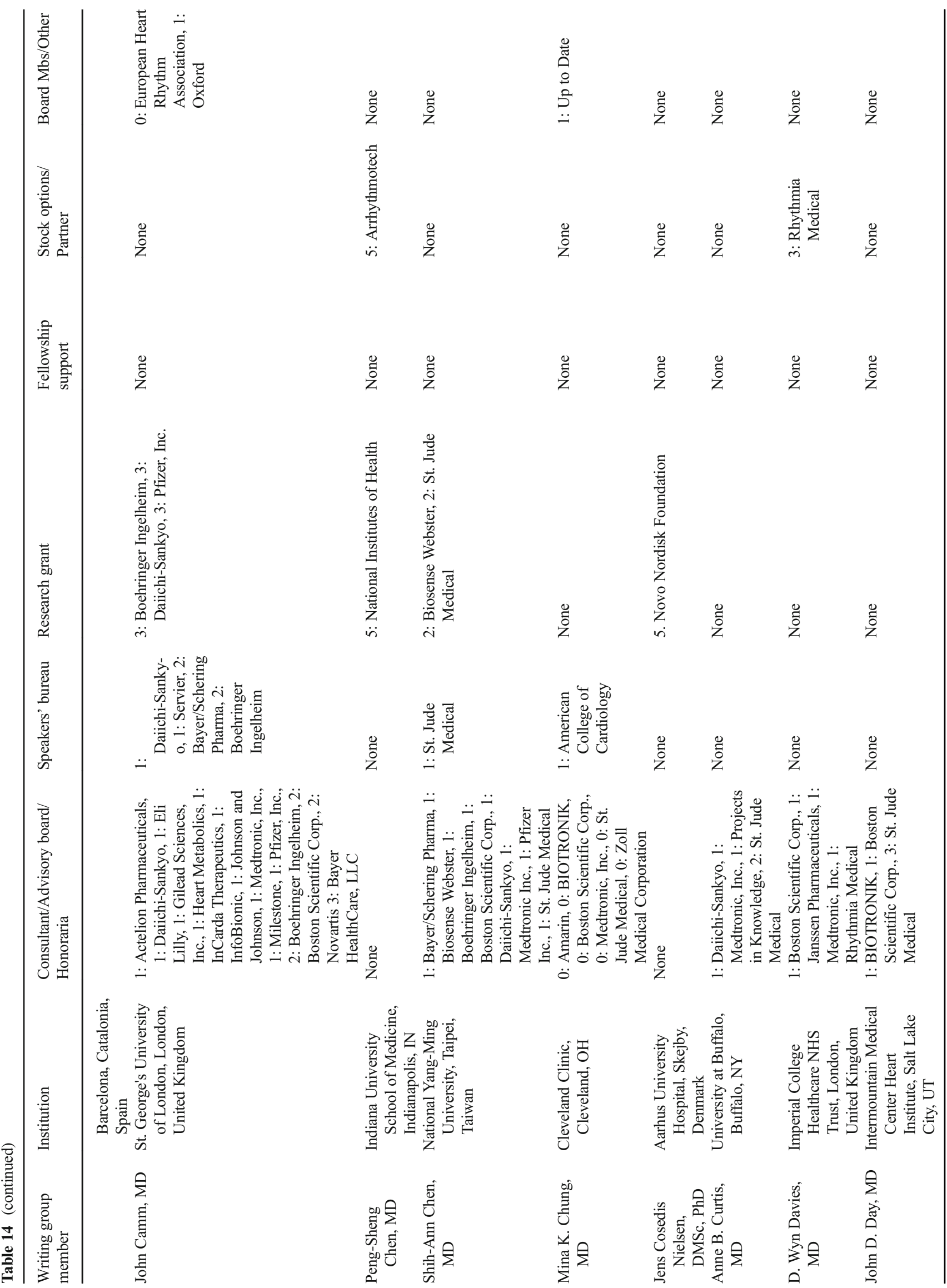




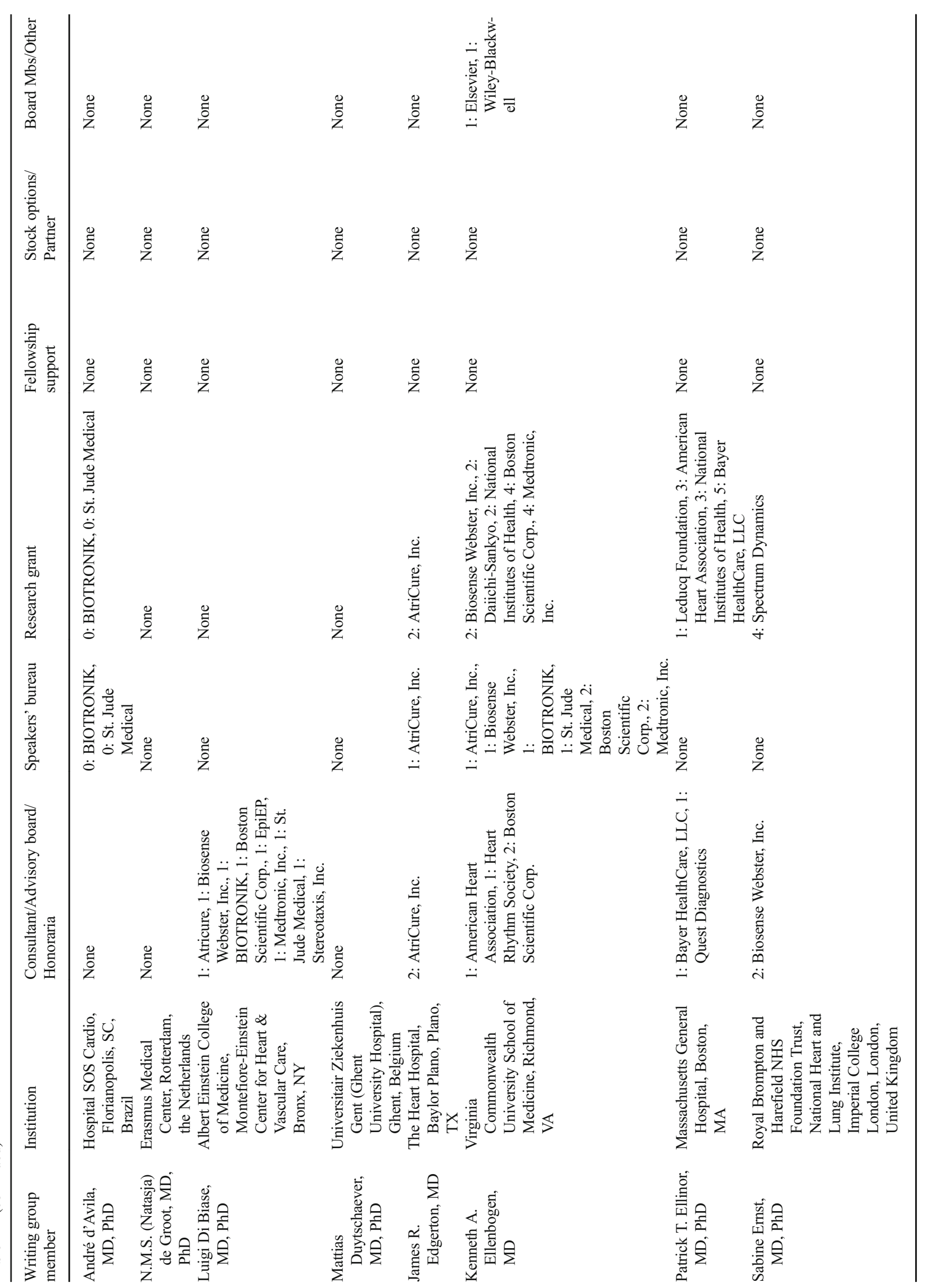




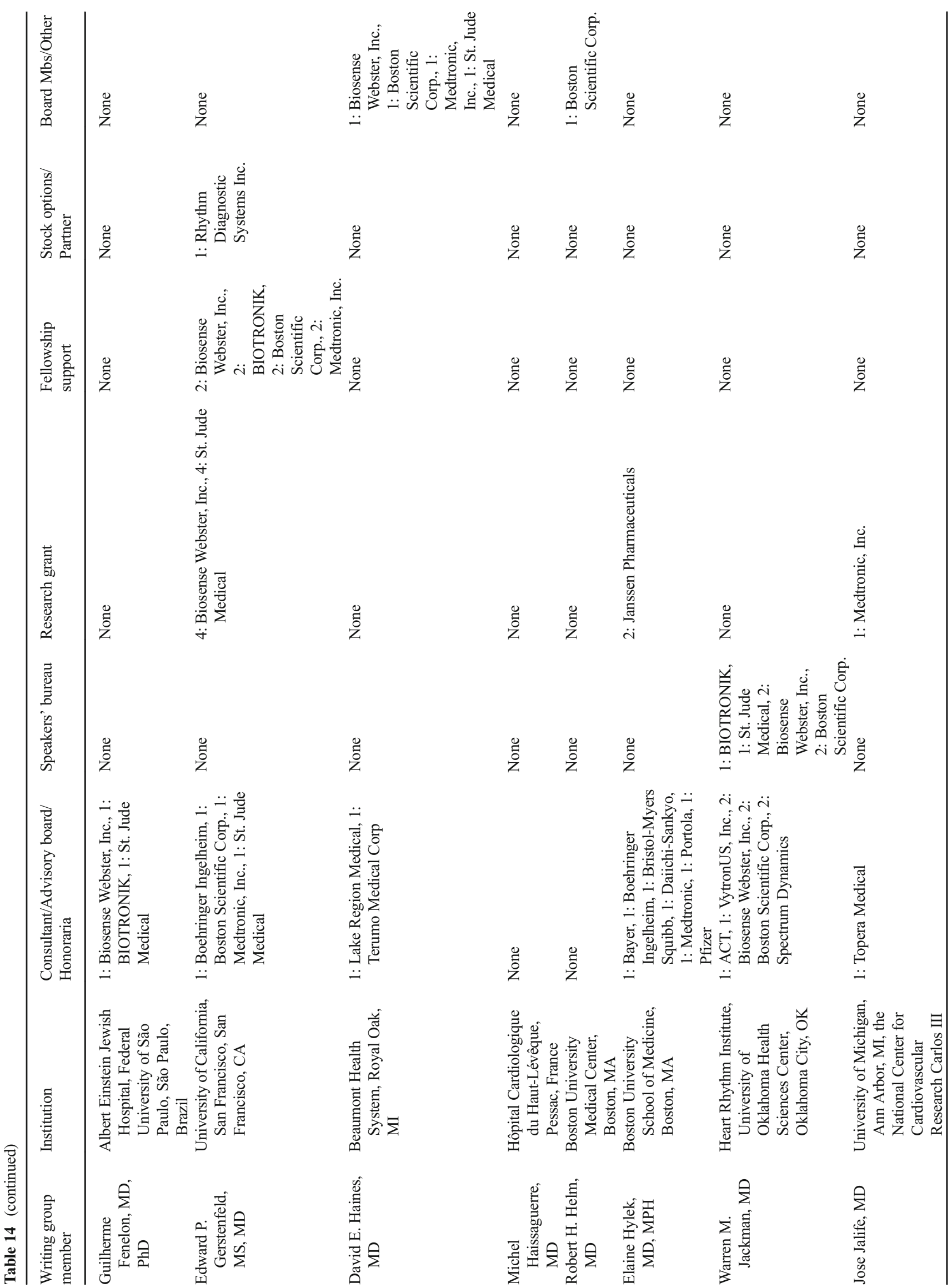




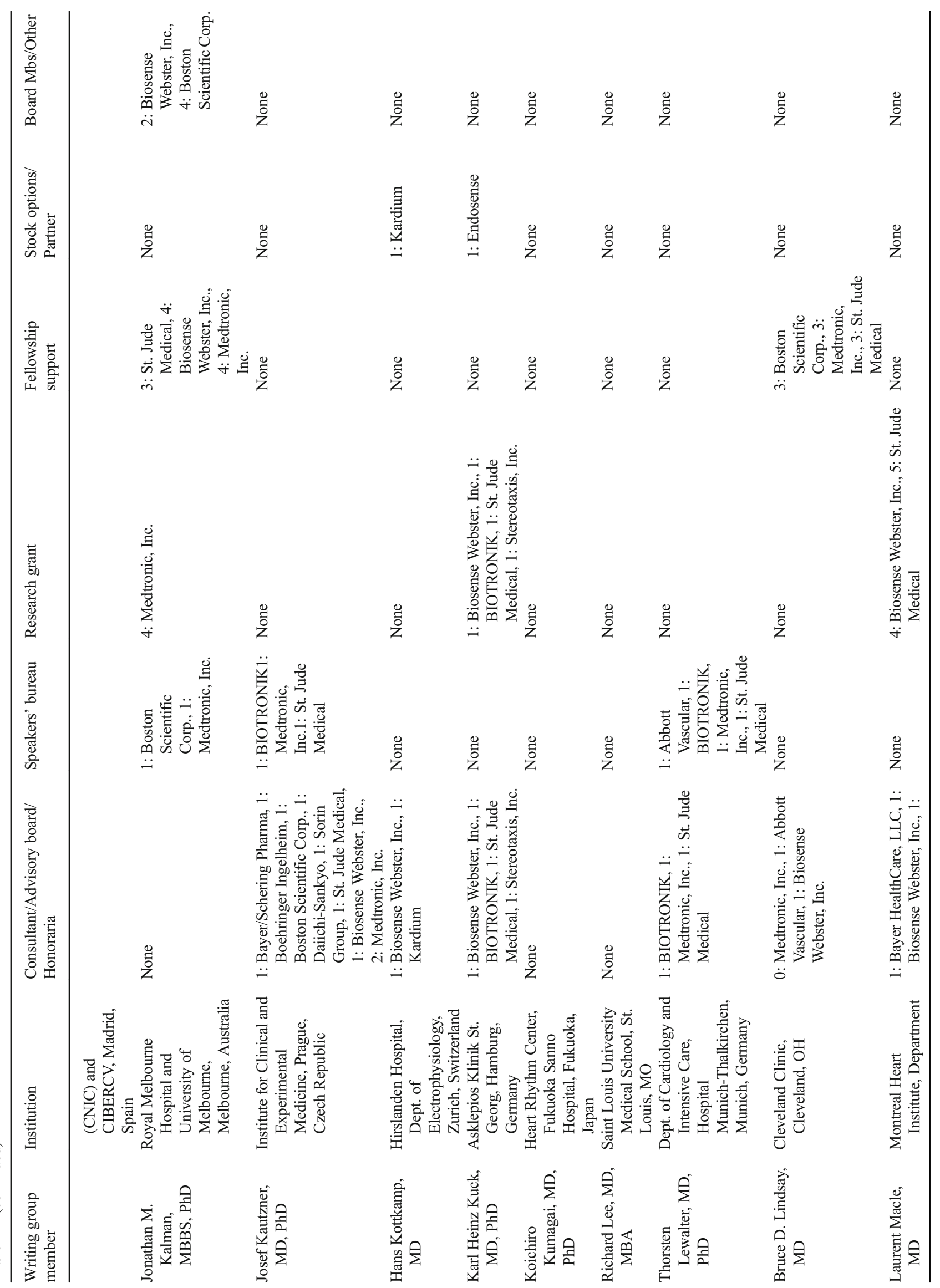




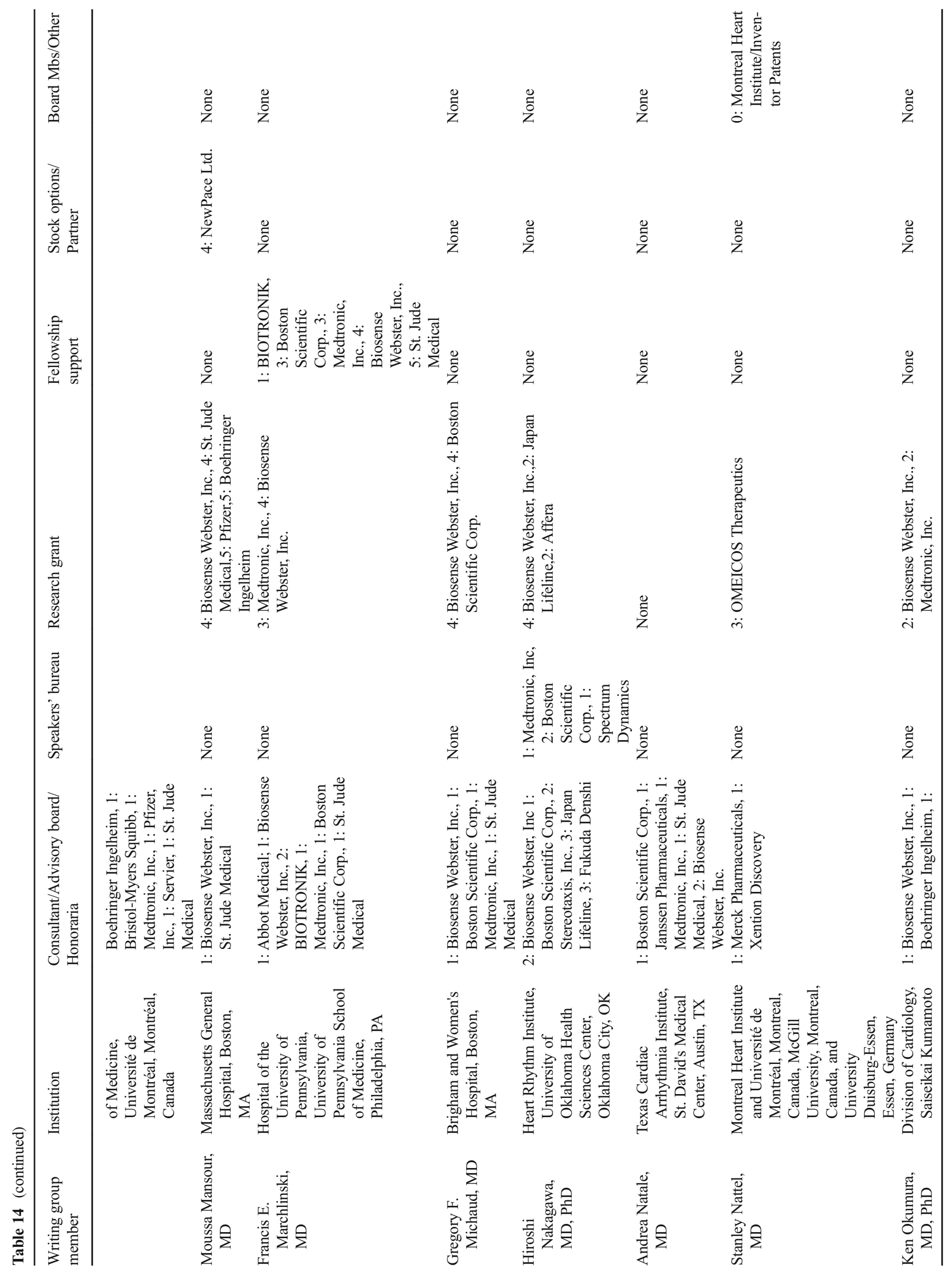




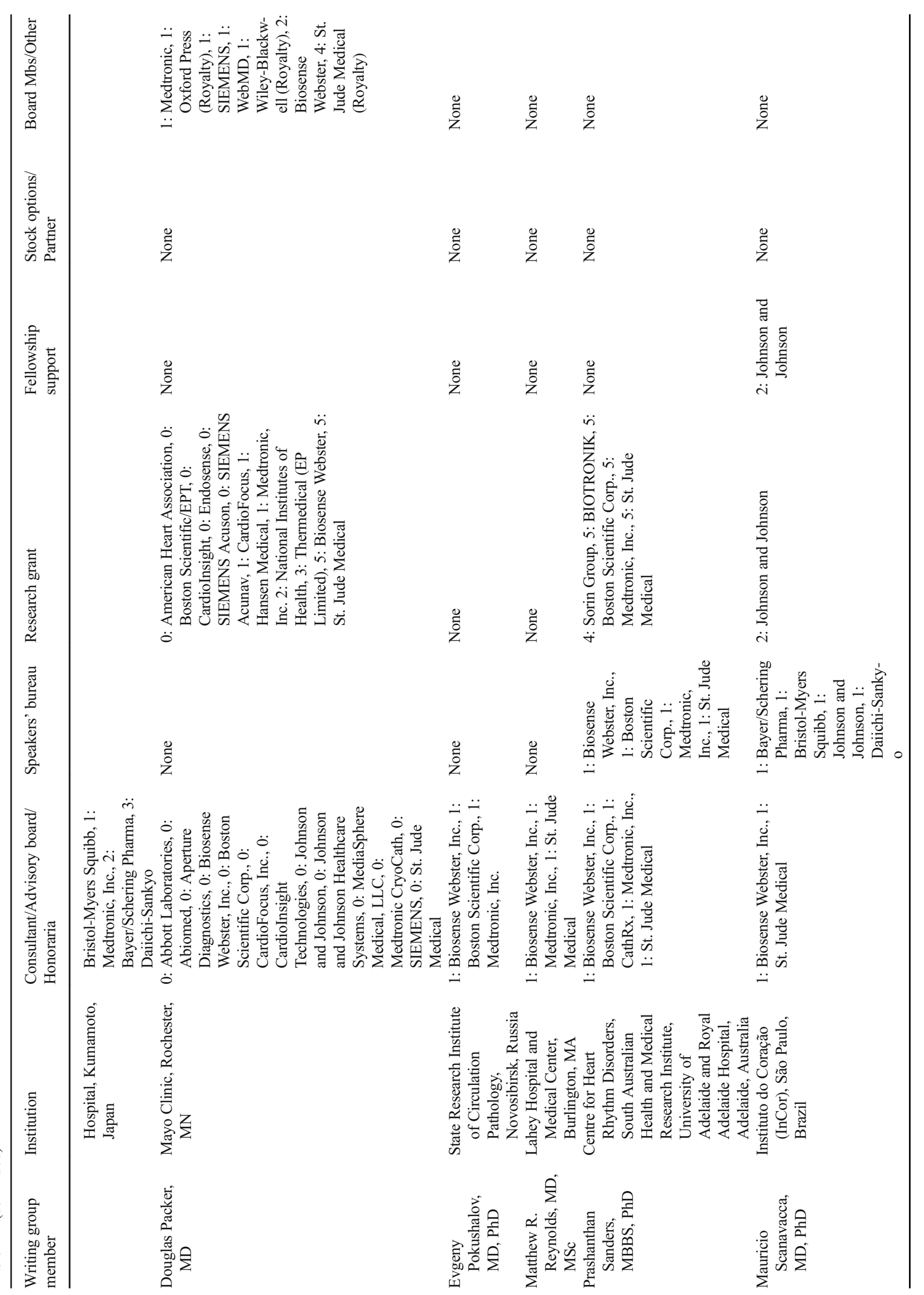




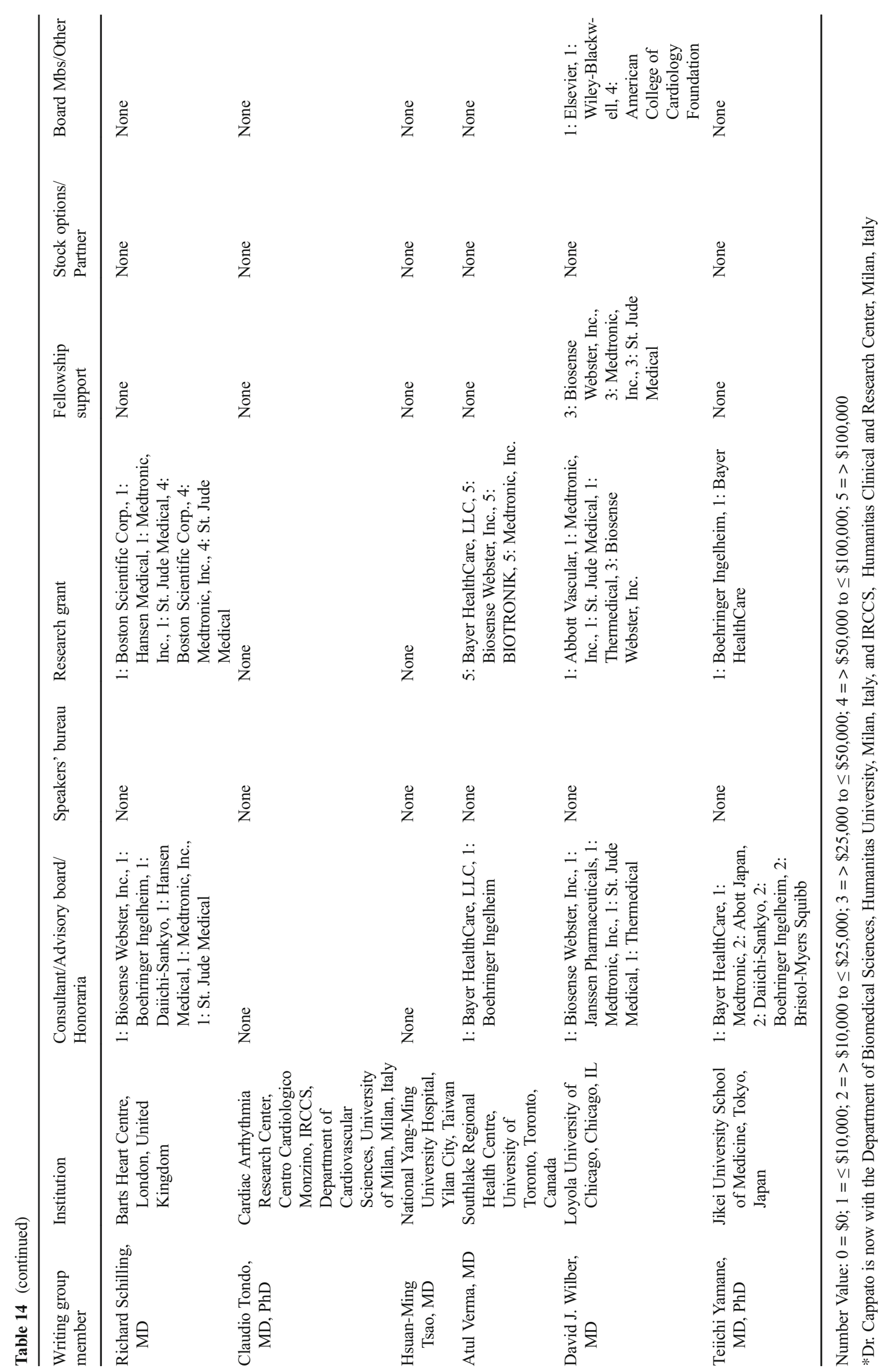


Table 15 Reviewer disclosure table

\begin{tabular}{|c|c|c|c|c|c|c|c|}
\hline Peer reviewer & Institution & $\begin{array}{l}\text { Consultant/Advisory board/ } \\
\text { Honoraria }\end{array}$ & Speakers' bureau & Research grant & $\begin{array}{l}\text { Fellows- } \\
\text { hip } \\
\text { support }\end{array}$ & $\begin{array}{l}\text { Stock } \\
\text { options/ } \\
\text { Partner }\end{array}$ & $\begin{array}{l}\text { Board } \\
\text { Mbs/ } \\
\text { Other }\end{array}$ \\
\hline $\begin{array}{l}\text { Carina } \\
\text { Blomström-L- } \\
\text { undqvist, MD, } \\
\mathrm{PhD}\end{array}$ & $\begin{array}{l}\text { Department of Cardiology and } \\
\text { Medical Science, Uppsala } \\
\text { University, Uppsala, } \\
\text { Sweden }\end{array}$ & $\begin{array}{l}\text { 1: Bayer/Schering Pharma, 1: } \\
\text { Boston Scientific Corp., 1: } \\
\text { Medtronic, Inc., 1: Sanofi, } \\
\text { 1: Pfizer, MSD, } \\
\text { Bristol-Myers Squibb, } \\
\text { Biosense Webster, Inc. }\end{array}$ & None & $\begin{array}{l}\text { 1: Cardiome } \\
\text { Pharma/Ast- } \\
\text { ellas, 1: } \\
\text { Medtronic, } \\
\text { Inc. }\end{array}$ & None & None & None \\
\hline $\begin{array}{l}\text { Angelo A.V. De } \\
\text { Paola, MD, } \\
\text { PhD }\end{array}$ & $\begin{array}{l}\text { Hospital São Paulo - Federal } \\
\text { University of São Paulo, } \\
\text { São Paulo, Brazil }\end{array}$ & None & None & None & None & None & None \\
\hline $\begin{array}{l}\text { Peter M. Kistler, } \\
\text { MBBS, PhD }\end{array}$ & $\begin{array}{l}\text { The Alfred Hospital Heart } \\
\text { Centre, Melbourne, } \\
\text { Australia }\end{array}$ & None & $\begin{array}{l}\text { 1: St. Jude } \\
\text { Medical }\end{array}$ & None & None & None & None \\
\hline $\begin{array}{l}\text { Gregory Y.H. Lip, } \\
\text { MD }\end{array}$ & $\begin{array}{l}\text { University of Birmingham, } \\
\text { Birmingham, United } \\
\text { Kingdom; Aalborg } \\
\text { University, Aalborg, } \\
\text { Denmark }\end{array}$ & $\begin{array}{l}\text { 1: Medtronic,3: } \\
\text { Bayer/Janssen, } \\
\text { BMS/Pfizer, Boehringer } \\
\text { Ingelheim, Daiichi-Sankyo }\end{array}$ & $\begin{array}{l}\text { 3: Bayer, } \\
\text { BMS/Pfizer, } \\
\text { Boehringer } \\
\text { Ingelheim, } \\
\text { Daiichi-Sanky- } \\
\text { o. No fees are } \\
\text { received } \\
\text { personally }\end{array}$ & None & None & None & None \\
\hline $\begin{array}{l}\text { Nicholas S. } \\
\text { Peters, MD }\end{array}$ & $\begin{array}{l}\text { St Mary's Hospital, Imperial } \\
\text { College London, London, } \\
\text { United Kingdom }\end{array}$ & $\begin{array}{l}\text { 1: Boston Scientific Corp., 1: } \\
\text { Cardialen, Inc., 1: } \\
\text { Cardiologs, 1: Magnetecs, } \\
\text { 1: Medtronic, Inc., 1: St. } \\
\text { Jude Medical }\end{array}$ & None & None & None & None & None \\
\hline $\begin{array}{l}\text { Cristiano F. } \\
\text { Pisani, MD }\end{array}$ & $\begin{array}{l}\text { InCor, Heart Insitute, } \\
\text { HCFMUSP, Arrhythmia } \\
\text { Unit }\end{array}$ & None & None & None & None & None & None \\
\hline $\begin{array}{l}\text { Antonio Raviele, } \\
\text { MD }\end{array}$ & $\begin{array}{l}\text { ALFA-Alliance to Fight Atrial } \\
\text { Fibrillation, Rimini, Italy }\end{array}$ & None & None & None & None & None & None \\
\hline $\begin{array}{l}\text { Eduardo B. Saad, } \\
\text { MD, PhD }\end{array}$ & $\begin{array}{l}\text { Hospital Pro-Cardiaco and } \\
\text { Hospital Samaritano, } \\
\text { Botafogo, Rio de Janeiro, } \\
\text { Brazil }\end{array}$ & None & None & None & None & None & None \\
\hline $\begin{array}{l}\text { Kazuhiro Satomi, } \\
\text { MD, PhD }\end{array}$ & $\begin{array}{l}\text { Tokyo Medical University, } \\
\text { Tokyo, Japan }\end{array}$ & $\begin{array}{l}\text { 1: Bayer/Schering Pharma, 1: } \\
\text { Boehringer Ingelheim, 1: } \\
\text { Bristol-Myers Squibb, 1: } \\
\text { Japan Lifeline, 1: Johnson } \\
\text { and Johnson, 1: Medtronic, } \\
\text { Inc., 1: Sankyo } \\
\text { Pharmaceuticals, 1: St. Jude } \\
\text { Medical }\end{array}$ & None & None & None & None & None \\
\hline $\begin{array}{l}\text { Martin K. Stiles, } \\
\text { MB ChB, PhD }\end{array}$ & $\begin{array}{l}\text { Waikato Hospital, Hamilton, } \\
\text { New Zealand }\end{array}$ & $\begin{array}{l}\text { 1: Boston Scientific Corp., 1: } \\
\text { Biosense Webster, Inc., 1: } \\
\text { BIOTRONIK, 1: } \\
\text { Medtronic, Inc. }\end{array}$ & None & None & $\begin{array}{l}\text { 1: } \\
\text { Medt- } \\
\text { ronic, } \\
\text { Inc. }\end{array}$ & None & None \\
\hline $\begin{array}{l}\text { Stephan Willems, } \\
\text { MD, PhD }\end{array}$ & $\begin{array}{l}\text { University Medical Center } \\
\text { Hamburg-Eppendorf, } \\
\text { Hamburg, Germany }\end{array}$ & $\begin{array}{l}\text { 1: Bayer HealthCare, LLC, 1: } \\
\text { Biosense Webster, Inc., 1: } \\
\text { Boehringer Ingelheim, 1: } \\
\text { Bristol-Myers Squibb, 1: } \\
\text { Sanofi, 1: St. Jude Medical, } \\
\text { 1: Medtronic }\end{array}$ & None & None & None & None & None \\
\hline
\end{tabular}

Number Value: $0=\$ 0 ; 1=\leq \$ 10,000 ; 2=>\$ 10,000$ to $\leq \$ 25,000 ; 3=>\$ 25,000$ to $\leq \$ 50,000 ; 4=>\$ 50,000$ to $\leq \$ 100,000 ; 5=>\$ 100,000$

Open Access This article is distributed under the terms of the Creative Commons Attribution 4.0 International License (http:// creativecommons.org/licenses/by/4.0/), which permits unrestricted use, distribution, and reproduction in any medium, provided you give appropriate credit to the original author(s) and the source, provide a link to the Creative Commons license, and indicate if changes were made. 


\section{References}

1. Calkins H, et al. HRS/EHRA/ECAS expert consensus statement on catheter and surgical ablation of atrial fibrillation: recommendations for personnel, policy, procedures and follow-up. A report of the Heart Rhythm Society (HRS) task force on catheter and surgical ablation of atrial fibrillation. Heart Rhythm. 2007;4(6):816-61.

2. Calkins H, et al. 2012 HRS/EHRA/ECAS expert consensus statement on catheter and surgical ablation of atrial fibrillation: recommendations for patient selection, procedural techniques, patient management and follow-up, definitions, endpoints, and research trial design. Heart Rhythm. 2012;9(4):632-696.e21.

3. Jacobs AK, Anderson JL, Halperin JL. The evolution and future of ACC/AHA clinical practice guidelines: a 30-year journey: a report of the American College of Cardiology/American Heart Association task force on practice guidelines. J Am Coll Cardiol. 2014;64(13):1373-84.

4. Anderson JL. Evolution of the ACC/AHA clinical practice guidelines in perspective: guiding the guidelines. J Am Coll Cardiol. 2015;65(25):2735-8.

5. January CT, et al. 2014 AHA/ACC/HRS guideline for the management of patients with atrial fibrillation: a report of the American College of Cardiology/American Heart Association task force on practice guidelines and the Heart Rhythm Society. J Am Coll Cardiol. 2014;64(21):e1-e76.

6. Kirchhof P, et al. 2016 ESC guidelines for the management of atrial fibrillation developed in collaboration with EACTS. Eur J Cardiothorac Surg. 2016;50(5):e1-e88.

7. Jais $\mathrm{P}$, et al. Catheter ablation versus antiarrhythmic drugs for atrial fibrillation: the A4 study. Circulation. 2008;18(24):2498-505.

8. Calkins $\mathrm{H}$, et al. Treatment of atrial fibrillation with antiarrhythmic drugs or radiofrequency ablation: two systematic literature reviews and meta-analyses. Circ Arrhythm Electrophysiol. 2009;2(4):349-61.

9. Packer DL, et al. Cryoballoon ablation of pulmonary veins for paroxysmal atrial fibrillation: first results of the north American Arctic front (STOP AF) pivotal trial. J Am Coll Cardiol. 2013;61(16):1713-23.

10. Kuck KH, et al. Cryoballoon or radiofrequency ablation for paroxysmal atrial fibrillation. N Engl J Med. 2016;374(23):2235-45.

11. Dukkipati SR, et al. Pulmonary vein isolation using the visually guided laser balloon: a prospective, multicenter, and randomized comparison to standard radiofrequency ablation. J Am Coll Cardiol. 2015;66(12):1350-60.

12. Reddy VY, et al. Randomized, controlled trial of the safety and effectiveness of a contact force-sensing irrigated catheter for ablation of paroxysmal atrial fibrillation: results of the TactiCath contact force ablation catheter study for atrial fibrillation (TOCCASTAR) study. Circulation. 2015;132(10):907-15.

13. Natale A, et al. Paroxysmal AF catheter ablation with a contact force sensing catheter: results of the prospective, multicenter SMART-AF trial. J Am Coll Cardiol. 2014;64(7):647-56.

14. Wilber DJ, et al. Comparison of antiarrhythmic drug therapy and radiofrequency catheter ablation in patients with paroxysmal atrial fibrillation: a randomized controlled trial. JAMA. 2010;303(4): 333-40.

15. Sohara $\mathrm{H}$, et al. HotBalloon ablation of the pulmonary veins for paroxysmal AF: a multicenter randomized trial in Japan. J Am Coll Cardiol. 2016;68(25):2747-57.

16. Pappone $\mathrm{C}$, et al. A randomized trial of circumferential pulmonary vein ablation versus antiarrhythmic drug therapy in paroxysmal atrial fibrillation: the APAF study. J Am Coll Cardiol. 2006:48(11):2340-7.

17. Stabile G, et al. Catheter ablation treatment in patients with drugrefractory atrial fibrillation: a prospective, multi-centre, randomized, controlled study (catheter ablation for the cure of atrial fibrillation study). Eur Heart J. 2006;27(2):216-21.

18. Forleo GB, et al. Catheter ablation of atrial fibrillation in patients with diabetes mellitus type 2: results from a randomized study comparing pulmonary vein isolation versus antiarrhythmic drug therapy. J Cardiovasc Electrophysiol. 2009;20(1):22-8.

19. Verma A, et al. Approaches to catheter ablation for persistent atrial fibrillation. N Engl J Med. 2015;372(19):1812-22.

20. Scherr D, et al. Five-year outcome of catheter ablation of persistent atrial fibrillation using termination of atrial fibrillation as a procedural endpoint. Circ Arrhythm Electrophysiol. 2015;8(1):18-24.

21. Tamborero $\mathrm{D}$, et al. Left atrial posterior wall isolation does not improve the outcome of circumferential pulmonary vein ablation for atrial fibrillation: a prospective randomized study. Circ Arrhythm Electrophysiol. 2009;2(1):35-40.

22. Hummel J, et al. Phased RF ablation in persistent atrial fibrillation. Heart Rhythm. 2014;11(2):202-9.

23. Bassiouny $\mathrm{M}$, et al. Randomized study of persistent atrial fibrillation ablation: ablate in sinus rhythm versus ablate complexfractionated atrial electrograms in atrial fibrillation. Circ Arrhythm Electrophysiol. 2016;9(2):e003596.

24. Krittayaphong R, et al. A randomized clinical trial of the efficacy of radiofrequency catheter ablation and amiodarone in the treatment of symptomatic atrial fibrillation. J Med Assoc Thail. 2003;86(Suppl 1):S8-S16.

25. Oral H, et al. Circumferential pulmonary-vein ablation for chronic atrial fibrillation. N Engl J Med. 2006;354(9):934-41.

26. Mont $\mathrm{L}$, et al. Catheter ablation vs. antiarrhythmic drug treatment of persistent atrial fibrillation: a multicentre, randomized, controlled trial (SARA study). Eur Heart J. 2014;35(8):501-7.

27. Calvo N, et al. Efficacy of circumferential pulmonary vein ablation of atrial fibrillation in endurance athletes. Europace. 2010;12(1):30-6.

28. Furlanello F, et al. Radiofrequency catheter ablation of atrial fibrillation in athletes referred for disabling symptoms preventing usual training schedule and sport competition. J Cardiovasc Electrophysiol. 2008;19(5):457-62.

29. Wazni OM, et al. Radiofrequency ablation vs antiarrhythmic drugs as first-line treatment of symptomatic atrial fibrillation: a randomized trial. JAMA. 2005;293(21):2634-40.

30. Cosedis Nielsen J, et al. Radiofrequency ablation as initial therapy in paroxysmal atrial fibrillation. N Engl J Med. 2012;367(17): 1587-95.

31. Morillo CA, et al. Radiofrequency ablation vs antiarrhythmic drugs as first-line treatment of paroxysmal atrial fibrillation (RAAFT-2): a randomized trial. JAMA. 2014;311(7):692-700.

32. Hakalahti A, et al. Radiofrequency ablation vs antiarrhythmic drug therapy as first line treatment of symptomatic atrial fibrillation: systematic review and meta-analysis. Europace. 2015;17(3): 370-8.

33. Hocini M, et al. Reverse remodeling of sinus node function after catheter ablation of atrial fibrillation in patients with prolonged sinus pauses. Circulation. 2003;108(10):1172-5.

34. Chen YW, et al. Pacing or ablation: which is better for paroxysmal atrial fibrillation-related tachycardia-bradycardia syndrome? Pacing Clin Electrophysiol. 2014;37(4):403-11.

35. Inada $\mathrm{K}$, et al. The role of successful catheter ablation in patients with paroxysmal atrial fibrillation and prolonged sinus pauses: outcome during a 5-year follow-up. Europace. 2014;16(2):20813. 
36. Chen MS, et al. Pulmonary vein isolation for the treatment of atrial fibrillation in patients with impaired systolic function. J Am Coll Cardiol. 2004;43(6):1004-9.

37. Gentlesk PJ, et al. Reversal of left ventricular dysfunction following ablation of atrial fibrillation. J Cardiovasc Electrophysiol. 2007;18(1):9-14.

38. Khan MN, et al. Pulmonary-vein isolation for atrial fibrillation in patients with HF. N Engl J Med. 2008;359(17):1778-85.

39. MacDonald MR, et al. Radiofrequency ablation for persistent atrial fibrillation in patients with advanced heart failure and severe left ventricular systolic dysfunction: a randomised controlled trial. Heart. 2011;97(9):740-7.

40. Hunter RJ, et al. A randomized controlled trial of catheter ablation versus medical treatment of atrial fibrillation in heart failure (the CAMTAF trial). Circ Arrhythm Electrophysiol. 2014;7(1):31-8.

41. Tondo C, et al. Pulmonary vein vestibule ablation for the control of atrial fibrillation in patients with impaired left ventricular function. Pacing Clin Electrophysiol. 2006;29(9):962-70.

42. Lutomsky BA, et al. Catheter ablation of paroxysmal atrial fibrillation improves cardiac function: a prospective study on the impact of atrial fibrillation ablation on left ventricular function assessed by magnetic resonance imaging. Europace. 2008;10(5): 593-9.

43. Choi AD, et al. Ablation vs medical therapy in the setting of symptomatic atrial fibrillation and left ventricular dysfunction. Congest Heart Fail. 2010;16(1):10-4.

44. De Potter T, et al. Left ventricular systolic dysfunction by itself does not influence outcome of atrial fibrillation ablation. Europace. 2010;12(1):24-9.

45. Cha YM, et al. Success of ablation for atrial fibrillation in isolated left ventricular diastolic dysfunction: a comparison to systolic dysfunction and normal ventricular function. Circ Arrhythm Electrophysiol. 2011;4(5):724-32.

46. Jones DG, et al. A randomized trial to assess catheter ablation versus rate control in the management of persistent atrial fibrillation in HF. J Am Coll Cardiol. 2013;61(18):1894-903.

47. Machino-Ohtsuka T, et al. Efficacy, safety, and outcomes of catheter ablation of atrial fibrillation in patients with heart failure with preserved ejection fraction. J Am Coll Cardiol. 2013;62(20): 1857-65.

48. Al Halabi S, et al. Catheter ablation for atrial fibrillation in heart failure patients: a meta-analysis of randomized controlled trials. JACC Clin Electrophysiol. 2015;1(3):200-9.

49. Bunch TJ, et al. Five-year outcomes of catheter ablation in patients with atrial fibrillation and left ventricular systolic dysfunction. J Cardiovasc Electrophysiol. 2015;26(4):363-70.

50. Lobo TJ, et al. Atrial fibrillation ablation in systolic dysfunction: clinical and echocardiographic outcomes. Arq Bras Cardiol. 2015;104(1):45-52.

51. Ling LH, et al. Sinus rhythm restores ventricular function in patients with cardiomyopathy and no late gadolinium enhancement on cardiac magnetic resonance imaging who undergo catheter ablation for atrial fibrillation. Heart Rhythm. 2013;10(9):1334-9.

52. Hsu LF, et al. Catheter ablation for atrial fibrillation in congestive HF. N Engl J Med. 2004;351(23):2373-83.

53. Spragg DD, et al. Complications of catheter ablation for atrial fibrillation: incidence and predictors. J Cardiovasc Electrophysiol. 2008;19(6):627-31.

54. Kusumoto F, et al. Radiofrequency catheter ablation of atrial fibrillation in older patients: outcomes and complications. J Interv Card Electrophysiol. 2009;25(1):31-5.

55. Bunch TJ, et al. Long-term clinical efficacy and risk of catheter ablation for atrial fibrillation in octogenarians. Pacing Clin Electrophysiol. 2010;33(2):146-52.
56. Santangeli P, et al. Catheter ablation of atrial fibrillation in octogenarians: safety and outcomes. J Cardiovasc Electrophysiol. 2012;23(7):687-93.

57. Nademanee K, et al. Benefits and risks of catheter ablation in elderly patients with atrial fibrillation. Heart Rhythm. 2015;12(1):44-51.

58. Bunch TJ, et al. The impact of age on 5-year outcomes after atrial fibrillation catheter ablation. J Cardiovasc Electrophysiol. 2016;27(2):141-6.

59. Metzner I, et al. Ablation of atrial fibrillation in patients $>/=75$ years: long-term clinical outcome and safety. Europace. 2016;18(4):543-9.

60. Bunch TJ, et al. Substrate and procedural predictors of outcomes after catheter ablation for atrial fibrillation in patients with hypertrophic cardiomyopathy. J Cardiovasc Electrophysiol. 2008;19(10):1009-14

61. Olivotto I, et al. Impact of atrial fibrillation on the clinical course of hypertrophic cardiomyopathy. Circulation. 2001;104(21): 2517-24.

62. Providencia $\mathrm{R}$, et al. Catheter ablation for atrial fibrillation in hypertrophic cardiomyopathy: a systematic review and meta-analysis. Heart. 2016;102(19):1533-43.

63. Leong-Sit $\mathrm{P}$, et al. Efficacy and risk of atrial fibrillation ablation before 45 years of age. Circ Arrhythm Electrophysiol. 2010;3(5): 452-7.

64. Chun KR, et al. Catheter ablation of atrial fibrillation in the young: insights from the German ablation registry. Clin Res Cardiol. 2013;102(6):459-68.

65. Koopman P, et al. Efficacy of radiofrequency catheter ablation in athletes with atrial fibrillation. Europace. 2011;13(10):1386-93.

66. Forleo GB, et al. Clinical impact of catheter ablation in patients with asymptomatic atrial fibrillation: the IRON-AF (Italian registry on NavX atrial fibrillation ablation procedures) study. Int $\mathrm{J}$ Cardiol. 2013;168(4):3968-70.

67. Wu L, et al. Comparison of radiofrequency catheter ablation between asymptomatic and symptomatic persistent atrial fibrillation: a propensity score matched analysis. J Cardiovasc Electrophysiol. 2016;27(5):531-5.

68. Mohanty S, et al. Catheter ablation of asymptomatic longstanding persistent atrial fibrillation: impact on quality of life, exercise performance, arrhythmia perception, and arrhythmia-free survival. J Cardiovasc Electrophysiol. 2014;25(10):1057-64.

69. U.S. Food and Drug Administration.Summary of Safety and Effectiveness Data: AtriCure Synergy Ablation System, PMA P100046. 2011.

70. Badhwar $\mathrm{V}$, et al. The society of thoracic surgeons mitral repair/ replacement composite score: a report of the society of thoracic surgeons quality measurement task force. Ann Thorac Surg. 2016;101(6):2265-71.

71. Abreu Filho CA, et al. Effectiveness of the maze procedure using cooled-tip radiofrequency ablation in patients with permanent atrial fibrillation and rheumatic mitral valve disease. Circulation. 2005;112(9 Suppl):I20-5.

72. Doukas G, et al. Left atrial radiofrequency ablation during mitral valve surgery for continuous atrial fibrillation: a randomized controlled trial. JAMA. 2005;294(18):2323-9.

73. Blomstrom-Lundqvist $\mathrm{C}$, et al. A randomized double-blind study of epicardial left atrial cryoablation for permanent atrial fibrillation in patients undergoing mitral valve surgery: the SWEDish multicentre atrial fibrillation study (SWEDMAF). Eur Heart J. 2007;28(23):2902-8.

74. Chevalier $\mathrm{P}$, et al. Left atrial radiofrequency ablation during mitral valve surgery: a prospective randomized multicentre study (SAFIR). Arch Cardiovasc Dis. 2009;102(11):769-75. 
75. Cheng DC, et al. Surgical ablation for atrial fibrillation in cardiac surgery: a meta-analysis and systematic review. Innovations (Phila). 2010;5(2):84-96.

76. Budera P, et al. Comparison of cardiac surgery with left atrial surgical ablation vs. cardiac surgery without atrial ablation in patients with coronary and/or valvular heart disease plus atrial fibrillation: final results of the PRAGUE-12 randomized multicentre study. Eur Heart J. 2012;33(21):2644-52.

77. Phan K, et al. Surgical ablation for treatment of atrial fibrillation in cardiac surgery: a cumulative meta-analysis of randomised controlled trials. Heart. 2014;100(9):722-30.

78. Gillinov AM, et al. Surgical ablation of atrial fibrillation during mitral-valve surgery. N Engl J Med. 2015;372(15):1399-409.

79. Rankin JS, et al. The society of thoracic surgeons risk model for operative mortality after multiple valve surgery. Ann Thorac Surg. 2013;95(4):1484-90.

80. Louagie $\mathrm{Y}$, et al. Improved patient survival with concomitant cox maze III procedure compared with heart surgery alone. Ann Thorac Surg. 2009;87(2):440-6.

81. Chiappini B, Di Bartolomeo R, Marinelli G. Radiofrequency ablation for atrial fibrillation: different approaches. Asian Cardiovasc Thorac Ann. 2004;12(3):272-7.

82. Barnett SD, Ad N. Surgical ablation as treatment for the elimination of atrial fibrillation: a meta-analysis. J Thorac Cardiovasc Surg. 2006;131(5):1029-35.

83. Edgerton JR, Jackman WM, Mack MJ. A new epicardial lesion set for minimal access left atrial maze: the Dallas lesion set. Ann Thorac Surg. 2009;88(5):1655-7.

84. Edgerton JR, et al. Totally thorascopic surgical ablation of persistent $\mathrm{AF}$ and long-standing persistent atrial fibrillation using the "Dallas" lesion set. Heart Rhythm. 2009;6(12 Suppl):S64-70.

85. Lockwood $\mathrm{D}$, et al. Linear left atrial lesions in minimally invasive surgical ablation of persistent atrial fibrillation: techniques for assessing conduction block across surgical lesions. Heart Rhythm. 2009;6(12 Suppl):S50-63.

86. Malaisrie SC, et al. Atrial fibrillation ablation in patients undergoing aortic valve replacement. J Heart Valve Dis. 2012;21(3):350 7.

87. Cherniavsky A, et al. Assessment of results of surgical treatment for persistent atrial fibrillation during coronary artery bypass grafting using implantable loop recorders. Interact Cardiovasc Thorac Surg. 2014;18(6):727-31.

88. Yoo JS, et al. Impact of concomitant surgical atrial fibrillation ablation in patients undergoing aortic valve replacement. Circ J. 2014;78(6):1364-71

89. Driessen AH, et al. Ganglion plexus ablation in advanced atrial fibrillation: the AFACT study. J Am Coll Cardiol. 2016;68(11): 1155-65.

90. Boersma LV, et al. Atrial fibrillation catheter ablation versus surgical ablation treatment (FAST): a 2-center randomized clinical trial. Circulation. 2012;125(1):23-30.

91. Henn MC, et al. Late outcomes after the Cox maze IV procedure for atrial fibrillation. J Thorac Cardiovasc Surg. 2015;150(5): 1168-76. 1178 e1-2

92. Krul SP, et al. Navigating the mini-maze: systematic review of the first results and progress of minimally-invasive surgery in the treatment of atrial fibrillation. Int J Cardiol. 2013;166(1):132-40.

93. Cox JL, et al. The surgical treatment of atrial fibrillation. III. Development of a definitive surgical procedure. J Thorac Cardiovasc Surg. 1991;101(4):569-83.

94. Rodriguez E, et al. Minimally invasive bi-atrial CryoMaze operation for atrial fibrillation. Oper Tech Thorac Cardiovasc Surg. 2009;14(3):208-23.

95. Wolf RK, et al. Video-assisted bilateral pulmonary vein isolation and left atrial appendage exclusion for atrial fibrillation. J Thorac Cardiovasc Surg. 2005;130(3):797-802.
96. Edgerton JR, et al. Minimally invasive pulmonary vein isolation and partial autonomic denervation for surgical treatment of atrial fibrillation. Ann Thorac Surg. 2008;86(1):35-8. discussion 39

97. Edgerton JR, et al. Minimally invasive surgical ablation of atrial fibrillation: six-month results. J Thorac Cardiovasc Surg. 2009;138(1):109-13. discussion 114

98. Beyer E, Lee R, Lam BK. Point: minimally invasive bipolar radiofrequency ablation of lone atrial fibrillation: early multicenter results. J Thorac Cardiovasc Surg. 2009;137(3):521-6.

99. Kearney K, et al. A systematic review of surgical ablation versus catheter ablation for atrial fibrillation. Ann Cardiothorac Surg. 2014;3(1):15-29.

100. Ad N, et al. Surgical ablation of atrial fibrillation trends and outcomes in North America. J Thorac Cardiovasc Surg. 2012;144(5): 1051-60.

101. Driessen AH, et al. Electrophysiologically guided thoracoscopic surgery for advanced atrial fibrillation: 5-year follow-up. J Am Coll Cardiol. 2017;69(13):1753-4.

102. Khargi K, et al. Surgical treatment of atrial fibrillation; a systematic review. Eur J Cardiothorac Surg. 2005;27(2):258-65.

103. Wazni OM, et al. Atrial arrhythmias after surgical maze: findings during catheter ablation. J Am Coll Cardiol. 2006;48(7):1405-9.

104. Magnano AR, et al. Mechanisms of atrial tachyarrhythmias following surgical atrial fibrillation ablation. J Cardiovasc Electrophysiol. 2006;17(4):366-73.

105. McElderry HT, et al. Proarrhythmic aspects of atrial fibrillation surgery: mechanisms of postoperative macroreentrant tachycardias. Circulation. 2008;117(2):155-62.

106. McCarthy PM, et al. Where does atrial fibrillation surgery fail? Implications for increasing effectiveness of ablation. J Thorac Cardiovasc Surg. 2010;139(4):860-7.

107. Zeng Y, et al. Recurrent atrial arrhythmia after minimally invasive pulmonary vein isolation for atrial fibrillation. Ann Thorac Surg. 2010;90(2):510-5.

108. Lee R, et al. Surgical treatment for isolated atrial fibrillation: minimally invasive vs. classic cut and sew maze. Innovations (Phila). 2011;6(6):373-7.

109. Kuck KH, et al. Impact of complete versus incomplete circumferential lines around the pulmonary veins during catheter ablation of paroxysmal atrial fibrillation: results from the gap-atrial fibrillation-German atrial fibrillation competence network 1 trial. Circ Arrhythm Electrophysiol. 2016;9(1):e003337.

110. Verma A, et al. Response of atrial fibrillation to pulmonary vein antrum isolation is directly related to resumption and delay of pulmonary vein conduction. Circulation. 2005;112(5):627-35.

111. Macle L, et al. Adenosine-guided pulmonary vein isolation for the treatment of paroxysmal atrial fibrillation: an international, multicentre, randomised superiority trial. Lancet. 2015;386(9994):672-9.

112. Cheema A, et al. Incidence and time course of early recovery of pulmonary vein conduction after catheter ablation of atrial fibrillation. J Cardiovasc Electrophysiol. 2007;18(4):387-91.

113. Rajappan $\mathrm{K}$, et al. Acute and chronic pulmonary vein reconnection after atrial fibrillation ablation: a prospective characterization of anatomical sites. Pacing Clin Electrophysiol. 2008;31(12):1598605.

114. Bansch D, et al. Circumferential pulmonary vein isolation: wait or stop early after initial successful pulmonary vein isolation? Europace. 2013;15(2):183-8.

115. Nakamura K, et al. Optimal observation time after completion of circumferential pulmonary vein isolation for atrial fibrillation to prevent chronic pulmonary vein reconnections. Int J Cardiol. 2013;168(6):5300-10.

116. Wang XH, et al. Early identification and treatment of PV re-connections: role of observation time and impact on clinical results of atrial fibrillation ablation. Europace. 2007;9(7):481-6. 
117. Sauer WH, et al. Atrioventricular nodal reentrant tachycardia in patients referred for atrial fibrillation ablation: response to ablation that incorporates slow-pathway modification. Circulation. 2006;114(3):191-5.

118. Ninomiya Y, et al. Usefulness of the adenosine triphosphate with a sufficient observation period for detecting reconduction after pulmonary vein isolation. Pacing Clin Electrophysiol. 2009;32(10): 1307-12.

119. Yamane T, et al. Repeated provocation of time- and ATP-induced early pulmonary vein reconnections after pulmonary vein isolation: eliminating paroxysmal atrial fibrillation in a single procedure. Circ Arrhythm Electrophysiol. 2011;4(5):601-8.

120. Kobori A, et al. Adenosine triphosphate-guided pulmonary vein isolation for atrial fibrillation: the UNmasking dormant electrical Reconduction by adenosine TriPhosphate (UNDER-ATP) trial. Eur Heart J. 2015;36(46):3276-87.

121. Pratola $\mathrm{C}$, et al. Radiofrequency ablation of atrial fibrillation: is the persistence of all intraprocedural targets necessary for long-term maintenance of sinus rhythm? Circulation. 2008;117(2):136-43.

122. Jiang RH, et al. Incidence of pulmonary vein conduction recovery in patients without clinical recurrence after ablation of paroxysmal atrial fibrillation: mechanistic implications. Heart Rhythm. 2014;11(6):969-76.

123. Arentz T, et al. "Dormant" pulmonary vein conduction revealed by adenosine after ostial radiofrequency catheter ablation. J Cardiovasc Electrophysiol. 2004;15(9):1041-7.

124. Tritto M, et al. Adenosine restores atrio-venous conduction after apparently successful ostial isolation of the pulmonary veins. Eur Heart J. 2004;25(23):2155-63.

125. Datino T, et al. Mechanisms by which adenosine restores conduction in dormant canine pulmonary veins. Circulation. 2010;121(8):963-72.

126. Dallaglio PD, et al. The role of adenosine in pulmonary vein isolation: a critical review. Cardiol Res Pract. 2016;2016: 8632509 .

127. Kapa S, et al. Dose-dependent pulmonary vein reconnection in response to adenosine: relevance of atrioventricular block during infusion. J Interv Card Electrophysiol. 2016;47(1):117-23.

128. Andrade JG, et al. Pulmonary vein isolation using "contact force" ablation: the effect on dormant conduction and long-term freedom from recurrent atrial fibrillation-a prospective study. Heart Rhythm. 2014;11(11):1919-24.

129. Eitel C, et al. Circumferential pulmonary vein isolation and linear left atrial ablation as a single-catheter technique to achieve bidirectional conduction block: the pace-and-ablate approach. Heart Rhythm. 2010;7(2):157-64.

130. Steven D, et al. Loss of pace capture on the ablation line: a new marker for complete radiofrequency lesions to achieve pulmonary vein isolation. Heart Rhythm. 2010;7(3):323-30.

131. Andrade JG, et al. Pulmonary vein isolation using a pace-captureguided versus an adenosine-guided approach: effect on dormant conduction and long-term freedom from recurrent atrial fibrillation-a prospective study. Circ Arrhythm Electrophysiol. 2013;6(6):1103-8

132. Steven $\mathrm{D}$, et al. Benefit of pulmonary vein isolation guided by loss of pace capture on the ablation line: results from a prospective 2center randomized trial. J Am Coll Cardiol. 2013;62(1):44-50.

133. Schaeffer B, et al. Loss of pace capture on the ablation line during pulmonary vein isolation versus "dormant conduction": is adenosine expendable? J Cardiovasc Electrophysiol. 2015;26(10): 1075-80.

134. Gerstenfeld EP, et al. Utility of exit block for identifying electrical isolation of the pulmonary veins. J Cardiovasc Electrophysiol. 2002;13(10):971-9.
135. Vijayaraman P, et al. Assessment of exit block following pulmonary vein isolation: far-field capture masquerading as entrance without exit block. Heart Rhythm. 2012;9(10):1653-9.

136. Ip JE, et al. Method for differentiating left superior pulmonary vein exit conduction from pseudo-exit conduction. Pacing Clin Electrophysiol. 2013;36(3):299-308.

137. Spector P. Principles of cardiac electric propagation and their implications for re-entrant arrhythmias. Circ Arrhythm Electrophysiol. 2013;6(3):655-61.

138. Chen S, et al. Blocking the pulmonary vein to left atrium conduction in addition to the entrance block enhances clinical efficacy in atrial fibrillation ablation. Pacing Clin Electrophysiol. 2012;35(5): 524-31.

139. Kim JY, et al. Achievement of successful pulmonary vein isolation: methods of adenosine testing and incremental benefit of exit block. J Interv Card Electrophysiol. 2016;46(3):315-24.

140. Perez FJ, et al. Long-term outcomes after catheter ablation of cavo-tricuspid isthmus dependent atrial flutter: a meta-analysis. Circ Arrhythm Electrophysiol. 2009;2(4):393-401.

141. Patel NJ, et al. Contemporary utilization and safety outcomes of catheter ablation of atrial flutter in the United States: analysis of 89,638 procedures. Heart Rhythm. 2016;13(6):1317-25.

142. Wazni O, et al. Randomized study comparing combined pulmonary vein-left atrial junction disconnection and cavotricuspid isthmus ablation versus pulmonary vein-left atrial junction disconnection alone in patients presenting with typical atrial flutter and atrial fibrillation. Circulation. 2003;108(20):2479-83.

143. Natale A, et al. Prospective randomized comparison of antiarrhythmic therapy versus first-line radiofrequency ablation in patients with atrial flutter. J Am Coll Cardiol. 2000;35(7):1898-904.

144. Pappone $\mathrm{C}$, et al. Prevention of iatrogenic atrial tachycardia after ablation of atrial fibrillation: a prospective randomized study comparing circumferential pulmonary vein ablation with a modified approach. Circulation. 2004;110(19):3036-42.

145. Sawhney N, et al. Circumferential pulmonary vein ablation with additional linear ablation results in an increased incidence of left atrial flutter compared with segmental pulmonary vein isolation as an initial approach to ablation of paroxysmal atrial fibrillation. Circ Arrhythm Electrophysiol. 2010;3(3):243-8.

146. Chae S, et al. Atrial tachycardia after circumferential pulmonary vein ablation of atrial fibrillation: mechanistic insights, results of catheter ablation, and risk factors for recurrence. J Am Coll Cardiol. 2007;50(18):1781-7.

147. Ouyang F, et al. Characterization of reentrant circuits in left atrial macroreentrant tachycardia: critical isthmus block can prevent atrial tachycardia recurrence. Circulation. 2002;105(16):1934-42.

148. Matsuo $\mathrm{S}$, et al. Peri-mitral atrial flutter in patients with atrial fibrillation ablation. Heart Rhythm. 2010;7(1):2-8.

149. Tzeis $\mathrm{S}$, et al. The modified anterior line: an alternative linear lesion in perimitral flutter. J Cardiovasc Electrophysiol. 2010;21(6):665-70.

150. Chen SA, Tai CT. Catheter ablation of atrial fibrillation originating from the non-pulmonary vein foci. J Cardiovasc Electrophysiol. 2005;16(2):229-32.

151. Haissaguerre M, et al. Spontaneous initiation of atrial fibrillation by ectopic beats originating in the pulmonary veins. N Engl J Med. 1998;339(10):659-66.

152. Lee SH, et al. Predictors of non-pulmonary vein ectopic beats initiating paroxysmal atrial fibrillation: implication for catheter ablation. J Am Coll Cardiol. 2005;46(6):1054-9.

153. Hsieh $\mathrm{MH}$, et al. Alterations of heart rate variability after radiofrequency catheter ablation of focal atrial fibrillation originating from pulmonary veins. Circulation. 1999;100(22):2237-43.

154. Shah D, et al. Nonpulmonary vein foci: do they exist? Pacing Clin Electrophysiol. 2003;26(7 Pt 2):1631-5. 
155. Lin D, et al. Provocability of atrial fibrillation triggers during pulmonary vein isolation in patients with infrequent $\mathrm{AF}$ [abstract]. Heart Rhythm. 2004;1(Suppl):S231.

156. Di Biase L, et al. Left atrial appendage: an underrecognized trigger site of atrial fibrillation. Circulation. 2010;122(2):109-18.

157. Santangeli $P$, et al. Prevalence and distribution of focal triggers in persistent and long-standing persistent atrial fibrillation. Heart Rhythm. 2016;13(2):374-82.

158. Lin WS, et al. Catheter ablation of paroxysmal atrial fibrillation initiated by non-pulmonary vein ectopy. Circulation. 2003;107(25):3176-83.

159. Lee RJ, et al. Percutaneous alternative to the maze procedure for the treatment of persistent or long-standing persistent atrial fibrillation (aMAZE trial): rationale and design. Am Heart J. 2015;170(6):1184-94.

160. Zhao Y, et al. Importance of non-pulmonary vein triggers ablation to achieve long-term freedom from paroxysmal atrial fibrillation in patients with low ejection fraction. Heart Rhythm. 2016;13(1): 141-9.

161. Dixit S, et al. Randomized ablation strategies for the treatment of persistent atrial fibrillation: RASTA study. Circ Arrhythm Electrophysiol. 2012;5(2):287-94.

162. Neuzil P, et al. Electrical reconnection after pulmonary vein isolation is contingent on contact force during initial treatment: results from the EFFICAS I study. Circ Arrhythm Electrophysiol. 2013;6(2):327-33.

163. Yokoyama K, et al. Novel contact force sensor incorporated in irrigated radiofrequency ablation catheter predicts lesion size and incidence of steam pop and thrombus. Circ Arrhythm Electrophysiol. 2008;1(5):354-62.

164. Ikeda A, et al. Relationship between catheter contact force and radiofrequency lesion size and incidence of steam pop in the beating canine heart: electrogram amplitude, impedance, and electrode temperature are poor predictors of electrode-tissue contact force and lesion size. Circ Arrhythm Electrophysiol. 2014;7(6):1174 80.

165. Nakagawa $\mathrm{H}$, et al. Locations of high contact force during left atrial mapping in atrial fibrillation patients: electrogram amplitude and impedance are poor predictors of electrode-tissue contact force for ablation of atrial fibrillation. Circ Arrhythm Electrophysiol. 2013;6(4):746-53.

166. Nakagawa $\mathrm{H}$, et al. Prospective study to test the ability to create $\mathrm{RF}$ lesions at predicted depth and diameter using a new formula incorporating contact force, radiofrequency power and application time (force-power-time index) in the beating heart [abstract]. Heart Rhythm. 2014;11(Suppl):S548.

167. Kumar S, et al. Predictive value of impedance changes for realtime contact force measurements during catheter ablation of atrial arrhythmias in humans. Heart Rhythm. 2013;10(7):962-9.

168. Kumar S, et al. Prospective characterization of catheter-tissue contact force at different anatomic sites during antral pulmonary vein isolation. Circ Arrhythm Electrophysiol. 2012;5(6):1124-9.

169. Reddy VY, et al. The relationship between contact force and clinical outcome during radiofrequency catheter ablation of atrial fibrillation in the TOCCATA study. Heart Rhythm. 2012;9(11): 1789-95.

170. Haldar $\mathrm{S}$, et al. Contact force sensing technology identifies sites of inadequate contact and reduces acute pulmonary vein reconnection: a prospective case control study. Int J Cardiol. 2013;168(2): 1160-6.

171. Perna F, et al. Assessment of catheter tip contact force resulting in cardiac perforation in swine atria using force sensing technology. Circ Arrhythm Electrophysiol. 2011;4(2):218-24.

172. Kimura M, et al. Comparison of lesion formation between contact force-guided and non-guided circumferential pulmonary vein isolation: a prospective, randomized study. Heart Rhythm. 2014;11(6):984-91.

173. Sohns C, et al. Quantitative magnetic resonance imaging analysis of the relationship between contact force and left atrial scar formation after catheter ablation of atrial fibrillation. J Cardiovasc Electrophysiol. 2014;25(2):138-45.

174. Martinek M, et al. Clinical impact of an open-irrigated radiofrequency catheter with direct force measurement on atrial fibrillation ablation. Pacing Clin Electrophysiol. 2012;35(11):1312-8.

175. Marijon E, et al. Real-time contact force sensing for pulmonary vein isolation in the setting of paroxysmal atrial fibrillation: procedural and 1-year results. J Cardiovasc Electrophysiol. 2014;25(2):130-7.

176. Sigmund E, et al. Optimizing radiofrequency ablation of paroxysmal and persistent atrial fibrillation by direct catheter force measurement-a case-matched comparison in 198 patients. Pacing Clin Electrophysiol. 2015;38(2):201-8.

177. Ullah W, et al. Randomized trial comparing pulmonary vein isolation using the SmartTouch catheter with or without real-time contact force data. Heart Rhythm. 2016;13(9):1761-7.

178. Wakili R, et al. Impact of real-time contact force and impedance measurement in pulmonary vein isolation procedures for treatment of atrial fibrillation. Clin Res Cardiol. 2014;103(2):97-106.

179. Kumagai $\mathrm{K}$, et al. A new approach for complete isolation of the posterior left atrium including pulmonary veins for atrial fibrillation. J Cardiovasc Electrophysiol. 2007;18(10):1047-52.

180. Yamaguchi Y, et al. Long-term effects of box isolation on sympathovagal balance in atrial fibrillation. Circ J. 2010;74(6):1096103.

181. Kumagai K. Catheter ablation of atrial fibrillation. State of the Art Circ J. 2011;75(10):2305-11.

182. Kim JS, et al. Does isolation of the left atrial posterior wall improve clinical outcomes after radiofrequency catheter ablation for persistent atrial fibrillation? A prospective randomized clinical trial. Int J Cardiol. 2015;181:277-83.

183. He X, et al. Left atrial posterior wall isolation reduces the recurrence of atrial fibrillation: a meta-analysis. J Interv Card Electrophysiol. 2016;46(3):267-74.

184. Di Biase L, et al. Left atrial appendage isolation in patients with long-standing persistent AF undergoing catheter ablation: BELIEF trial. J Am Coll Cardiol. 2016;68(18):1929-40.

185. Di Biase L, et al. Ablation versus amiodarone for treatment of persistent atrial fibrillation in patients with congestive heart failure and an implanted device: results from the AATAC multicenter randomized trial. Circulation. 2016;133(17):1637-44.

186. Morillo CA, et al. Chronic rapid atrial pacing. Structural, functional, and electrophysiological characteristics of a new model of sustained atrial fibrillation. Circulation. 1995;91(5):1588-95.

187. Harada A, et al. Atrial activation during chronic atrial fibrillation in patients with isolated mitral valve disease. Ann Thorac Surg. 1996;61(1):104-11. discussion 111-112

188. Gray RA, Pertsov AM, Jalife J. Spatial and temporal organization during cardiac fibrillation. Nature. 1998;392(6671):75-8.

189. Berenfeld O, et al. Spatially distributed dominant excitation frequencies reveal hidden organization in atrial fibrillation in the Langendorff-perfused sheep heart. J Cardiovasc Electrophysiol. 2000;11(8):869-79.

190. Mansour M, et al. Left-to-right gradient of atrial frequencies during acute atrial fibrillation in the isolated sheep heart. Circulation. 2001;103(21):2631-6.

191. Lazar S, et al. Presence of left-to-right atrial frequency gradient in paroxysmal but not persistent atrial fibrillation in humans. Circulation. 2004;110(20):3181-6.

192. Atienza F, et al. Real-time dominant frequency mapping and ablation of dominant frequency sites in atrial fibrillation with left-to- 
right frequency gradients predicts long-term maintenance of sinus rhythm. Heart Rhythm. 2009;6(1):33-40.

193. Atienza F, et al. Comparison of radiofrequency catheter ablation of drivers and circumferential pulmonary vein isolation in atrial fibrillation: a noninferiority randomized multicenter RADAR-AF trial. J Am Coll Cardiol. 2014;64(23):2455-67.

194. Vogler J, et al. Pulmonary vein isolation versus defragmentation: the CHASE-AF clinical trial. J Am Coll Cardiol. 2015;66(24): 2743-52.

195. Haissaguerre M, et al. Catheter ablation of long-lasting persistent atrial fibrillation: clinical outcome and mechanisms of subsequent arrhythmias. J Cardiovasc Electrophysiol. 2005;16(11):1138-47.

196. Nademanee K, et al. A new approach for catheter ablation of atrial fibrillation: mapping of the electrophysiologic substrate. J Am Coll Cardiol. 2004;43(11):2044-53.

197. O'Neill MD, et al. Long-term follow-up of persistent atrial fibrillation ablation using termination as a procedural endpoint. Eur Heart J. 2009;30(9):1105-12.

198. Lo LW, et al. Predicting factors for atrial fibrillation acute termination during catheter ablation procedures: implications for catheter ablation strategy and long-term outcome. Heart Rhythm. 2009;6(3):311-8.

199. Zhang Z, et al. Linear ablation following pulmonary vein isolation in patients with atrial fibrillation: a meta-analysis. Pacing Clin Electrophysiol. 2016;39(6):623-30.

200. Kim TH, et al. Linear ablation in addition to circumferential pulmonary vein isolation (Dallas lesion set) does not improve clinical outcome in patients with paroxysmal atrial fibrillation: a prospective randomized study. Europace. 2015;17(3):388-95.

201. Wynn GJ, et al. Biatrial linear ablation in sustained nonpermanent AF: results of the substrate modification with ablation and antiarrhythmic drugs in nonpermanent atrial fibrillation (SMAN-PAF) trial. Heart Rhythm. 2016;13(2):399-406.

202. Kottkamp H, et al. Box isolation of fibrotic areas (BIFA): a patient-tailored substrate modification approach for ablation of atrial fibrillation. J Cardiovasc Electrophysiol. 2016;27(1):22-30.

203. Kottkamp H, Bender R, Berg J. Catheter ablation of atrial fibrillation: how to modify the substrate? J Am Coll Cardiol. 2015;65(2): 196-206.

204. Rolf S, et al. Tailored atrial substrate modification based on lowvoltage areas in catheter ablation of atrial fibrillation. Circ Arrhythm Electrophysiol. 2014;7(5):825-33.

205. Bai R, et al. Proven isolation of the pulmonary vein antrum with or without left atrial posterior wall isolation in patients with persistent atrial fibrillation. Heart Rhythm. 2016;13(1):132-40.

206. Cutler MJ, et al. Impact of voltage mapping to guide whether to perform ablation of the posterior wall in patients with persistent atrial fibrillation. J Cardiovasc Electrophysiol. 2016;27(1):13-21.

207. Yang G, et al. Catheter ablation of nonparoxysmal atrial fibrillation using electrophysiologically guided substrate modification during sinus rhythm after pulmonary vein isolation. Circ Arrhythm Electrophysiol. 2016;9(2):e003382.

208. Verma A, et al. Pre-existent left atrial scarring in patients undergoing pulmonary vein antrum isolation: an independent predictor of procedural failure. J Am Coll Cardiol. 2005;45(2):285-92.

209. Kapa S, et al. Contact electroanatomic mapping derived voltage criteria for characterizing left atrial scar in patients undergoing ablation for atrial fibrillation. J Cardiovasc Electrophysiol. 2014;25(10):1044-52.

210. Oakes RS, et al. Detection and quantification of left atrial structural remodeling with delayed-enhancement magnetic resonance imaging in patients with atrial fibrillation. Circulation. 2009;119(13):1758-67.

211. McGann C, et al. Atrial fibrillation ablation outcome is predicted by left atrial remodeling on MRI. Circ Arrhythm Electrophysiol. 2014;7(1):23-30.
212. Dagres N, et al. Current ablation techniques for persistent atrial fibrillation: results of the European heart rhythm association survey. Europace. 2015;17(10):1596-600.

213. Nademanee K, et al. Clinical outcomes of catheter substrate ablation for high-risk patients with atrial fibrillation. J Am Coll Cardiol. 2008;51(8):843-9.

214. Haissaguerre $\mathrm{M}$, et al. Localized sources maintaining atrial fibrillation organized by prior ablation. Circulation. 2006;113(5):61625.

215. Haissaguerre $\mathrm{M}$, et al. Catheter ablation of long-lasting persistent atrial fibrillation: critical structures for termination. J Cardiovasc Electrophysiol. 2005;16(11):1125-37.

216. Takahashi Y, et al. Characterization of electrograms associated with termination of chronic atrial fibrillation by catheter ablation. J Am Coll Cardiol. 2008;51(10):1003-10.

217. Singh SM, et al. Intraprocedural use of ibutilide to organize and guide ablation of complex fractionated atrial electrograms: preliminary assessment of a modified step-wise approach to ablation of persistent atrial fibrillation. J Cardiovasc Electrophysiol. 2010;21(6):608-16.

218. Narayan SM, et al. Classifying fractionated electrograms in human atrial fibrillation using monophasic action potentials and activation mapping: evidence for localized drivers, rate acceleration, and nonlocal signal etiologies. Heart Rhythm. 2011;8(2):244-53.

219. Verma A, et al. Selective CFAE targeting for atrial fibrillation study (SELECT AF): clinical rationale, design, and implementation. J Cardiovasc Electrophysiol. 2011;22(5):541-7.

220. Quintanilla JG, et al. Mechanistic approaches to detect, target, and ablate the drivers of atrial fibrillation. Circ Arrhythm Electrophysiol. 2016;9(1):e002481.

221. Hansen BJ, et al. Atrial fibrillation driven by micro-anatomic intramural re-entry revealed by simultaneous sub-epicardial and sub-endocardial optical mapping in explanted human hearts. Eur Heart J. 2015;36(35):2390-401.

222. Cuculich PS, et al. Noninvasive characterization of epicardial activation in humans with diverse atrial fibrillation patterns. Circulation. 2010;122(S):1364-72.

223. Haissaguerre M, et al. Driver domains in persistent atrial fibrillation. Circulation. 2014;130(7):530-8.

224. Narayan SM, et al. Ablation of rotor and focal sources reduces late recurrence of atrial fibrillation compared with trigger ablation alone: extended follow-up of the CONFIRM trial (conventional ablation for atrial fibrillation with or without focal impulse and rotor modulation). J Am Coll Cardiol. 2014;63(17):1761-8.

225. Lin YJ, et al. Prevalence, characteristics, mapping, and catheter ablation of potential rotors in nonparoxysmal atrial fibrillation. Circ Arrhythm Electrophysiol. 2013;6(5):851-8.

226. Lin Y-J, et al. Benefits of atrial substrate modification guided by electrogram similarity and phase mapping techniques to eliminate rotors and focal sources versus conventional defragmentation in persistent atrial fibrillation. JACC: Clinical Electrophysiology. 2016;2(6):667-78.

227. Miller JM, et al. Initial independent outcomes from focal impulse and rotor modulation ablation for atrial fibrillation: multicenter FIRM registry. J Cardiovasc Electrophysiol. 2014;25(9):921-9.

228. Lin YJ, et al. Electrophysiological characteristics and catheter ablation in patients with paroxysmal right atrial fibrillation. Circulation. 2005;112(12):1692-700.

229. Narayan SM, et al. Treatment of atrial fibrillation by the ablation of localized sources: CONFIRM (conventional ablation for atrial fibrillation with or without focal impulse and rotor modulation) trial. J Am Coll Cardiol. 2012;60(7):628-36.

230. Rappel WJ, Narayan SM. Theoretical considerations for mapping activation in human cardiac fibrillation. Chaos. 2013;23(2): 023113. 
231. Gianni C, et al. Acute and early outcomes of focal impulse and rotor modulation (FIRM)-guided rotors-only ablation in patients with nonparoxysmal atrial fibrillation. Heart Rhythm. 2016;13(4): $830-5$.

232. Narayan SM, Zaman JA. Mechanistically based mapping of human cardiac fibrillation. J Physiol. 2016;594(9):2399-415.

233. Sommer P, et al. Successful repeat catheter ablation of recurrent long-standing persistent atrial fibrillation with rotor elimination as the procedural endpoint: a case series. J Cardiovasc Electrophysiol. 2016;27(3):274-80.

234. Buch E, et al. Long-term clinical outcomes of focal impulse and rotor modulation for treatment of atrial fibrillation: a multicenter experience. Heart Rhythm. 2016;13(3):636-41.

235. Benharash P, et al. Quantitative analysis of localized sources identified by focal impulse and rotor modulation mapping in atrial fibrillation. Circ Arrhythm Electrophysiol. 2015;8(3):554-61.

236. Ramanathan $\mathrm{C}$, et al. Noninvasive electrocardiographic imaging for cardiac electrophysiology and arrhythmia. Nat Med. 2004;10(4):422-8.

237. Lim HS, et al. Noninvasive mapping to guide atrial fibrillation ablation. Card Electrophysiol Clin. 2015;7(1):89-98.

238. Yamashita $\mathrm{S}$, et al. Body surface mapping to guide atrial fibrillation ablation. Arrhythmia Electrophysiol Rev. 2015;4(3):172-6.

239. Guillem MS, et al. Noninvasive mapping of human atrial fibrillation. J Cardiovasc Electrophysiol. 2009;20(5):507-13.

240. Guillem MS, et al. Noninvasive localization of maximal frequency sites of atrial fibrillation by body surface potential mapping. Circ Arrhythm Electrophysiol. 2013;6(2):294-301.

241. Rodrigo M, et al. Body surface localization of left and right atrial high-frequency rotors in atrial fibrillation patients: a clinicalcomputational study. Heart Rhythm. 2014;11(9):1584-91.

242. Armour JA, et al. Gross and microscopic anatomy of the human intrinsic cardiac nervous system. Anat Rec. 1997;247(2):289-98.

243. Po SS, Nakagawa H, Jackman WM. Localization of left atrial ganglionated plexi in patients with atrial fibrillation. J Cardiovasc Electrophysiol. 2009;20(10):1186-9.

244. Patterson E, et al. Triggered firing in pulmonary veins initiated by in vitro autonomic nerve stimulation. Heart Rhythm. 2005;2(6): 624-31.

245. Choi EK, et al. Intrinsic cardiac nerve activity and paroxysmal atrial tachyarrhythmia in ambulatory dogs. Circulation. 2010;121(24):2615-23.

246. Katritsis DG, et al. Autonomic denervation added to pulmonary vein isolation for paroxysmal atrial fibrillation: a randomized clinical trial. J Am Coll Cardiol. 2013;62(24):2318-25.

247. Nakagawa H, et al. Pathophysiologic basis of autonomic ganglionated plexus ablation in patients with atrial fibrillation. Heart Rhythm. 2009;6(12 Suppl):S26-34.

248. Bettoni M, Zimmermann M. Autonomic tone variations before the onset of paroxysmal atrial fibrillation. Circulation. 2002;105(23): 2753-9.

249. Pauza DH, et al. Morphology, distribution, and variability of the epicardiac neural ganglionated subplexuses in the human heart. Anat Rec. 2000;259(4):353-82.

250. Scherlag BJ, et al. Electrical stimulation to identify neural elements on the heart: their role in atrial fibrillation. J Interv Card Electrophysiol. 2005;13(Suppl 1):37-42.

251. Patterson E, et al. Sodium-calcium exchange initiated by the $\mathrm{Ca} 2+$ transient: an arrhythmia trigger within pulmonary veins. J Am Coll Cardiol. 2006;47(6):1196-206.

252. Lemola K, et al. Pulmonary vein region ablation in experimental vagal atrial fibrillation: role of pulmonary veins versus autonomic ganglia. Circulation. 2008;117(4):470-7.

253. Nishida $\mathrm{K}$, et al. The role of pulmonary veins vs. autonomic ganglia in different experimental substrates of canine atrial fibrillation. Cardiovasc Res. 2011;89(4):825-33.
254. Nishida K, et al. Atrial fibrillation ablation: translating basic mechanistic insights to the patient. J Am Coll Cardiol. 2014;64:823-31.

255. Stavrakis $\mathrm{S}$, et al. The role of the autonomic ganglia in atrial fibrillation. JACC Clin Electrophysiol. 2015;1(1-2):1-13.

256. Pokushalov E, et al. Left atrial ablation at the anatomic areas of ganglionated plexi for paroxysmal atrial fibrillation. Pacing Clin Electrophysiol. 2010;33(10):1231-8.

257. Pokushalov E, et al. Ganglionated plexi ablation for long-standing persistent atrial fibrillation. Europace. 2010;12(3):342-6.

258. Pokushalov E, et al. Catheter versus surgical ablation of atrial fibrillation after a failed initial pulmonary vein isolation procedure: a randomized controlled trial. J Cardiovasc Electrophysiol. 2013;24(12):1338-43.

259. Pokushalov E, et al. Ganglionated plexus ablation vs linear ablation in patients undergoing pulmonary vein isolation for persistent/ long-standing persistent atrial fibrillation: a randomized comparison. Heart Rhythm. 2013;10(9):1280-6.

260. Lloyd-Jones DM, et al. Lifetime risk for development of atrial fibrillation: the Framingham heart study. Circulation. 2004;110(9):1042-6.

261. Mahajan R, et al. Electrophysiological, electroanatomical, and structural remodeling of the atria as consequences of sustained obesity. J Am Coll Cardiol. 2015;66(1):1-11.

262. Wokhlu A, et al. Long-term outcome of atrial fibrillation ablation: impact and predictors of very late recurrence. J Cardiovasc Electrophysiol. 2010;21(10):1071-8.

263. Dublin S, et al. Risk of new-onset atrial fibrillation in relation to body mass index. Arch Intern Med. 2006;166(21):2322-8.

264. Gami AS, et al. Obstructive sleep apnea, obesity, and the risk of incident atrial fibrillation. J Am Coll Cardiol. 2007;49(5):565-71.

265. Tedrow UB, et al. The long- and short-term impact of elevated body mass index on the risk of new atrial fibrillation the WHS (Women's health study). J Am Coll Cardiol. 2010;55(21):2319 27.

266. Huxley RR, et al. Absolute and attributable risks of atrial fibrillation in relation to optimal and borderline risk factors: the atherosclerosis risk in communities (ARIC) study. Circulation. 2011;123(14):1501-8.

267. Munger TM, et al. Electrophysiological and hemodynamic characteristics associated with obesity in patients with atrial fibrillation. J Am Coll Cardiol. 2012;60(9):851-60.

268. Abed HS, et al. Obesity results in progressive atrial structural and electrical remodeling: implications for atrial fibrillation. Heart Rhythm. 2013;10(1):90-100.

269. Richter B, et al. Is inducibility of atrial fibrillation after radio frequency ablation really a relevant prognostic factor? Eur Heart J. 2006;27(21):2553-9.

270. Jongnarangsin $\mathrm{K}$, et al. Body mass index, obstructive sleep apnea, and outcomes of catheter ablation of atrial fibrillation. J Cardiovasc Electrophysiol. 2008;19(7):668-72.

271. Shah AN, et al. Long-term outcome following successful pulmonary vein isolation: pattern and prediction of very late recurrence. $\mathrm{J}$ Cardiovasc Electrophysiol. 2008;19(7):661-7.

272. Chang SL, et al. Comparison of outcome in catheter ablation of atrial fibrillation in patients with versus without the metabolic syndrome. Am J Cardiol. 2009;103(1):67-72.

273. Letsas KP, et al. Pre-ablative predictors of atrial fibrillation recurrence following pulmonary vein isolation: the potential role of inflammation. Europace. 2009;11(2):158-63.

274. Tang RB, et al. Metabolic syndrome and risk of recurrence of atrial fibrillation after catheter ablation. Circ J. 2009;73(3):438-43.

275. Jin Hwang $\mathrm{H}$, et al. Atrial electroanatomical remodeling as a determinant of different outcomes between two current ablation strategies: circumferential pulmonary vein isolation vs pulmonary vein isolation. Clin Cardiol. 2010;33(3):E69-74. 
276. Patel D, et al. Outcomes and complications of catheter ablation for atrial fibrillation in females. Heart Rhythm. 2010;7(2):167-72.

277. Patel D, et al. Safety and efficacy of pulmonary vein antral isolation in patients with obstructive sleep apnea: the impact of continuous positive airway pressure. Circ Arrhythm Electrophysiol. 2010;3(5):445-51.

278. Patel D, et al. The impact of statins and renin-angiotensinaldosterone system blockers on pulmonary vein antrum isolation outcomes in post-menopausal females. Europace. 2010;12(3): 322-30.

279. Chao TF, et al. Associations between renal function, atrial substrate properties and outcome of catheter ablation in patients with paroxysmal atrial fibrillation. Circ J. 2011;75(10):2326-32.

280. Winkle RA, et al. Relation of early termination of persistent atrial fibrillation by cardioversion or drugs to ablation outcomes. Am J Cardiol. 2011;108(3):374-9.

281. Wong CX, et al. Pericardial fat is associated with atrial fibrillation severity and ablation outcome. J Am Coll Cardiol. 2011;57(17): 1745-51.

282. Kang JH, et al. Prediction of long-term outcomes of catheter ablation of persistent atrial fibrillation by parameters of preablation DC cardioversion. J Cardiovasc Electrophysiol. 2012;23(11): 1165-70.

283. Mohanty S, et al. Impact of metabolic syndrome on procedural outcomes in patients with atrial fibrillation undergoing catheter ablation. J Am Coll Cardiol. 2012;59(14):1295-301.

284. Ejima K, et al. Impact of diastolic dysfunction on the outcome of catheter ablation in patients with atrial fibrillation. Int J Cardiol. 2013;164(1):88-93.

285. Letsas KP, et al. The impact of body mass index on the efficacy and safety of catheter ablation of atrial fibrillation. Int $\mathrm{J}$ Cardiol. 2013;164(1):94-8.

286. Wong CX, et al. Obesity and the risk of incident, post-operative, and post-ablation atrial fibrillation: a meta-analysis of 626,603 individuals in 51 studies. JACC: Clinical Electrophysiology. 2015;1(3):139-52.

287. Alonso A, et al. Effect of an intensive lifestyle intervention on atrial fibrillation risk in individuals with type 2 diabetes: the Look AHEAD randomized trial. Am Heart J. 2015;170(4):770 777.e5.

288. Pathak RK, et al. Aggressive risk factor reduction study for atrial fibrillation and implications for the outcome of ablation: the ARREST-AF cohort study. J Am Coll Cardiol. 2014;64(21): 2222-31.

289. Bitter T, et al. Sleep-disordered breathing and cardiac arrhythmias. Can J Cardiol. 2015;31(7):928-34.

290. Fletcher EC. Effect of episodic hypoxia on sympathetic activity and blood pressure. Respir Physiol. 2000;119(2-3):189-97.

291. Kraiczi H, et al. Increased vasoconstrictor sensitivity in obstructive sleep apnea. J Appl Physiol. 1985;89(2):493-8.

292. Ghias M, et al. The role of ganglionated plexi in apnea-related atrial fibrillation. J Am Coll Cardiol. 2009;54(22):2075-83.

293. Linz D, et al. Negative tracheal pressure during obstructive respiratory events promotes atrial fibrillation by vagal activation. Heart Rhythm. 2011;8(9):1436-43.

294. Linz D, et al. Renal sympathetic denervation suppresses postapneic blood pressure rises and atrial fibrillation in a model for sleep apnea. Hypertension. 2012;60(1):172-8.

295. Linz D, et al. Effect of renal denervation on neurohumoral activation triggering atrial fibrillation in obstructive sleep apnea. Hypertension. 2013;62(4):767-74.

296. Iwasaki YK, et al. Determinants of atrial fibrillation in an animal model of obesity and acute obstructive sleep apnea. Heart Rhythm. 2012;9(9):1409-1416.e1.
297. Iwasaki YK, et al. Atrial fibrillation promotion with long-term repetitive obstructive sleep apnea in a rat model. J Am Coll Cardiol. 2014;64(19):2013-23.

298. Dimitri H, et al. Atrial remodeling in obstructive sleep apnea: implications for atrial fibrillation. Heart Rhythm. 2012;9(3):3217.

299. Stevenson IH, et al. Atrial electrophysiology is altered by acute hypercapnia but not hypoxemia: implications for promotion of atrial fibrillation in pulmonary disease and sleep apnea. Heart Rhythm. 2010;7(9):1263-70.

300. Holmqvist F, et al. Impact of obstructive sleep apnea and continuous positive airway pressure therapy on outcomes in patients with atrial fibrillation-results from the Outcomes Registry for Better Informed Treatment of Atrial Fibrillation (ORBIT-AF). Am Heart J. 2015;169(5):647-654.e2.

301. Kwon Y, et al. Association of sleep characteristics with atrial fibrillation: the multi-ethnic study of atherosclerosis. Thorax. 2015;70(9):873-9.

302. Kanagala R, et al. Obstructive sleep apnea and the recurrence of atrial fibrillation. Circulation. 2003;107(20):2589-94.

303. Fein AS, et al. Treatment of obstructive sleep apnea reduces the risk of atrial fibrillation recurrence after catheter ablation. J Am Coll Cardiol. 2013;62(4):300-5.

304. Matiello M, et al. Low efficacy of atrial fibrillation ablation in severe obstructive sleep apnoea patients. Europace. 2010;12(8): 1084-9.

305. Naruse Y, et al. Concomitant obstructive sleep apnea increases the recurrence of atrial fibrillation following radiofrequency catheter ablation of atrial fibrillation: clinical impact of continuous positive airway pressure therapy. Heart Rhythm. 2013;10(3):331-7.

306. Neilan TG, et al. Effect of sleep apnea and continuous positive airway pressure on cardiac structure and recurrence of atrial fibrillation. J Am Heart Assoc. 2013;2(6):e000421.

307. Li L, et al. Efficacy of catheter ablation of atrial fibrillation in patients with obstructive sleep apnoea with and without continuous positive airway pressure treatment: a meta-analysis of observational studies. Europace. 2014;16(9):1309-14.

308. Raitt MH, et al. Reversal of electrical remodeling after cardioversion of persistent atrial fibrillation. J Cardiovasc Electrophysiol. 2004;15(5):507-12.

309. Chalfoun N, et al. Reverse electrical remodeling of the atria post cardioversion in patients who remain in sinus rhythm assessed by signal averaging of the P-wave. Pacing Clin Electrophysiol. 2007;30(4):502-9.

310. Igarashi M, et al. Effect of restoration of sinus rhythm by extensive antiarrhythmic drugs in predicting results of catheter ablation of persistent atrial fibrillation. Am J Cardiol. 2010;106(1):62-8.

311. Rivard L, et al. Improved outcome following restoration of sinus rhythm prior to catheter ablation of persistent atrial fibrillation: a comparative multicenter study. Heart Rhythm. 2012;9(7):102530 .

312. Mohanty S, et al. Effect of periprocedural amiodarone on procedure outcome in patients with long-standing persistent atrial fibrillation undergoing extended pulmonary vein antrum isolation: results from a randomized study (SPECULATE). Heart Rhythm. 2015;12(3):477-83.

313. Robbins IM, et al. Pulmonary vein stenosis after catheter ablation of atrial fibrillation. Circulation. 1998;98(17):1769-75.

314. Ernst S, et al. Total pulmonary vein occlusion as a consequence of catheter ablation for atrial fibrillation mimicking primary lung disease. J Cardiovasc Electrophysiol. 2003;14(4):366-70.

315. Mansour M, et al. Assessment of pulmonary vein anatomic variability by magnetic resonance imaging: implications for catheter ablation techniques for atrial fibrillation. J Cardiovasc Electrophysiol. 2004;15(4):387-93. 
316. Holmes DR Jr, Monahan KH, Packer D. Pulmonary vein stenosis complicating ablation for atrial fibrillation: clinical spectrum and interventional considerations. JACC Cardiovasc Interv. 2009;2(4): 267-76.

317. Fender EA, Packer DL, Holmes Jr. DR. Pulmonary vein stenosis after atrial fibrillation ablation. EuroIntervention. 2016;12(Suppl $\mathrm{X)}: \mathrm{X} 31-4$.

318. Di Biase L, et al. Pulmonary vein total occlusion following catheter ablation for atrial fibrillation: clinical implications after longterm follow-up. J Am Coll Cardiol. 2006;48(12):2493-9.

319. Prieto LR, et al. Comparison of stent versus balloon angioplasty for pulmonary vein stenosis complicating pulmonary vein isolation. J Cardiovasc Electrophysiol. 2008;19(7):673-8.

320. Packer DL, et al. Clinical presentation, investigation, and management of pulmonary vein stenosis complicating ablation for atrial fibrillation. Circulation. 2005;111(5):546-54.

321. Taylor GW, et al. Pathological effects of extensive radiofrequency energy applications in the pulmonary veins in dogs. Circulation. 2000;101(14):1736-42.

322. Arentz $\mathrm{T}$, et al. Incidence of pulmonary vein stenosis 2 years after radiofrequency catheter ablation of refractory atrial fibrillation. Eur Heart J. 2003;24(10):963-9.

323. Tse HF, et al. Pulmonary vein isolation using transvenous catheter cryoablation for treatment of atrial fibrillation without risk of pulmonary vein stenosis. J Am Coll Cardiol. 2003;42(4):752-8.

324. Kasper L, et al. Hemoptysis and lung disease as a manifestation of pulmonary vein stenosis after cryoballoon catheter ablation for atrial fibrillation. Pol Arch Med Wewn. 2016;126(1-2):94-6.

325. Dong J, et al. Incidence and predictors of pulmonary vein stenosis following catheter ablation of atrial fibrillation using the anatomic pulmonary vein ablation approach: results from paired magnetic resonance imaging. J Cardiovasc Electrophysiol. 2005;16(8):84552.

326. Hoyt RH, et al. Transvenous catheter cryoablation for treatment of atrial fibrillation: results of a feasibility study. Pacing Clin Electrophysiol. 2005;28(Suppl 1):S78-82.

327. Saad EB, et al. Pulmonary vein stenosis after catheter ablation of atrial fibrillation: emergence of a new clinical syndrome. Ann Intern Med. 2003;138(8):634-8.

328. Hilbert S, et al. Pulmonary vein collateral formation as a long-term result of post-interventional pulmonary vein stenosis. Eur Heart J. 2016;37(31):2474

329. Hilbert S, Sommer P, Bollmann A. Pulmonary vein dilatation in a case of total pulmonary vein occlusion: contemporary approach using a combination of 3D-mapping system and image integration. Catheter Cardiovasc Interv. 2016;88(7):E227-32.

330. Fender EA, et al. Severe pulmonary vein stenosis resulting from ablation for atrial fibrillation: presentation, management, and clinical outcomes. Circulation. 2016;134(23):1812-21.

331. De Potter TJ, et al. Drug-eluting stents for the treatment of pulmonary vein stenosis after atrial fibrillation ablation. Europace. 2011;13(1):57-61.

332. Kanter KR, Kirshbom PM, Kogon BE. Surgical repair of pulmonary venous stenosis: a word of caution. Ann Thorac Surg. 2014;98(5):1687-91. discussion 1691-1692

333. Patel NS, et al. Successful surgical repair of iatrogenic pulmonary vein stenosis. J Cardiovasc Electrophysiol. 2012;23(6):656-8.

334. Bharat A, et al. Lung transplant is a viable treatment option for patients with congenital and acquired pulmonary vein stenosis. J Heart Lung Transplant. 2013;32(6):621-5.

335. Ponamgi SP, et al. Catheter-based intervention for pulmonary vein stenosis due to fibrosing mediastinitis: the Mayo Clinic experience. Int J Cardiol Heart Vasc. 2015;8:103-7.

336. Mohanty $\mathrm{S}$, et al. Impact of alcohol intake on thromboembolic events following catheter ablation for atrial fibrillation. J Am Coll Cardiol. 2014;63(12_S).
337. Di Biase L, et al. Esophageal capsule endoscopy after radiofrequency catheter ablation for atrial fibrillation: documented higher risk of luminal esophageal damage with general anesthesia as compared with conscious sedation. Circ Arrhythm Electrophysiol. 2009;2(2):108-12.

338. Cappato R, et al. Worldwide survey on the methods, efficacy, and safety of catheter ablation for human atrial fibrillation. Circulation. 2005;111(9):1100-5.

339. Pappone $\mathrm{C}$, et al. Atrio-esophageal fistula as a complication of percutaneous transcatheter ablation of atrial fibrillation. Circulation. 2004;109(22):2724-6.

340. Martinek M, et al. Identification of a high-risk population for esophageal injury during radiofrequency catheter ablation of atrial fibrillation: procedural and anatomical considerations. Heart Rhythm. 2010;7(9):1224-30.

341. Singh SM, et al. Clinical outcomes after repair of left atrial esophageal fistulas occurring after atrial fibrillation ablation procedures. Heart Rhythm. 2013;10(11):1591-7.

342. Bunch TJ, et al. Temporary esophageal stenting allows healing of esophageal perforations following atrial fibrillation ablation procedures. J Cardiovasc Electrophysiol. 2006;17(4):435-9.

343. Cappato R, et al. Prevalence and causes of fatal outcome in catheter ablation of atrial fibrillation. J Am Coll Cardiol. 2009;53(19): 1798-803.

344. Tan C, Coffey A. Atrioesophageal fistula after surgical unipolar radiofrequency atrial ablation for atrial fibrillation. Ann Thorac Surg. 2013;95(3):e61-2.

345. Mohanty S. Outcomes of atrio-esophageal fistula following catheter ablation of atrial fibrillation treated with surgical repair versus esophageal stenting. J Cardiovasc Electrophysiol. 2014;25(9):E6.

346. Mohanty S, et al. Outcomes of atrioesophageal fistula following catheter ablation of atrial fibrillation treated with surgical repair versus esophageal stenting. J Cardiovasc Electrophysiol. 2014;25(6):579-84.

347. Cappato R, et al. Updated worldwide survey on the methods, efficacy, and safety of catheter ablation for human atrial fibrillation. Circ Arrhythm Electrophysiol. 2010;3(1):32-8.

348. Gillinov AM, Pettersson G, Rice TW. Esophageal injury during radiofrequency ablation for atrial fibrillation. J Thorac Cardiovasc Surg. 2001;122(6):1239-40.

349. Mohr FW, et al. Curative treatment of atrial fibrillation with intraoperative radiofrequency ablation: short-term and midterm results. J Thorac Cardiovasc Surg. 2002;123(5):919-27.

350. Doll N, et al. Esophageal perforation during left atrial radiofrequency ablation: is the risk too high? J Thorac Cardiovasc Surg. 2003;125(4):836-42.

351. Sonmez B, et al. A fatal complication due to radiofrequency ablation for atrial fibrillation: atrio-esophageal fistula. Ann Thorac Surg. 2003;76(1):281-3.

352. Scanavacca MI, et al. Left atrial-esophageal fistula following radiofrequency catheter ablation of atrial fibrillation. J Cardiovasc Electrophysiol. 2004;15(8):960-2.

353. Borchert B, et al. Lethal atrioesophageal fistula after pulmonary vein isolation using high-intensity focused ultrasound (HIFU). Heart Rhythm. 2008;5(1):145-8.

354. Ghia KK, et al. A nationwide survey on the prevalence of atrioesophageal fistula after left atrial radiofrequency catheter ablation. J Interv Card Electrophysiol. 2009;24(1):33-6.

355. Gilcrease GW, Stein JB. A delayed case of fatal atrioesophageal fistula following radiofrequency ablation for atrial fibrillation. J Cardiovasc Electrophysiol. 2010;21(6):708-11.

356. Stockigt F, et al. Atrioesophageal fistula after cryoballoon pulmonary vein isolation. J Cardiovasc Electrophysiol. 2012;23(11): 1254-7. 
357. Yousuf O, Calkins H. Sounding the warning on the potential for oesophageal injury resulting from use of the nMARQ for ablation of atrial fibrillation. Europace. 2015;17(3):343-4.

358. Jackson PG, et al. The vagus plays a role in the anti-reflux barrier by controlling both the lower esophageal sphincter pressure and crural diaphragm activity. J Am Coll Surg. 2005;201(3 Suppl): S11.

359. Nolker G, et al. Esophageal acid levels after pulmonary vein isolation for atrial fibrillation. Pacing Clin Electrophysiol. 2009;32(Suppl 1):S228-30.

360. Medeiros De Vasconcelos JT, et al. Atrial-oesophageal fistula following percutaneous radiofrequency catheter ablation of atrial fibrillation: the risk still persists. Europace. 2017;19(2):250-8.

361. Rillig A, et al. Modified energy settings are mandatory to minimize oesophageal injury using the novel multipolar irrigated radiofrequency ablation catheter for pulmonary vein isolation. Europace. 2015;17(3):396-402.

362. Chavez P, et al. Atrioesophageal fistula following ablation procedures for atrial fibrillation: systematic review of case reports. Open Heart. 2015;2(1):e000257.

363. Mateos JC, et al. Simplified method for esophagus protection during radiofrequency catheter ablation of atrial fibrillation-prospective study of 704 cases. Rev Bras Cir Cardiovasc. 2015;30(2): 139-47.

364. Shim HB, et al. Successful management of atrio-esophageal fistula after cardiac radiofrequency catheter ablation. Korean J Thorac Cardiovasc Surg. 2013;46(2):142-5.

365. Black-Maier E, et al. Risk of atrioesophageal fistula formation with contact-force sensing catheters. Heart Rhythm. 2017;S1547-5271(17):30452-6.

366. Santangeli P, et al. Ablation of atrial fibrillation under therapeutic warfarin reduces periprocedural complications: evidence from a meta-analysis. Circ Arrhythm Electrophysiol. 2012;5(2):302-11.

367. Di Biase L, et al. Periprocedural stroke and management of major bleeding complications in patients undergoing catheter ablation of atrial fibrillation: the impact of periprocedural therapeutic international normalized ratio. Circulation. 2010;121(23):2550-6.

368. Wazni OM, et al. Atrial fibrillation ablation in patients with therapeutic international normalized ratio: comparison of strategies of anticoagulation management in the periprocedural period. Circulation. 2007;116(22):2531-4.

369. Schmidt M, et al. Atrial fibrillation ablation in patients with therapeutic international normalized ratios. Pacing Clin Electrophysiol. 2009;32(8):995-9.

370. Hakalahti A, et al. Catheter ablation of atrial fibrillation in patients with therapeutic oral anticoagulation treatment. Europace. 2011;13(5):640-5.

371. Di Biase L, et al. Periprocedural stroke and bleeding complications in patients undergoing catheter ablation of atrial fibrillation with different anticoagulation management: results from the role of Coumadin in preventing thromboembolism in atrial fibrillation (AF) patients undergoing catheter ablation (COMPARE) randomized trial. Circulation. 2014;129(25):2638-44.

372. Hohnloser SH, Camm AJ. Safety and efficacy of dabigatran etexilate during catheter ablation of atrial fibrillation: a metaanalysis of the literature. Europace. 2013;15(10):1407-11.

373. Calkins H, et al. RE-CIRCUIT study-randomized evaluation of dabigatran etexilate compared to warfarin in pulmonary vein ablation: assessment of an uninterrupted periprocedural anticoagulation strategy. Am J Cardiol. 2015;115(1):154-5.

374. Cappato R, et al. Uninterrupted rivaroxaban vs. uninterrupted vitamin $\mathrm{K}$ antagonists for catheter ablation in non-valvular atrial fibrillation. Eur Heart J. 2015;36(28):1805-11.

375. Di Biase L, et al. Feasibility and safety of uninterrupted periprocedural apixaban administration in patients undergoing radiofrequency catheter ablation for atrial fibrillation: results from a multicenter study. Heart Rhythm. 2015;12(6):1162-8.

376. Bassiouny $M$, et al. Use of dabigatran for periprocedural anticoagulation in patients undergoing catheter ablation for atrial fibrillation. Circ Arrhythm Electrophysiol. 2013;6(3):460-6.

377. Bin Abdulhak AA, et al. Safety and efficacy of interrupted dabigatran for peri-procedural anticoagulation in catheter ablation of atrial fibrillation: a systematic review and meta-analysis. Europace. 2013;15(10):1412-20.

378. Providencia R, et al. Rivaroxaban and dabigatran in patients undergoing catheter ablation of atrial fibrillation. Europace. 2014;16(8):1137-44.

379. Winkle RA, et al. Peri-procedural interrupted oral anticoagulation for atrial fibrillation ablation: comparison of aspirin, warfarin, dabigatran, and rivaroxaban. Europace. 2014;16(10):1443-9.

380. Armbruster HL, et al. Safety of novel oral anticoagulants compared with uninterrupted warfarin for catheter ablation of atrial fibrillation. Ann Pharmacother. 2015;49(3):278-84.

381. Ren JF, Marchlinski FE, Callans DJ. Left atrial thrombus associated with ablation for atrial fibrillation: identification with intracardiac echocardiography. J Am Coll Cardiol. 2004;43(10):18617.

382. Saksena S, et al. A prospective comparison of cardiac imaging using intracardiac echocardiography with transesophageal echocardiography in patients with atrial fibrillation: the intracardiac echocardiography guided cardioversion helps interventional procedures study. Circ Arrhythm Electrophysiol. 2010;3(6):571-7.

383. Baran $\mathrm{J}$, et al. Intracardiac echocardiography for detection of thrombus in the left atrial appendage: comparison with transesophageal echocardiography in patients undergoing ablation for atrial fibrillation: the action-ice I study. Circ Arrhythm Electrophysiol. 2013;6(6):1074-81.

384. Ren JF, et al. Intracardiac echocardiographic diagnosis of thrombus formation in the left atrial appendage: a complementary role to transesophageal echocardiography. Echocardiography. 2013;30(1):72-80.

385. Anter E, et al. Comparison of intracardiac echocardiography and transesophageal echocardiography for imaging of the right and left atrial appendages. Heart Rhythm. 2014;11(11):1890-7.

386. Sriram CS, et al. Detection of left atrial thrombus by intracardiac echocardiography in patients undergoing ablation of atrial fibrillation. J Interv Card Electrophysiol. 2015;43(3):227-36.

387. Maleki K, et al. Intracardiac ultrasound detection of thrombus on transseptal sheath: incidence, treatment, and prevention. J Cardiovasc Electrophysiol. 2005;16(6):561-5.

388. Wazni OM, et al. Embolic events and char formation during pulmonary vein isolation in patients with atrial fibrillation: impact of different anticoagulation regimens and importance of intracardiac echo imaging. J Cardiovasc Electrophysiol. 2005;16(6):576-81.

389. Shah D. Filamentous thrombi during left-sided sheath-assisted catheter ablations. Europace. 2010;12(12):1657-8.

390. Ren JF, et al. Increased intensity of anticoagulation may reduce risk of thrombus during atrial fibrillation ablation procedures in patients with spontaneous echo contrast. J Cardiovasc Electrophysiol. 2005;16(5):474-7.

391. Bruce CJ, et al. Early heparinization decreases the incidence of left atrial thrombi detected by intracardiac echocardiography during radiofrequency ablation for atrial fibrillation. J Interv Card Electrophysiol. 2008;22(3):211-9.

392. Asbach S, et al. Early heparin administration reduces risk for left atrial thrombus formation during atrial fibrillation ablation procedures. Cardiol Res Pract. 2011;2011:615087.

393. Briceno DF, et al. Clinical impact of heparin kinetics during catheter ablation of atrial fibrillation: meta-analysis and meta-regression. J Cardiovasc Electrophysiol. 2016;27(6):683-93. 
394. Chilukuri K, et al. Incidence and outcomes of protamine reactions in patients undergoing catheter ablation of atrial fibrillation. $\mathrm{J}$ Interv Card Electrophysiol. 2009;25(3):175-81.

395. Thygesen $\mathrm{K}$, et al. Universal definition of myocardial infarction. J Am Coll Cardiol. 2007;50(22):2173-95.

396. Helps SC, et al. The effect of gas emboli on rabbit cerebral blood flow. Stroke. 1990;21(1):94-9.

397. Krivonyak GS, Warren SG. Cerebral arterial air embolism treated by a vertical head-down maneuver. Catheter Cardiovasc Interv. 2000;49(2):185-7.

398. Cauchemez B, et al. High-flow perfusion of sheaths for prevention of thromboembolic complications during complex catheter ablation in the LA. J Cardiovasc Electrophysiol. 2004;15(3):276-83.

399. Kuwahara T, et al. Clinical characteristics of massive air embolism complicating left atrial ablation of atrial fibrillation: lessons from five cases. Europace. 2012;14(2):204-8.

400. Franzen OW, et al. Mechanisms underlying air aspiration in patients undergoing left atrial catheterization. Catheter Cardiovasc Interv. 2008;71(4):553-8.

401. Ryu KH, et al. Heparin reduces neurological impairment after cerebral arterial air embolism in the rabbit. Stroke. 1996;27(2): 303-9. discussion 310

402. Gaita F, et al. Incidence of silent cerebral thromboembolic lesions after atrial fibrillation ablation may change according to technology used: comparison of irrigated radiofrequency, multipolar nonirrigated catheter and cryoballoon. J Cardiovasc Electrophysiol. 2011;22(9):961-8.

403. Herrera Siklody C, et al. Incidence of asymptomatic intracranial embolic events after pulmonary vein isolation: comparison of different atrial fibrillation ablation technologies in a multicenter study. J Am Coll Cardiol. 2011;58(7):681-8.

404. Verma A, et al. Evaluation and reduction of asymptomatic cerebral embolism in ablation of atrial fibrillation, but high prevalence of chronic silent infarction: results of the evaluation of reduction of asymptomatic cerebral embolism trial. Circ Arrhythm Electrophysiol. 2013;6(5):835-42.

405. De Greef Y, et al. Low rate of asymptomatic cerebral embolism and improved procedural efficiency with the novel pulmonary vein ablation catheter GOLD: results of the PRECISION GOLD trial. Europace. 2016;18(5):687-95.

406. Deneke T, et al. Silent cerebral events/lesions related to atrial fibrillation ablation: a clinical review. J Cardiovasc Electrophysiol. 2015;26(4):455-63.

407. Merchant FM, Delurgio DB. Catheter ablation of atrial fibrillation and risk of asymptomatic cerebral embolism. Pacing Clin Electrophysiol. 2014;37(3):389-97.

408. Lickfett $\mathrm{L}$, et al. Cerebral diffusion-weighted magnetic resonance imaging: a tool to monitor the thrombogenicity of left atrial catheter ablation. J Cardiovasc Electrophysiol. 2006;17(1):1-7.

409. Gaita F, et al. Radiofrequency catheter ablation of atrial fibrillation: a cause of silent thromboembolism? Magnetic resonance imaging assessment of cerebral thromboembolism in patients undergoing ablation of atrial fibrillation. Circulation. 2010;122(17): 1667-73.

410. Schrickel JW, et al. Incidence and predictors of silent cerebral embolism during pulmonary vein catheter ablation for atrial fibrillation. Europace. 2010;12(1):52-7.

411. Deneke T, et al. Postablation asymptomatic cerebral lesions: longterm follow-up using magnetic resonance imaging. Heart Rhythm. 2011;8(11):1705-11.

412. Sauren LD, et al. Transcranial measurement of cerebral microembolic signals during endocardial pulmonary vein isolation: comparison of three different ablation techniques. J Cardiovasc Electrophysiol. 2009;20(10):1102-7.
413. Wieczorek M, et al. Investigation into causes of abnormal cerebral MRI findings following PVAC duty-cycled, phased RF ablation of atrial fibrillation. J Cardiovasc Electrophysiol. 2013;24(2):121-8.

414. Bendszus M, Stoll G. Silent cerebral ischaemia: hidden fingerprints of invasive medical procedures. Lancet Neurol. 2006;5(4): 364-72.

415. Kruis RW, Vlasveld FA, Van Dijk D. The (un)importance of cerebral microemboli. Semin Cardiothorac Vasc Anesth. 2010;14(2): $111-8$.

416. Medi C, et al. Subtle post-procedural cognitive dysfunction after atrial fibrillation ablation. J Am Coll Cardiol. 2013;62(6):531-9.

417. Ichiki $\mathrm{H}$, et al. The incidence of asymptomatic cerebral microthromboembolism after atrial fibrillation ablation: comparison of warfarin and dabigatran. Pacing Clin Electrophysiol. 2013;36(11):1328-35.

418. Nagy-Balo E, et al. Transcranial measurement of cerebral microembolic signals during pulmonary vein isolation: a comparison of two ablation techniques. Circ Arrhythm Electrophysiol. 2013;6(3):473-80.

419. Vermeer SE, et al. Silent brain infarcts and the risk of dementia and cognitive decline. N Engl J Med. 2003;348(13):1215-22.

420. Neven K, et al. Fatal end of a safety algorithm for pulmonary vein isolation with use of high-intensity focused ultrasound. Circ Arrhythm Electrophysiol. 2010;3(3):260-5.

421. Ripley KL, et al. Time course of esophageal lesions after catheter ablation with cryothermal and radiofrequency ablation: implication for atrio-esophageal fistula formation after catheter ablation for atrial fibrillation. J Cardiovasc Electrophysiol. 2007;18(6): 642-6.

422. Ahmed $\mathrm{H}$, et al. The esophageal effects of cryoenergy during cryoablation for atrial fibrillation. Heart Rhythm. 2009;6(7):9629.

423. Kawasaki R, et al. Atrioesophageal fistula complicating cryoballoon pulmonary vein isolation for paroxysmal atrial fibrillation. J Cardiovasc Electrophysiol. 2014;25(7):787-92.

424. Lim HW, et al. Atrioesophageal fistula during cryoballoon ablation for atrial fibrillation. J Cardiovasc Electrophysiol. 2014;25(2): 208-13.

425. Yokoyama K, et al. Canine model of esophageal injury and atrialesophageal fistula after applications of forward-firing high-intensity focused ultrasound and side-firing unfocused ultrasound in the left atrium and inside the pulmonary vein. Circ Arrhythm Electrophysiol. 2009;2(1):41-9.

426. Singh SM, et al. Esophageal injury and temperature monitoring during atrial fibrillation ablation. Circ Arrhythm Electrophysiol. 2008;1(3):162-8.

427. Kuwahara T, et al. Safe and effective ablation of atrial fibrillation: importance of esophageal temperature monitoring to avoid periesophageal nerve injury as a complication of pulmonary vein isolation. J Cardiovasc Electrophysiol. 2009;20(1):1-6.

428. Contreras-Valdes FM, et al. Severity of esophageal injury predicts time to healing after radiofrequency catheter ablation for atrial fibrillation. Heart Rhythm. 2011;8(12):1862-8.

429. Leite LR, et al. Luminal esophageal temperature monitoring with a deflectable esophageal temperature probe and intracardiac echocardiography may reduce esophageal injury during atrial fibrillation ablation procedures: results of a pilot study. Circ Arrhythm Electrophysiol. 2011;4(2):149-56.

430. Tschabrunn CM, et al. Comparison between single- and multisensor oesophageal temperature probes during atrial fibrillation ablation: thermodynamic characteristics. Europace. 2015;17(6): 891-7.

431. Deneke T, et al. Utility of esophageal temperature monitoring during pulmonary vein isolation for atrial fibrillation using dutycycled phased radiofrequency ablation. J Cardiovasc Electrophysiol. 2011;22(3):255-61. 
432. Carroll BJ, et al. Multi-sensor esophageal temperature probe used during radiofrequency ablation for atrial fibrillation is associated with increased intraluminal temperature detection and increased risk of esophageal injury compared to single-sensor probe. J Cardiovasc Electrophysiol. 2013;24(9):958-64.

433. Muller P, et al. Higher incidence of esophageal lesions after ablation of atrial fibrillation related to the use of esophageal temperature probes. Heart Rhythm. 2015;12(7):1464-9.

434. Tsuchiya T, et al. Atrial fibrillation ablation with esophageal cooling with a cooled water-irrigated intraesophageal balloon: a pilot study. J Cardiovasc Electrophysiol. 2007;18(2):145-50.

435. Arruda MS, et al. Feasibility and safety of using an esophageal protective system to eliminate esophageal thermal injury: implications on atrial-esophageal fistula following AF ablation. J Cardiovasc Electrophysiol. 2009;20(11):1272-8.

436. Kuwahara $\mathrm{T}$, et al. Oesophageal cooling with ice water does not reduce the incidence of oesophageal lesions complicating catheter ablation of atrial fibrillation: randomized controlled study. Europace. 2014;16(6):834-9.

437. Kuwahara T, et al. Incidences of esophageal injury during esophageal temperature monitoring: a comparative study of a multithermocouple temperature probe and a deflectable temperature probe in atrial fibrillation ablation. J Interv Card Electrophysiol. 2014;39(3):251-7.

438. Chugh A, et al. Mechanical displacement of the esophagus in patients undergoing left atrial ablation of atrial fibrillation. Heart Rhythm. 2009;6(3):319-22.

439. Koruth JS, et al. Mechanical esophageal displacement during catheter ablation for atrial fibrillation. J Cardiovasc Electrophysiol. 2012;23(2):147-54.

440. Zellerhoff S, Lenze F, Eckardt L. Prophylactic proton pump inhibition after atrial fibrillation ablation: is there any evidence? Europace. 2011;13(9):1219-21.

441. Zellerhoff S, et al. Fatal course of esophageal stenting of an atrioesophageal fistula after atrial fibrillation ablation. Heart Rhythm. 2011;8(4):624-6.

442. Khan M, et al. Medical treatments in the short term management of reflux oesophagitis. Cochrane Database Syst Rev. 2007;2: CD003244.

443. Kahrilas PJ. Clinical practice. Gastroesophageal reflux disease. $\mathrm{N}$ Engl J Med. 2008;359(16):1700-7.

444. Shaheen NJ, et al. Pantoprazole reduces the size of postbanding ulcers after variceal band ligation: a randomized, controlled trial. Hepatology. 2005;41(3):588-94.

445. Halm U, et al. Thermal esophageal lesions after radiofrequency catheter ablation of left atrial arrhythmias. Am J Gastroenterol. 2010;105(3):551-6.

446. Knopp $\mathrm{H}$, et al. Incidental and ablation-induced findings during upper gastrointestinal endoscopy in patients after ablation of atrial fibrillation: a retrospective study of 425 patients. Heart Rhythm. 2014;11(4):574-8.

447. Dagres N, et al. Rapid detection and successful treatment of esophageal perforation after radiofrequency ablation of atrial fibrillation: lessons from five cases. J Cardiovasc Electrophysiol. 2006;17(11): 1213-5.

448. Eitel C, et al. Successful nonsurgical treatment of esophagopericardial fistulas after atrial fibrillation catheter ablation: a case series. Circ Arrhythm Electrophysiol. 2013;6(4):67581.

449. Hazell W, et al. Atrio-oesophageal fistula: an emergent complication of radiofrequency ablation. Emerg Med Australas. 2009;21(4):329-32.

450. Cazavet A, et al. Successful surgery for atrioesophageal fistula caused by transcatheter ablation of atrial fibrillation. J Thorac Cardiovasc Surg. 2010;140(3):e43-5.
451. Podgaetz E, Deschamps C. Esophageal complications of catheter ablation for atrial fibrillation: a case report. J Thorac Cardiovasc Surg. 2013;145(1):e9-e13.

452. Queneherve L, et al. Endoscopic management of an esophagopericardial fistula after radiofrequency ablation for atrial fibrillation. World J Gastroenterol. 2013;19(21):3352-3.

453. Gunes MF, et al. Ablating the posterior heart: cardioesophageal fistula complicating radiofrequency ablation in the coronary sinus. J Cardiovasc Electrophysiol. 2015;26(12):1376-8.

454. Qadeer MA, et al. Endoscopic clips for closing esophageal perforations: case report and pooled analysis. Gastrointest Endosc. 2007;66(3):605-11.

455. Ellis CR, et al. Successful treatment of esophageal perforation following atrial fibrillation ablation with a fully covered esophageal stent: prevention of atrial-esophageal fistula. J Innov Cardiac Rhythm Management. 2012;3:874-8.

456. Markar SR, et al. Novel multimodality endoscopic closure of postoperative esophageal fistula. Int J Surg Case Rep. 2012;3(11): 577-9.

457. Andrade JG, et al. Efficacy and safety of cryoballoon ablation for atrial fibrillation: a systematic review of published studies. Heart Rhythm. 2011;8(9):1444-51.

458. Deshmukh A, et al. In-hospital complications associated with catheter ablation of atrial fibrillation in the United States between 2000 and 2010: analysis of 93801 procedures. Circulation. 2013;128(19):2104-12.

459. Cappato R, et al. Delayed cardiac tamponade after radiofrequency catheter ablation of atrial fibrillation: a worldwide report. J Am Coll Cardiol. 2011;58(25):2696-7.

460. Eick OJ, Gerritse B, Schumacher B. Popping phenomena in temperature-controlled radiofrequency ablation: when and why do they occur? Pacing Clin Electrophysiol. 2000;23(2):253-8.

461. Fisher JD, et al. Internal transcardiac pericardiocentesis for acute tamponade. Am J Cardiol. 2000;86(12):1388-9. A6

462. Hsu LF, et al. Transcardiac pericardiocentesis: an emergency lifesaving technique for cardiac tamponade. J Cardiovasc Electrophysiol. 2003;14(9):1001-3.

463. Bunch TJ, et al. Outcomes after cardiac perforation during radiofrequency ablation of the atrium. J Cardiovasc Electrophysiol. 2005;16(11):1172-9.

464. Hsu LF, et al. Incidence and prevention of cardiac tamponade complicating ablation for atrial fibrillation. Pacing Clin Electrophysiol. 2005;28(Suppl 1):S106-9.

465. Michowitz Y, et al. Effects of sex on the incidence of cardiac tamponade after catheter ablation of atrial fibrillation: results from a worldwide survey in 34943 atrial fibrillation ablation procedures. Circ Arrhythm Electrophysiol. 2014;7(2):274-80.

466. Tsang TS, et al. Consecutive 1127 therapeutic echocardiographically guided pericardiocenteses: clinical profile, practice patterns, and outcomes spanning 21 years. Mayo Clin Proc. 2002;77(5):429-36.

467. O'Neill MD, et al. Two techniques to avoid surgery for cardiac tamponade occurring during catheter ablation of atrial fibrillation. J Cardiovasc Electrophysiol. 2008;19(3):323-5.

468. Takahashi Y, et al. Acute occlusion of the left circumflex coronary artery during mitral isthmus linear ablation. J Cardiovasc Electrophysiol. 2005;16(10):1104-7.

469. Chugh A, et al. Manifestations of coronary arterial injury during catheter ablation of atrial fibrillation and related arrhythmias. Heart Rhythm. 2013;10(11):1638-45.

470. Makimoto H, et al. Aborted sudden cardiac death due to radiofrequency ablation within the coronary sinus and subsequent total occlusion of the circumflex artery. J Cardiovasc Electrophysiol. 2013;24(8):929-32.

471. Kitamura T, et al. Transient sinus node dysfunction following sinus node artery occlusion due to radiofrequency catheter 
ablation of the septal superior vena cava-right atrium junction. $\mathrm{J}$ Electrocardiol. 2016;49(1):18-22.

472. Ouali $\mathrm{S}$, et al. Acute coronary occlusion during radiofrequency catheter ablation of typical atrial flutter. J Cardiovasc Electrophysiol. 2002;13(10):1047-9.

473. Mykytsey A, et al. Right coronary artery occlusion during RF ablation of typical atrial flutter. J Cardiovasc Electrophysiol. 2010;21(7):818-21.

474. Sticherling C, Pfister O, Osswald S. Thrombo-embolic occlusion of the left anterior descending coronary artery complicating left atrial radiofrequency ablation. Europace. 2009;11(1):117-8.

475. Wong KC, et al. High incidence of acute sub-clinical circumflex artery 'injury' following mitral isthmus ablation. Eur Heart J. 2011;32(15):1881-90.

476. Fayad G, et al. Circumflex artery stenosis induced by intraoperative radiofrequency ablation. Ann Thorac Surg. 2003;76(4):12913.

477. Piccini JP, et al. Outcomes of Medicare beneficiaries undergoing catheter ablation for atrial fibrillation. Circulation. 2012;126(18): 2200-7.

478. Lakkireddy D, et al. Effect of atrial fibrillation ablation on gastric motility: the atrial fibrillation gut study. Circ Arrhythm Electrophysiol. 2015;8(3):531-6.

479. Dumonceau JM, et al. Acute delayed gastric emptying after ablation of atrial fibrillation: treatment with botulinum toxin injection. Endoscopy. 2006;38(5):543.

480. Bunch TJ, et al. Vagus nerve injury after posterior atrial radiofrequency ablation. Heart Rhythm. 2008;5(9):1327-30.

481. Kuwahara T, et al. Clinical characteristics and management of periesophageal vagal nerve injury complicating left atrial ablation of atrial fibrillation: lessons from eleven cases. J Cardiovasc Electrophysiol. 2013;24(8):847-51.

482. Miyazaki S, et al. Factors associated with periesophageal vagal nerve injury after pulmonary vein antrum isolation. J Am Heart Assoc. 2014;3(5):e001209.

483. Chopra N, Shadchehr A. Achalasia cardia as a unique complication of pulmonary vein isolation. Heart Rhythm. 2014;11(12): 2297-9.

484. Schwartz TW, et al. Pancreatic-polypeptide response to food in duodenal-ulcer patients before and after vagotomy. Lancet. 1976;1(7969):1102-5.

485. Ajaj W, et al. Real time high resolution magnetic resonance imaging for the assessment of gastric motility disorders. Gut. 2004;53(9):1256-61.

486. Pisani $\mathrm{CF}$, et al. Gastric hypomotility following epicardial vagal denervation ablation to treat atrial fibrillation. J Cardiovasc Electrophysiol. 2008;19(2):211-3.

487. Kanaeda T, et al. Evaluation of periesophageal nerve injury after pulmonary vein isolation using the (13)C-acetate breath test. J Arrhythm. 2015;31(6):364-70.

488. Lo LW, et al. A novel finding-impairment of gastric myoelectricity after catheter ablation of atrial fibrillation. Circ J. 2013;77(8):2014-23.

489. Janssens $\mathbf{J}$, et al. Improvement of gastric emptying in diabetic gastroparesis by erythromycin. Preliminary studies. N Engl J Med. 1990;322(15):1028-31.

490. Jones MP, Maganti K. A systematic review of surgical therapy for gastroparesis. Am J Gastroenterol. 2003;98(10):2122-9.

491. Tavernier R, Duytschaever M, Taeymans Y. Fracture of a circular mapping catheter after entrapment in the mitral valve apparatus during segmental pulmonary vein isolation. Pacing Clin Electrophysiol. 2003;26(8):1774-5.

492. Grove R, et al. Demand for open heart surgery due to entrapment of a circular mapping catheter in the mitral valve in a patient undergoing atrial fibrillation ablation. Clin Res Cardiol. 2008;97(9):628-9.
493. Lakkireddy D, et al. Radiofrequency ablation of atrial fibrillation in patients with mitral or aortic mechanical prosthetic valves: a feasibility, safety, and efficacy study. Heart Rhythm. 2011;8(7): 975-80.

494. Zeljko HM, et al. Entrapment of the circular mapping catheter in the mitral valve in two patients undergoing atrial fibrillation ablation. Europace. 2011;13(1):132-3.

495. Desimone $\mathrm{CV}$, et al. Catheter ablation related mitral valve injury: the importance of early recognition and rescue mitral valve repair J Cardiovasc Electrophysiol. 2014;25(9):971-5.

496. Gurbuz O, et al. Case report: paravalvular leak as a complication of percutaneous catheter ablation for atrial fibrillation. J Cardiothorac Surg. 2014;9:187.

497. Mansour M, et al. Successful release of entrapped circumferential mapping catheters in patients undergoing pulmonary vein isolation for atrial fibrillation. Heart Rhythm. 2004;1(5):558-61.

498. Wu RC, et al. Circular mapping catheter entrapment in the mitral valve apparatus: a previously unrecognized complication of focal atrial fibrillation ablation. J Cardiovasc Electrophysiol. 2002;13(8):819-21.

499. Deftereos S, et al. Colchicine for prevention of early atrial fibrillation recurrence after pulmonary vein isolation: a randomized controlled study. J Am Coll Cardiol. 2012;60(18):1790-6.

500. Deftereos S, et al. Colchicine for prevention of atrial fibrillation recurrence after pulmonary vein isolation: mid-term efficacy and effect on quality of life. Heart Rhythm. 2014;11(4):620-8.

501. Stabile G, et al. Low incidence of permanent complications during catheter ablation for atrial fibrillation using open-irrigated catheters: a multicentre registry. Europace. 2014;16(8):1154-9.

502. Luckie M, et al. Dressler's syndrome following pulmonary vein isolation for atrial fibrillation. Acute Card Care. 2008;10(4):234 5 .

503. Lambert $\mathrm{T}$, et al. Cardiac tamponade following pericarditis 18 days after catheter ablation of atrial fibrillation. Clin Res Cardiol. 2010;99(9):595-7.

504. Torihashi S, et al. Two cases of delayed cardiac tamponade due to pericarditis after pulmonary vein (PV) isolation for atrial fibrillation. Intern Med. 2015;54(7):791-6.

505. Kim DR, et al. Comparison of two different doses of single bolus steroid injection to prevent atrial fibrillation recurrence after radiofrequency catheter ablation. Yonsei Med J. 2015;56(2):324-31.

506. Kesek M, et al. Entrapment of circular mapping catheter in the mitral valve. Heart Rhythm. 2007;4(1):17-9.

507. Kuck KH, et al. Cryoballoon or radiofrequency ablation for symptomatic paroxysmal atrial fibrillation: reintervention, rehospitalization, and quality-of-life outcomes in the FIRE AND ICE trial. Eur Heart J. 2016;37(38):2858-65.

508. Sohara H, et al. Feasibility of the radiofrequency hot balloon catheter for isolation of the posterior left atrium and pulmonary veins for the treatment of atrial fibrillation. Circ Arrhythm Electrophysiol. 2009;2(3):225-32.

509. Evonich RF, Nori DM, Haines DE. Efficacy of pulmonary vein isolation with a novel hot balloon ablation catheter. J Interv Card Electrophysiol. 2012;34(1):29-36.

510. Chun KR, et al. The 'single big cryoballoon' technique for acute pulmonary vein isolation in patients with paroxysmal atrial fibrillation: a prospective observational single centre study. Eur Heart J. 2009;30(6):699-709.

511. Hoyt $\mathrm{H}$, et al. Complications arising from catheter ablation of atrial fibrillation: temporal trends and predictors. Heart Rhythm. 2011;8(12):1869-74.

512. Guhl EN, et al. Efficacy of cryoballoon pulmonary vein isolation in patients with persistent atrial fibrillation. J Cardiovasc Electrophysiol. 2016;27(4):423-7. 
513. Earley MJ, et al. Radiofrequency ablation of arrhythmias guided by non-fluoroscopic catheter location: a prospective randomized trial. Eur Heart J. 2006;27(10):1223-9.

514. Sarabanda AV, et al. Efficacy and safety of circumferential pulmonary vein isolation using a novel cryothermal balloon ablation system. J Am Coll Cardiol. 2005;46(10):1902-12.

515. Guiot A, et al. Collateral nervous damages after cryoballoon pulmonary vein isolation. J Cardiovasc Electrophysiol. 2012;23(4): $346-51$.

516. Metzner A, et al. The incidence of phrenic nerve injury during pulmonary vein isolation using the second-generation $28 \mathrm{~mm}$ cryoballoon. J Cardiovasc Electrophysiol. 2014;25(5):466-70.

517. Okumura Y, et al. Distortion of right superior pulmonary vein anatomy by balloon catheters as a contributor to phrenic nerve injury. J Cardiovasc Electrophysiol. 2009;20(10):1151-7.

518. Arruda M, et al. Electrical isolation of the superior vena cava: an adjunctive strategy to pulmonary vein antrum isolation improving the outcome of AF ablation. J Cardiovasc Electrophysiol. 2007;18(12):1261-6.

519. Miyazaki S, et al. Prevalence and clinical outcome of phrenic nerve injury during superior vena cava isolation and circumferential pulmonary vein antrum isolation using radiofrequency energy. Am Heart J. 2014;168(6):846-53.

520. Wissner E, et al. Catheter ablation of atrial fibrillation in patients with persistent left superior vena cava is associated with major intraprocedural complications. Heart Rhythm. 2010;7(12):175560.

521. Elayi CS, et al. Left superior vena cava isolation in patients undergoing pulmonary vein antrum isolation: impact on atrial fibrillation recurrence. Heart Rhythm. 2006;3(9):1019-23.

522. Liu H, et al. Electrogram-guided isolation of the left superior vena cava for treatment of atrial fibrillation. Europace. 2007;9(9):77580 .

523. Yong Ji S, et al. Phrenic nerve injury: an underrecognized and potentially preventable complication of pulmonary vein isolation using a wide-area circumferential ablation approach. J Cardiovasc Electrophysiol. 2013;24(10):1086-91.

524. Franceschi F, et al. Phrenic nerve monitoring with diaphragmatic electromyography during cryoballoon ablation for atrial fibrillation: the first human application. Heart Rhythm. 2011;8(7):106871.

525. Miyazaki S, et al. Prospective evaluation of bilateral diaphragmatic electromyograms during cryoballoon ablation of atrial fibrillation. J Cardiovasc Electrophysiol. 2015;26(6):622-8.

526. Mondesert B, et al. Clinical experience with a novel electromyographic approach to preventing phrenic nerve injury during cryoballoon ablation in atrial fibrillation. Circ Arrhythm Electrophysiol. 2014;7(4):605-11.

527. Sacher F, et al. Phrenic nerve injury after atrial fibrillation catheter ablation: characterization and outcome in a multicenter study. $\mathrm{J}$ Am Coll Cardiol. 2006;47(12):2498-503.

528. Andrade JG, et al. Histopathology of cryoballoon ablationinduced phrenic nerve injury. J Cardiovasc Electrophysiol. 2014;25(2):187-94.

529. Pappone C, et al. Circumferential radiofrequency ablation of pulmonary vein ostia: a new anatomic approach for curing atrial fibrillation. Circulation. 2000;102(21):2619-28.

530. Dukkipati SR, et al. Pulmonary vein isolation using a visually guided laser balloon catheter: the first 200-patient multicenter clinical experience. Circ Arrhythm Electrophysiol. 2013;6(3):467-72.

531. Katz ES, et al. Surgical left atrial appendage ligation is frequently incomplete: a transesophageal echocardiograhic study. J Am Coll Cardiol. 2000;36(2):468-71.

532. Caponi $\mathrm{D}$, et al. Ablation of atrial fibrillation: does the addition of three-dimensional magnetic resonance imaging of the left atrium to electroanatomic mapping improve the clinical outcome? A randomized comparison of Carto-merge vs. Carto-XP three-dimensional mapping ablation in patients with paroxysmal and persistent atrial fibrillation. Europace. 2010;12(8):1098-104.

533. Proietti R, et al. Remote magnetic with open-irrigated catheter vs. manual navigation for ablation of atrial fibrillation: a systematic review and meta-analysis. Europace. 2013;15(9):1241-8.

534. Ferguson JD, et al. Catheter ablation of atrial fibrillation without fluoroscopy using intracardiac echocardiography and electroanatomic mapping. Circ Arrhythm Electrophysiol. 2009;2(6):611-9.

535. Calkins $\mathrm{H}$, et al. Radiation exposure during radiofrequency catheter ablation of accessory atrioventricular connections. Circulation. 1991;84(6):2376-82.

536. Lindsay BD, et al. Radiation exposure to patients and medical personnel during radiofrequency catheter ablation for supraventricular tachycardia. Am J Cardiol. 1992;70(2):218-23.

537. Kovoor $\mathrm{P}$, et al. Risk to patients from radiation associated with radiofrequency ablation for supraventricular tachycardia. Circulation. 1998;98(15):1534-40.

538. Macle L, et al. Radiation exposure during radiofrequency catheter ablation for atrial fibrillation. Pacing Clin Electrophysiol. 2003;26(1 Pt 2):288-91.

539. Lickfett L, et al. Radiation exposure during catheter ablation of atrial fibrillation. Circulation. 2004;110(19):3003-10.

540. Ector J, et al. Obesity is a major determinant of radiation dose in patients undergoing pulmonary vein isolation for atrial fibrillation. J Am Coll Cardiol. 2007;50(3):234-42.

541. Chen J, et al. Cumulative exposure to ionizing radiation from diagnostic and therapeutic cardiac imaging procedures: a population-based analysis. J Am Coll Cardiol. 2010;56(9):70211.

542. Khaykin Y, et al. CARTO-guided vs. NavX-guided pulmonary vein antrum isolation and pulmonary vein antrum isolation performed without 3-D mapping: effect of the 3-D mapping system on procedure duration and fluoroscopy time. J Interv Card Electrophysiol. 2011;30(3):233-40.

543. Stabile G, et al. Reduced fluoroscopy exposure during ablation of atrial fibrillation using a novel electroanatomical navigation system: a multicentre experience. Europace. 2012;14(1):60-5.

544. De Ponti R, et al. Simulator training reduces radiation exposure and improves trainees' performance in placing electrophysiologic catheters during patient-based procedures. Heart Rhythm. 2012;9(8):1280-5

545. Kleemann T, et al. Development of radiation exposure in patients undergoing pulmonary vein isolation in Germany between 2007 and 2014: great potential to minimize radiation dosage. Clin Res Cardiol. 2016;105(10):858-64.

546. Steven D, et al. Reduced fluoroscopy during atrial fibrillation ablation: benefits of robotic guided navigation. J Cardiovasc Electrophysiol. 2010;21(1):6-12.

547. Weiss JP, et al. A comparison of remote magnetic irrigated tip ablation versus manual catheter irrigated tip catheter ablation with and without force sensing feedback. J Cardiovasc Electrophysiol. 2016;27(Suppl 1):S5-S10.

548. Dragusin O, et al. Evaluation of a radiation protection cabin for invasive electrophysiological procedures. Eur Heart J. 2007;28(2): 183-9.

549. Reddy VY, et al. Catheter ablation of atrial fibrillation without the use of fluoroscopy. Heart Rhythm. 2010;7(11):1644-53.

550. Bulava A, Hanis J, Eisenberger M. Catheter ablation of atrial fibrillation using zero-fluoroscopy technique: a randomized trial. Pacing Clin Electrophysiol. 2015;38(7):797-806.

551. Cochet $\mathrm{H}$, et al. Atrial structure and function 5 years after successful ablation for persistent atrial fibrillation: an MRI study. J Cardiovasc Electrophysiol. 2014;25(7):671-9. 
552. Gibson DN, et al. Stiff left atrial syndrome after catheter ablation for atrial fibrillation: clinical characterization, prevalence, and predictors. Heart Rhythm. 2011;8(9):1364-71.

553. Shoemaker MB, et al. Left atrial hypertension after repeated catheter ablations for atrial fibrillation. J Am Coll Cardiol. 2011;57(19):1918-9.

554. Welch TD, et al. Symptomatic pulmonary hypertension with giant left atrial $\mathrm{v}$ waves after surgical maze procedures: evaluation by comprehensive hemodynamic catheterization. Heart Rhythm. 2013;10(12):1839-42.

555. Witt $\mathrm{C}$, et al. Recurrent dyspnea following multiple ablations for atrial fibrillation explained by the "stiff left atrial syndrome". Catheter Cardiovasc Interv. 2013;82(5):E747-9.

556. Pilote L, et al. Stiff left atrial syndrome. Can J Cardiol. 1988;4(6): 255-7.

557. Khurram IM, et al. Association between left atrial stiffness index and atrial fibrillation recurrence in patients undergoing left atrial ablation. Circ Arrhythm Electrophysiol. 2016;9(3)

558. Kosiuk J, et al. Prevalence and predictors of worsened left ventricular diastolic dysfunction after catheter ablation of atrial fibrillation. Int J Cardiol. 2013;168(4):3613-5.

559. Ghanbari H, et al. Mortality and cerebrovascular events after radiofrequency catheter ablation of atrial fibrillation. Heart Rhythm. 2014;11(9):1503-11.

560. Scherr D, et al. Incidence and predictors of left atrial thrombus prior to catheter ablation of atrial fibrillation. J Cardiovasc Electrophysiol. 2009;20(4):379-84.

561. Liu Y, et al. Incidence and outcomes of cerebrovascular events complicating catheter ablation for atrial fibrillation. Europace. 2016;18(9):1357-65.

562. Noseworthy PA, et al. Risk of stroke after catheter ablation versus cardioversion for atrial fibrillation: a propensity-matched study of 24,244 patients. Heart Rhythm. 2015;12(6):1154-61.

563. Patel D, et al. Long-term functional and neurocognitive recovery in patients who had an acute cerebrovascular event secondary to catheter ablation for atrial fibrillation. J Cardiovasc Electrophysiol. 2010;21(4):412-7.

564. Kochhauser S, et al. Comparison of outcomes after cardioversion or atrial fibrillation ablation in patients with differing periprocedural anticoagulation regimens. Can J Cardiol. 2014;30(12):1541-6.
565. Kosiuk J, et al. Early cerebral thromboembolic complications after radiofrequency catheter ablation of atrial fibrillation: incidence, characteristics, and risk factors. Heart Rhythm. 2014;11(11): 1934-40.

566. Abhishek F, et al. Effectiveness of a strategy to reduce major vascular complications from catheter ablation of atrial fibrillation. J Interv Card Electrophysiol. 2011;30(3):211-5.

567. Aldhoon B, et al. Complications of catheter ablation for atrial fibrillation in a high-volume centre with the use of intracardiac echocardiography. Europace. 2013;15(1):24-32.

568. Mugnai G, et al. Complications in the setting of percutaneous atrial fibrillation ablation using radiofrequency and cryoballoon techniques: a single-center study in a large cohort of patients. Int J Cardiol. 2015;196:42-9.

569. Murakawa Y, et al. Nationwide survey of catheter ablation for atrial fibrillation: the Japanese catheter ablation registry of atrial fibrillation (J-CARAF)-a report on periprocedural oral anticoagulants. J Arrhythm. 2015;31(1):29-32.

570. Palaniswamy C, et al. Catheter ablation of postinfarction ventricular tachycardia: ten-year trends in utilization, in-hospital complications, and in-hospital mortality in the United States. Heart Rhythm. 2014;11(11):2056-63.

571. Peichl P, et al. Complications of catheter ablation of ventricular tachycardia: a single-center experience. Circ Arrhythm Electrophysiol. 2014;7(4):684-90.

572. Waigand J, et al. Percutaneous treatment of pseudoaneurysms and arteriovenous fistulas after invasive vascular procedures. Catheter Cardiovasc Interv. 1999;47(2):157-64.

573. Lakkireddy D, et al. Feasibility and safety of uninterrupted rivaroxaban for periprocedural anticoagulation in patients undergoing radiofrequency ablation for atrial fibrillation: results from a multicenter prospective registry. J Am Coll Cardiol. 2014;63(10): 982-8.

574. Tanaka-Esposito CC, et al. Real-time ultrasound guidance reduces total and major vascular complications in patients undergoing pulmonary vein antral isolation on therapeutic warfarin. J Interv Card Electrophysiol. 2013;37(2):163-8.

575. Errahmouni A, et al. Ultrasound-guided venous puncture in electrophysiological procedures: a safe method, rapidly learned. Pacing Clin Electrophysiol. 2014;37(8):1023-8. 